\title{
A Review of the Fossil Record of Basal Mesozoic Turtles
}

\author{
Walter G. Joyce \\ Department of Geosciences, University of Fribourg, 1700 Fribourg, Switzerland \\ —walter.joyce@unifr.ch
}

\begin{abstract}
Turtles (Testudinata) are the clade of amniotes characterized by a complete turtle shell. New insights into the phylogeny of the group have revealed that a diverse assemblage of fossil turtles populate the stem lineage that lead to the turtle crown (Testudines). To aid communication, the terms Mesochelydia and Perichelydia are herein defined for two internested clades more inclusive than Testudines but less inclusive than Testudinata. The earliest representatives of Testudinata are found globally in Late Triassic (Norian) to Middle Jurassic deposits. In concert with the vicariant split of crown Testudines into three primary clades (i.e., Paracryptodira, Pan-Pleurodira, and Pan-Cryptodira), basal perichelydians diversify into three additional clades with overlapping geographic distributions: Helochelydridae in Euramerica, Sichuanchelyidae in Asia, and Meiolaniformes in southern Gondwana. Sedimentological, anatomical, and histological data universally hint at terrestrial habitat preference among the earliest stem turtles, but a more mixed, though unambiguously continental signal is apparent further towards the crown. A taxonomic review of Mesozoic stem turtles, excluding representatives of the Gondwanan Meiolaniformes, concludes that of 48 named taxa, 26 are nomina valida, 18 are nomina invalida, 4 are nomina dubia, 1 is a nomen nudum, and that 9 do not represent turtles.
\end{abstract}

KEYWORDS

Phylogeny, biogeography, paleoecology, Testudinata, Mesochelydia, Perichelydia, Helochelydridae, Sichuanchelyidae

\section{Introduction}

The name Testudinata (herein colloquially referred to as testudinates or turtles) is defined as the clade that originates from the first amniote to possess a fully developed turtle shell (sensu Gaffney and Meylan 1988) homologous with that developed in the extant turtle Chelonia mydas (Linnaeus, 1758) (Joyce et al. 2004). Following this definition, a growing number of potential stem turtles from the Permian to Middle Triassic, including the Middle Permian Eunotosaurus africanus Seeley, 1892, the Middle Triassic Pappochelys rosinae Schoch and Sues, 2015, and the Late Triassic Odontochelys semitestacea Li et al., 2008, are not considered to be turtles. The name Testudines (colloquially crown turtles), on the other hand, is referred to the crown clade formed by all extant testudinates (Joyce et al. 2004). The purpose of this contribution is to summarize the fossil record of the paraphyletic assemblage of all basal testudinates that populate the stem lineage leading to crown Testudines, with exception of the clade Meiolaniformes, which was already discussed elsewhere (Sterli 2015).

The first workers to describe basal turtles did not yet appreciate the currently established difference between crown groups and total groups, and simply classified their animals as "turtles" (e.g., Mantell 1833; Meyer 1855, 1865; Matheron 1869; Owen 1886). In 1889, Lydekker (1889a, 1889b) created the taxon Amphichelydia to account for some Mesozoic turtles that showed what he felt to be ancestral characters relative to Pleurodira and Cryptodira, the two primary lineages of crown Testudines. Although Lydekker's (1889a, 1889b) Amphichelydia can superficially be equated with the modern understanding of a paraphyletic stem lineage, his classification at heart disagrees with modern insights into the classification of turtles by accepting that all 
shelled turtles, his Testudinata, are more derived than the leather-shelled sea turtles, his Athecata, an idea initially forwarded by Cope (1875) and otherwise emphatically supported by Dollo (1886), Boulenger (1889), and Hay (1905, 1908, 1922). Even with this caveat in mind, however, Lydekker's (1889a, 1889b) Amphichelydia differs substantially from the basal turtle lineage described herein, by including, among others, the paracryptodire Pleurosternon bullockii, the stem pleurodire Platychelys oberndorferi, the stem cryptodire Brodiechelys brodiei (his Archaeochelys valdensis), but not the currently recognized basal turtles Meiolania platyceps or "Helochelys" bakewelli (his Tretosternon bakewelli).

Nopcsa (1928b) provided an improved classification some decades later that surprisingly converges upon the currently emerging consensus regarding the turtle stem lineage. In addition to all newly discovered Triassic taxa, his Amphichelydia included all then known helochelydrids (included in his Pleurosternidae), meiolaniids, and Kallokibotion bajazidi, but also all turtles currently recognized as paracryptodires, plesiochelyids, and some protostegids. This arrangement was later closely replicated by Williams (1950), Kuhn (1964), Sukhanov (1964), and Romer (1956), though often with modified groupings within Amphichelydia.

Following the cladistic revolution, Gaffney (1975) noted that the term Amphichelydia is undesirable because the grouping was not supported by any shared derived characters and therefore, at best, did not connote a monophyletic group. Gaffney (1975) proposed an alternative classification scheme that grouped turtles using characters he thought to be derived. In particular, turtles with a pterygoid trochlea and a sutured pelvis were grouped into the clade Pleurodira and turtles with an otic trochlea and a braincase braced by the pterygoid were grouped into the clade Cryptodira. As a result, only the Late Triassic Proganochelys quenstedtii was recognized as a stem turtle, whereas all other known fossil turtles were assigned to the crown. This classification was at first further supported by additional manually generated cladograms (e.g., Gaffney 1984; Gaffney and Meylan 1988), but soon after further codified through the use of numerical methods (e.g., Gaffney et al. 1991, 1998, 2007).

The idea that all fossil turtles but Proganochelys quenstedtii are assignable to the crown group was more recently undermined in a series of papers that concluded that some of the characters utilized to unite pleurodires and cryptodires were either homoplastic, such as the suturing of the pelvis to the shell or the full bracing of the braincase by the pterygoid, or at least potentially ancestral to other derived characters, such as the otic trochlea relative to the pterygoid trochlea (e.g., Rougier et al. 1995; Sukhanov 2006; Joyce 2007; Sterli 2008; Anquetin 2012; Joyce and Sterli 2012; Joyce, Schoch, and Lyson 2013). According to these updated phylogenetic hypotheses, the stem turtle lineage is populated by a diverse group of turtles from all continents that may have persisted as late as the Holocene. This novel conclusion, however, could only be achieved after a number of historic specimens had been described in greater detail (e.g., Gaffney 1983, 1985, 1990, 1996; Gaffney et al. 1987; Gaffney and Meylan 1992), until new material had been described (e.g., Gaffney et al. 1987, 1998, 2007; Rougier et al. 1995; Sukhanov 2006), and until phylogenies were more densely sampled at the species level. For an alternative view on this progression, please refer to Gaffney and Jenkins (2010).

Although the general structure of the turtle tree now appears to be consolidating, the exact composition of the turtle stem is still under discussion. I here follow the emerging consensus (see Joyce et al. 2016) that all Triassic to Early Jurassic turtles are referable to the stem, in addition to all helochelydrids, sichuanchelyids, meiolaniforms, and an eclectic mix of fossil turtles with less certain affinities, such as Kallokibotion bajazidi and Spoochelys ormondea. The arrangement of the three primary lineages of derived turtles (i.e., PanCryptodira, Pan-Pleurodira, and Paracryptodira) is not fully resolved and it is therefore plausible that Paracryptodira may eventually be shown to belong to the stem as well. The representatives of this clade are nevertheless treated elsewhere (e.g., Joyce and Lyson 2015).

For institutional abbreviations see Appendix 1. Named basal Mesozoic turtle genera are listed in Appendix 2.

\section{Skeletal Morphology of Basal Mesozoic Turtles}

The currently known basal testudinates not only document the morphological transition from the 
earliest known turtles to the turtle crown but also specializations that occurred in numerous clades that diversified in parallel with the crown. In this section I will therefore attempt to distinguish between these two, often-opposing evolutionary trends.

\section{Cranium}

The cranial morphology is fortunately known for a broad selection of Mesozoic stem turtles. For Triassic stem turtles, descriptions are available for Palaeochersis talampayensis (Sterli et al. 2007) and Proganochelys quenstedtii (Gaffney 1990). Among Jurassic stem turtles, the cranial morphology is known for Australochelys africanus (Gaffney and Kitching 1995), Condorchelys antiqua (Sterli and de la Fuente 2010), Eileanchelys waldmani (Anquetin 2010), Heckerochelys romani (Sukhanov 2006), Kayentachelys aprix (Sterli and Joyce 2007; Gaffney and Jenkins 2010), and "Sichuanchelys" palatodentata (Joyce et al. 2016). The cranial anatomy of Cretaceous stem turtles is finally known for Chubutemys copelloi (Gaffney et al. 2007; Sterli et al. 2015), Helochelydra nopcsai (Joyce et al. 2011), Kallokibotion bajazidi (Gaffney and Meylan 1992), Mongolochelys efremovi (Khosatzky 1997; Sukhanov 2000; Suzuki and Chinzorig 2010), Naomichelys speciosa (Joyce et al. 2014), Patagoniaemys gasparinae (Sterli and de la Fuente 2011), Spoochelys ormondea (Smith and Kear 2013), and Trapalcochelys sulcata (Sterli, de la Fuente, and Cerda 2013).

The skull of stem turtles varies greatly in shape, but the snouts are usually short, the eyes and nose vertically oriented, and temporal emarginations poorly developed to absent (Figure 1). Nasals with a midline contact are universally present, but reduction trend is apparent towards the crown. The prefrontals of stem turtles range in size from large to reduced, but they universally lack a midline contact. The descending process is well developed and distally contacts the vomer and palatines. The prefrontals and other elements surrounding the eye are sometimes embossed (Figure 1A), but typically smooth. The frontals are large elements and their contribution to the orbits is highly variable. The parietals are large elements that generally form the posterior margin of the skull and have broad contacts with the postorbitals and parietals. The descending process of the most basal stem turtles is poorly developed and the trigeminal nerve therefore exits the braincase through a notch (e.g., Proganochelys quenstedtii). In more derived stem turtles the trigeminal nerve is either enclosed through an expanded descending process of the parietal (e.g., Helochelys nopcsai) or through an expanded ascending process of the epipterygoid (e.g., Meiolania platyceps). The postorbitals are large, elongate elements that universally contact the squamosal posteriorly and do not contribute to the upper and lower temporal emarginations. The most basal turtles are reported to have supratemporals (Figure 1A), but these elements are otherwise absent.

The premaxillae are paired elements that form the anterior portion of the snout. In the most basal representatives, the premaxillae form elongate ascending processes that contact the nasals dorsally and fully subdivide the external nares (Figure 1A). The external nares of more derived stem turtles are partially or fully confluent (Figure 1B, C). The maxillae are large elements that define the anterior and ventral aspects of the orbit. A posterior contact with the quadratojugal is lacking among most basal turtles (Figure 1A, B), but present among helochelydrids (Figure 1C). A lacrimal with lacrimal foramen is present in the most basal stem turtles (Figure 1A), but otherwise absent (Figure 1B, C). The jugal of the most basal stem turtles is a large element that contributes substantially to the orbit and the lower temporal emargination (Figure 1A, B), but this element does not contribute to either in helochelydrids (Figure 1C). A posterior contact with the quadrate is present in some sichuanchelyids (Figure 1B). The quadratojugal generally is a high element that is located anterior to the quadrate (Figure 1A, C), but it shifts dorsally and does not contribute to the lower temporal emargination in some sichuanchelyids (Figure 1B). The squamosal of the most basal turtles is a relatively small, flat element that contributes to the upper temporal roofing (Figure 1A), but in all more derived turtles this elements shifts to the posterior margin of the skull and caps the antrum postoticum (Figure 1B, C). This element also often expands significantly to help further roof the anterior neck region, particularly in sichuanchelyids (Figure 1B).

The palate of stem turtles is generally formed by the premaxillae and maxillae, and contributions from the vomer, palatines, and jugals are minor at best. The triturating surfaces are variously narrow 


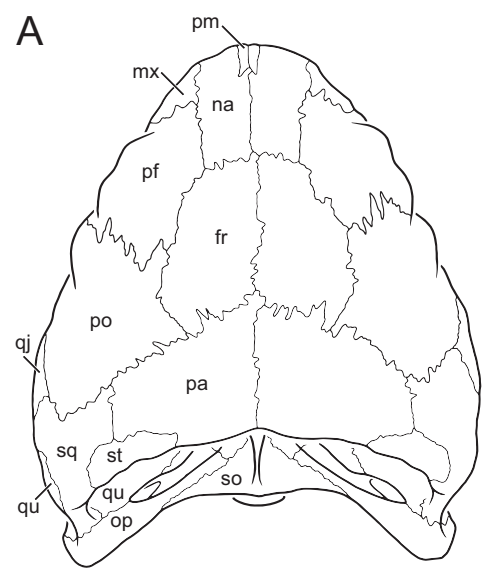

Proganochelys quenstedtii
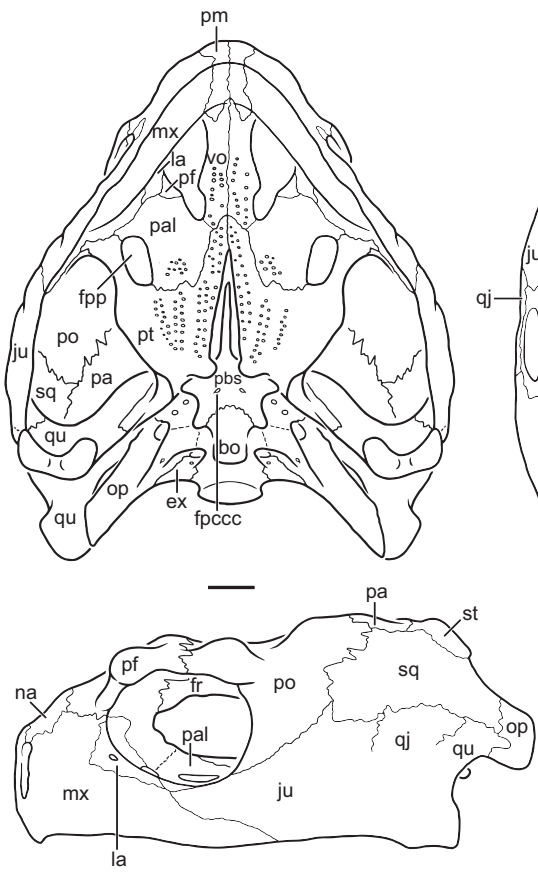

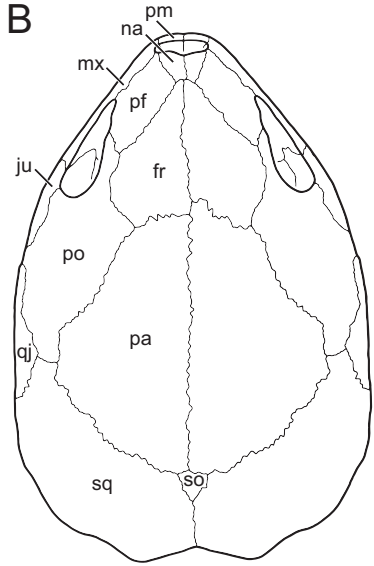

Mongolochelys efremovi

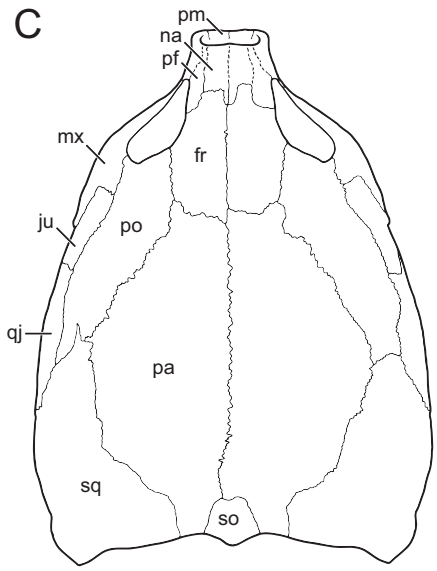

Helochelydra nopcsai
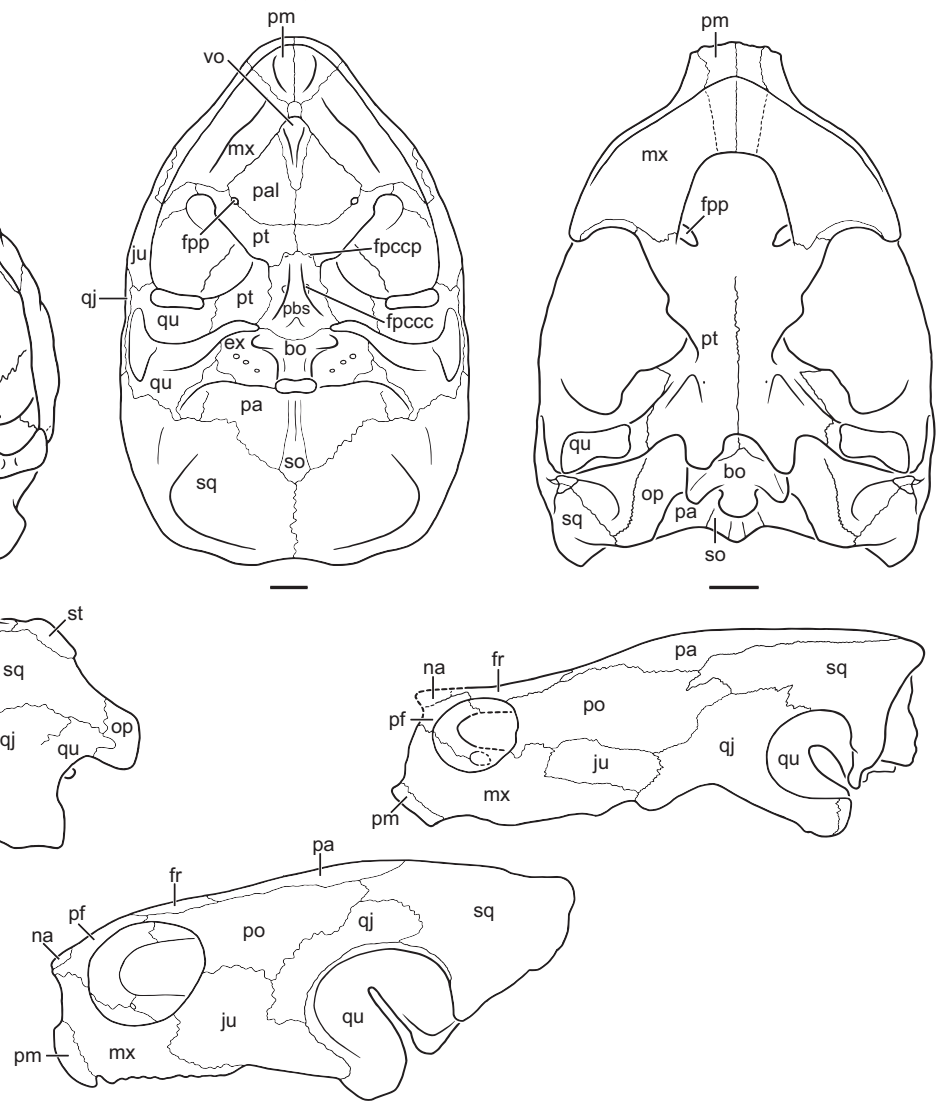

FIGURE 1. Cranial morphology of basal testudinates exemplified by three species. A, Proganochelys quenstedtii (redrawn from Gaffney 1990). B, Mongolochelys efremovi (modified from Sukhanov 2000; Suzuki and Chinzorig 2010; Rabi, Zhou, et al. 2013). C, Helochelydra nopcsai (modified from Joyce et al. 2011). Abbreviations: bo, basioccipital; ex, exoccipital; fpccc, foramen posterius canalis carotici cerebralis; fpccp, foramen posterius canalis carotici palatinum; fpp, foramen palatinum posterius; fr, frontal; ju, jugal; la, lacrimal; mx, maxilla; na, nasal; op, opisthotic; pa, parietal; pal, palatine; pbs, parabasisphenoid; pf, prefrontal; pm, premaxilla; po, postorbital; pt, pterygoid; qj, quadratojugal; qu, quadrate; so, supraoccipital; sq, squamosal; st, supratemporal; vo, vomer. Scale bars approximate $1 \mathrm{~cm}$. 
(Figure 1A), broadened and decorated with accessory ridges (Figure $1 \mathrm{~B}$ ), or broad and flat (Figure 1C), but secondary palates are universally absent. The vomers are notably large, paired elements in the most basal turtles (Figure 1A), but they are otherwise reduced in size and unpaired in more derived forms (Figure 1B, C). The vomers, palatines, and pterygoids possess residual palatal teeth in the most basal turtles (Figure 1A), but these are sequentially lost in later forms (Figure 1B, C). The palatines are flat elements that form much of the primary palate. The presence and size of a midline contact varies. The foramen palatinum posterior is universally present and varies greatly in size. The pterygoids of the most basal turtles are large elements that are anteriorly sutured to the maxillae, palatines, and vomers and posteriorly to the quadrates, but that articulate with the braincase via the kinetic basicranial joint. These elements furthermore form a well-developed interpterygoid vacuity, but the external processes are not particularly distinct (Figure 1A). The pterygoids of the stem turtle lineages increasingly stabilize the basipterygoid joint, first by surrounding the joint and then by suturing to the parabasisphenoid (Figure 1B) and even the basioccipital (Figure $1 \mathrm{C}$ ). The interpterygoid vacuity is closed in concert. The initial blocking of the interpterygoid joint likely occurred only once, but the full closure occurred multiple times. This process entrapped a number of nerves and vessels, in particular the carotid system and the vidian nerve, in a number of different patterns, which can therefore be used to retrieve phylogenetic relationships (Sterli et al. 2010; Rabi, Zhou, et al. 2013). The parabasisphenoid has a long rostrum in the most basal turtles (Figure 1A), which is significantly reduced in all more derived forms (Figure 1B, C). A ventral exposure is absent in some helochelydrids (Figure 1C). The basioccipital forms a single tubercle in the most basal turtles (Figure 1A), but the vast majority of derived turtles possess a pair of tubercles (Figure 1B), which is supplemented by a secondary pair formed by the pterygoids in helochelydrids (Figure 1C).

The turtle stem lineage documents the independent acquisition of an impedance matching ear relative to that of all other extant amniotes. In the most basal turtles (e.g., Proganochelys quenstedtii), the columella is a thick, rodlike element that attaches directly to the medial side of the vertically oriented quadrate, which only reveals a minor posterior arching in lateral view onto which the tympanum is attached. In this arrangement sound is picked up by the tympanum, but is inefficiently transferred to the inner ear via the quadrate and stapes. This system is improved by having the stapes articulate directly with the tympanum. In this arrangement the stapes is an elongate, slender element that is guided by a notch formed by the quadrate, the incisura columella auris, that remains open posteriorly in all stem turtles. The quadrate produces a kidney-shaped funnel on its lateral side, the cavum tympani, thereby increasing the size of the tympanum. The quadrates and squamosals finally expand the volume of the middle ear by forming a posterior expansion of the cavum tympani, the antrum postoticum (Figure $1 \mathrm{~B}, \mathrm{C})$. In this arrangement, sound is transmitted directly from the enlarged tympanum to the inner ear via the slim columella that operates within an inflated, air-filled middle ear cavity.

The posttemporal fenestra of the earliest stem turtles is already enlarged relative to various outgroups, but the geometry of the skull suggests that the temporal musculature still attached to the insides of the temporal fossa. In addition to closing the basicranial joint, bite force was further increased in the stem turtle lineage by suturing the paroccipital process to the quadrate (see above), by expanding the anterior wall of the braincase, either by expanding the descending process of the parietal or the ascending process of the epipterygoid (see above), and by providing the expanding temporal musculature with an expanded attachment surface by further opening the posttemporal fossa and forming a supraoccipital crest (Sterli and de la Fuente 2010). These changes to the geometry of the skull demand redirecting the temporal muscles past the otic capsule, which is accomplished by having the quadrate and prootic form an otic trochlea, a lubricated contact along the anterior edge of the otic capsule, which redirects the musculature around this obstacle. These adaptations are further improved among various lineages of crown turtles.

The posterior portions of the inner ear are posteriorly open among the most basal stem turtles and the inner ear capsule can therefore be seen in ventral view (Figure 1A). This area is variously ossified through the development of a slender, descending processus interfenestralis, the posterior 
process of the pterygoid, and through a lateral expansion of the exoccipitals (Figure 1B, C). The fenestra postotica and the posterior jugular foramen nevertheless remain confluent in all known stem turtles.

The triturating surfaces of the mandibles of stem turtles generally mimic those of the upper jaw by varying their width or by developing accessory ridges. Splenials are universally present and well developed in all stem turtles.

\section{Shell}

All here recognized stem turtles are known from postcranial material, but not all taxa are known from substantial material or have been adequately described. I therefore here list only the most informative sources.

Among Triassic stem turtles, the shell anatomy is best understood for Palaeochersis talampayensis (Sterli et al. 2007), Proganochelys quenstedtii (Gaffney 1990), and Proterochersis porebensis (Szczygielski and Sulej 2016). Among Jurassic material, meaningful descriptions are available for Condorchelys antiqua (Sterli and de la Fuente 2010), Eileanchelys waldmani (Anquetin 2010), Heckerochelys romani (Sukhanov 2006), and "Sichuanchelys" palatodentata (Joyce et al. 2016). Rich material is available for Kayentachelys aprix, but it remains to be described. I nevertheless had access to this material in the past and therefore provide an updated reconstruction herein (Figure 2A). Many details regarding the description of Indochelys spatulata (Datta et al. 2000) remain questionable. Among Cretaceous stem turtles, the shell anatomy is best known for Chubutemys copelloi (Sterli et al. 2015), Kallokibotion bajazidi (Gaffney and Meylan 1992), Mongolochelys efremovi (Khosatzky 1997; Sukhanov 2000; Suzuki and Chinzorig 2010), Naomichelys speciosa (Joyce et al. 2014), Otwayemys cunicularius (Gaffney et al. 1998), and Solemys vermiculata (Lapparent de Broin and Murelaga 1999). The bone histology of a surprisingly broad sample of stem turtles is also available (e.g., Scheyer and Sander 2007; Scheyer and Anquetin 2008; Pérez-García et al. 2013; Scheyer et al. 2014, 2015; Cerda et al. 2016).

All representatives of Testudinata, by definition, are characterized by having a complete turtle shell, or at least by deriving from an ancestor that had a complete turtle shell. The turtle shell is here defined as composite formed of sutured plas- tral and carapacial bones, but the exact number and arrangement of bones in the most basal turtles is currently not understood, as none is currently known from sufficiently preserved material. It nevertheless is apparent that the carapace of the most basal stem turtles consists of ten vertebrae and their associated ribs, of which the posterior nine interacted with the dermis to form the neurals and costals. The ribs of the anterior vertebrae are shifted towards the posterior to contact the subsequent vertebra, but this shift becomes less notable towards the posterior and the most posterior ribs therefore only contact their own vertebra. The overlying dermal portion of the carapace consists of a nuchal, nine neurals, and nine pairs of costals. The pygal area is not preserved in any specimen and it therefore remains unclear if suprapygals and pygal were present, though it is quite likely. No basal turtle preserves an unfused peripheral ring, but if the number of marginals is taken as a proxy for the number of peripherals, it is clear that the most basal turtles possess more than 11 pairs of peripherals. The homology of the carapacial scutes is not yet fully understood, but it appears that the shell is covered by a cervical, four to five vertebrals, four to five pleurals, and up to 17 marginals. A variable number of supramarginals partially to fully separate the pleurals from the marginals. The plastron of the most basal turtles consists of an entoplastron, two pairs of mesoplastra, and a pair of epi-, hyo-, hypo-, and xiphiplastra. The epiplastra lack a midline contact, but a dorsal contact of the ascending process of the epiplastra (here not interpreted as cleithra sensu Joyce et al. 2006) with the carapace is only known to occur in Proganochelys quenstedtii and Palaeochersis talampayensis. A pair of gulars, extragulars, humerals, pectorals, femorals, anals, and two pairs of abdominals cover the plastron. A number of supernumerary caudal scales are situated at the posterior margin of the plastron in representatives of the Proterochersis lineage. Four pairs of inframarginals cover the bridge. Plastral fontanelles are absent.

The stem turtle lineage documents the origin of the modern turtle shell. The number of bony elements in the carapace is eventually reduced to the nuchal, eight neurals, up to three suprapygals, a pygal, and eight pairs of costals, and eleven pairs of peripherals (Figure 2). Much variation is apparent to this arrangement, particularly to the num- 
A

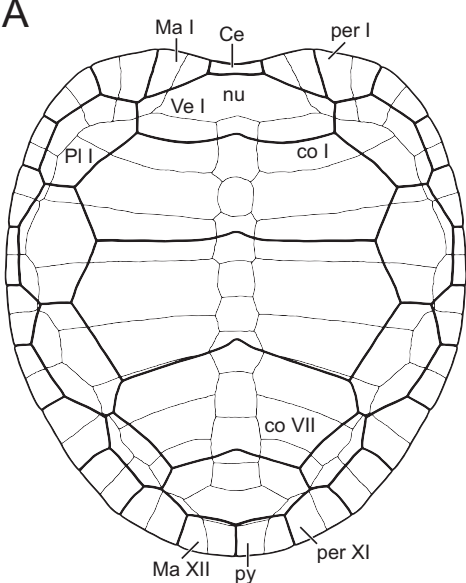

Kayentachelys aprix

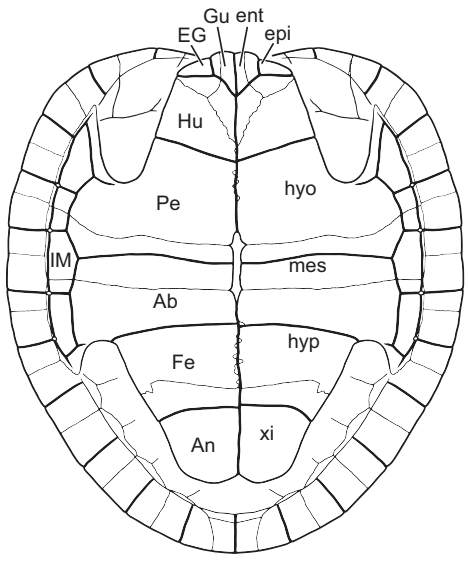

B



Naomichelys speciosa

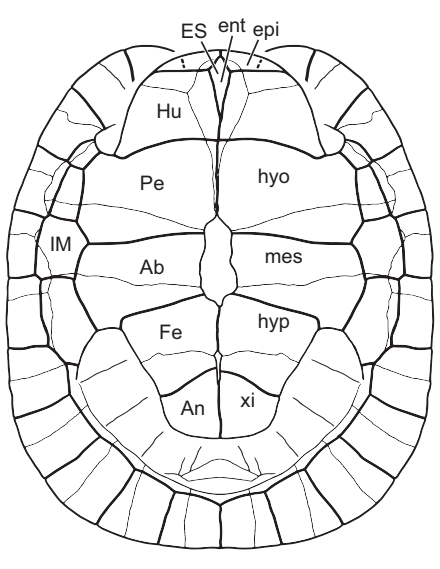

C



Mongolochelys efremovi

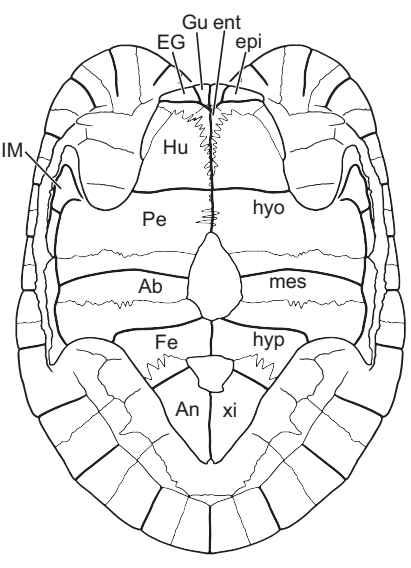

FIGURE 2. Shell morphology of basal testudinates exemplified by three species. A, Kayentachelys aprix (reconstructed from MCZ 8917). B, Naomichelys speciosa (modified from Joyce et al. 2014). C, Mongolochelys efremovi (modified from Sukhanov 2000; Suzuki and Chinzorig 2010). Abbreviations: Ab, abdominal scute; An, anal scute; Ce, cervical scute; co, costal; EG, extragular; ent, entoplastron; epi, epiplastron; ES, entoplastral scute; Fe, femoral scute; Gu, gular scute; Hu, humeral scute; hyo, hyoplastron; hyp, hypoplastron; IM, inframarginal scute; Ma, marginal scute; mes, mesoplastron; nu, nuchal; Pe, pectoral scute; per, peripheral; Pl, pleural scute; PP, prepleural scute; py, pygal; spy, suprapygal; Ve, vertebral scute; xi, xiphiplastron. Scale bars approximate $5 \mathrm{~cm}$.

ber of neurals and suprapygals (Figure 2). A single cervical, five vertebrals, four pairs of pleurals, and twelve pairs of marginals cover the carapace in return. The number and arrangement of carapacial scutes is relatively stable, but supernumerary scutes, in particular prepleurals, are often present (Figure 2B). The plastron is generally broad, consists of a single entoplastron and a pair of epi-, hyo-, meso-, hypo-, and xiphiplastra, and is variously connected to the carapace via an osseous bridge (Figure 2A, B) or ligaments (Figure
2C). The contribution of the entoplastron to the margin of the plastron (Figure 2A) is eventually lost (Figure 2C). The posterior process of the entoplastron is particularly large among the most basal turtles, but is reduced towards the crown. The presence of plastral fontanelles (Figure 2) is highly variable. A pair of gulars, extragulars, humerals, pectorals, abdominals, femorals, anals, and four pairs of inframarginals cover the plastron. The arrangement of plastral bones and scutes is highly conserved among derived stem 
turtles, although occasional supernumerary scutes are added to the plastron, such as the entoplastral scute of helochelydrids (Figure 2B).

\section{Postcranium}

Fragmentary postcranial remains have been reported for many basal turtles, but the postcranial morphology is mostly informed by a small selection of taxa. Among Triassic stem turtles, the postcranial anatomy is particularly well known for Proganochelys quenstedtii (Gaffney 1990) and Palaeochersis talampayensis (Sterli et al. 2007), but informative remains are also available for Proterochersis limendorsa (Joyce, Schoch, and Lyson 2013; Szczygielski and Sulej 2016) and Proterochersis porebensis (Szczygielski and Sulej 2016). Among Jurassic stem turtles, the most meaningful remains have been described for Condorchelys antiqua (Sterli and de la Fuente 2010), Eileanchelys waldmani (Anquetin 2010), and "Sichuanchelys" palatodentata (Joyce et al. 2016). Among Cretaceous stem turtles, particularly informative material is available for Mongolochelys efremovi (Suzuki and Chinzorig 2010) and Naomichelys speciosa (Joyce et al. 2014), but notable remains are also available for Kallokibotion bajazidi (Gaffney and Meylan 1992), Patagoniaemys gasparinae (Sterli and de la Fuente 2011), and Trapalcochelys sulcata (Sterli, de la Fuente, and Cerda 2013).

The eight cervical vertebrae of all stem turtles are massive, short bones with broad, horizontally oriented pre- and postzygapophyses, dorsal processes that increase in size towards the posterior, and central articulations that are as high as wide. The most basal turtles have well-developed cervical vertebrae, of which the most posterior is nearly as long as the most anterior thoracic vertebra. These elements, however, are greatly reduced towards the crown. The centra are generally amphicoelous, but formed centra are developed in numerous lineages, including sichuanchelyids, helochelydrids, and meiolaniforms. All stem turtles appear to have had cervical ribs, of which the most posterior is particularly elongate in the most basal representatives. The neck is protected by osteoderms in Proganochelys spp. and has been shown to have had enough flexibility to diagonally tuck below the shell (Werneburg et al. 2015). The first thoracic rib is as long as all other ribs in the most basal stem turtles, but progressively shortens towards the crown. All remaining thoracic ribs have vertically oriented proximal rib heads in the most basal turtles, but these flatten horizontally towards the crown. The tenth rib articulates with a peripheral distally in most basal turtles, but the rib is reduced and the contact with the peripherals is lost towards the crown. The sacrum consists of two vertebrae. The ribs of the anterior sacral vertebra are significantly larger than the posterior one. The tails of stem turtles are elongate, consist of approximately 20 amphicoelous vertebrae, and chevrons typically adorn the posterior portions of the tail. Osteoderms and a tail club protect the tail in Proganochelys quenstedtii and derived, post-Mesozoic meiolaniforms.

The pectoral girdle of the most basal stem turtles is a triradiate element, but the acromion process of the scapula is notably shorter than the other two elements. A wide lamella spans between the coracoid and the acromion process that is punctured by a larger coracoid foramen. Less prominent laminae are otherwise developed between the dorsal process and the acromion and the coracoid. The acromion becomes longer and the laminae are reduced towards the crown, but the coracoid retains a broad expansion in helochelydrids, meiolaniforms, and sichuanchelyids. The pelvic girdle of the most basal turtles shows great variation in that it is either sutured to the carapace and plastron, as in Proterochersis spp., or articulates with carapace via the sacrum and with the plastron via three or four pubic and ischial processes, as in the vast majority of other basal turtles. The height of the ilium mostly reflects the geometry of the shell.

The limbs of the most basal stem turtles are notably stout. The digital formula of the manus and pes is 2-2-2-2-2. The humeri have broadly splaying medial and lateral processes, the head has a distinct shoulder, and the ectepicondylar fossa is enclosed. The femur is stout but straight. The metacarpals and the metatarsal and the proximal row of phalanges of the manus and pes are extremely short, but the distal row of phalanges is massive and claw bearing. The fifth digit of the pes is fully aligned with the remaining digits. The transition to the limbs of crown turtles is poorly documented as few complete limbs are preserved, but it is apparent that the limbs become more elongate towards the crown, both through the slimming of elements and the addition of phalanges. In parallel, the efficiency of the foot is increased by repurposing the ansula, the fused 
fifth distal tarsal and metatarsal (Joyce, Werneburg, and Lyson 2013), as a heel that is aligned with the tarsals and adjusting the fifth phalanx to operate as a metatarsal. The claw of the fifth digit is lost in parallel.

\section{Phylogenetic Relationships}

The vast majority of recent phylogenies have concluded that the turtle stem lineage is populated by a diverse assortment of fossil taxa with a global distribution (e.g., Rougier et al. 1995; Sukhanov 2006; Joyce 2007; Sterli 2008; Anquetin 2012; Sterli, Pol, and Laurin 2013; Rabi, Zhou, et al. 2013; Rabi et al. 2014; Zhou and Rabi 2015; Joyce et al. 2016). Although much disagreement is still apparent among various hypotheses, some general trends are apparent. First, all named Triassic turtles and the Early Jurassic Australochelys africanus are universally retrieved as the most basal turtles. The monophyly of the three named representatives of Proterochersis is well supported (Szczygielski and Sulej 2016). I furthermore hypothesize the monophyly of the three named species of Proganochelys using derived characters, but this has yet to be shown in a global context. A sister group relationship is commonly retrieved for Palaeochersis talampayensis and Australochelys africanus. Finally, the most recent analyses place Proterochersis spp. at the very base of the tree, but the $P$. talampayensis/A. africanus clade closer to the crown. Second, all remaining turtles universally form a more derived clade, herein named Mesochelydia, that is supported by a long list of characters. The most basal representatives of this clade, in particular Condorchelys antiqua, Eileanchelys waldmani, Heckerochelys romani, Indochelys spatulata, and Kayentachelys aprix, have been recovered from Early to Middle Jurassic deposits, but their interrelationships are unclear. I therefore here place them in a basal mesochelydian polytomy. Third, all remaining turtles are consistently retrieved in a more derived clade, though with less character support. I herein name this clade Perichelydia. Fourth, three basal perichelydian clades have been retrieved with a strong biogeographic signal: Helochelydridae, from the Late Jurassic to Late Cretaceous of Eurasia, Sichuanchelyidae, from the Middle Jurassic to Late Cretaceous of Asia, and Meiolaniformes, restricted to the Cretaceous to Holocene of southern Gondwana (Joyce et al. 2016). All other basal perichelydians, in particular Kallokibotion bajazidi and Spoochelys ormondea, have less clear phylogenetic relationships and I therefore place them in a basal polytomy within Perichelydia. This simplified consensus topology is provided in Figures 3 and 4.

\section{Paleoecology}

The habitat preferences of the most basal turtles have been intensively debated over the course of the last two decades, as a terrestrial stem lineage is more consistent with a terrestrial origin of the group, whereas an aquatic stem lineage favors an aquatic origin of turtles (Joyce and Gauthier 2004). To aid my discussion herein, I here follow Foth et al. (in press) by recognizing four primary habitat categories among turtles: terrestrial (turtles that predominantly live and feed on land), semiaquatic (turtles that variously live and feed on land or in water), freshwater aquatic (turtles that predominantly live and feed in freshwater habitats ranging from swamps to lakes to rivers), and marine (turtles that live and feed in oceans). In this regard, turtles that live in swamps can either be freshwater aquatic, semiaquatic, or terrestrial, as swampy ecosystems typically consist of a patchwork of dry and submerged land areas.

The habitat preferences of fossil turtles are typically first assessed by reference to the sedimentary environment in which they were found. This approach generally yields good results, but must always be viewed with caution, as turtle carcasses can be transported postmortem, and because a certain sedimentary environment may actually contain several turtle habitats, such as the lowland swamps mentioned above (Foth et al. in press). With this caveat in mind, it is notable that Triassic turtles are universally absent from fossilrich lowland facies dominated by temnospondyls and phytosaurs, but rather are found in upland facies characterized by basal sauropodomorph dinosaurs (Joyce et al. 2009). All reports of purported marine turtles from the Late Triassic, such as the types of Chelyzoon latum and Chelyzoon blezingeri, have since been shown to be nonturtle in nature (see Systematic Paleontology below). Jurassic and Cretaceous stem turtles have been reported from a broad suite of terrestrial habitats, ranging from near-coastal swamps (e.g., Anquetin et al. 2009) to fissure fills (Sukhanov 2006) to dry uplands (Khosatzky 1997), but these turtles are 

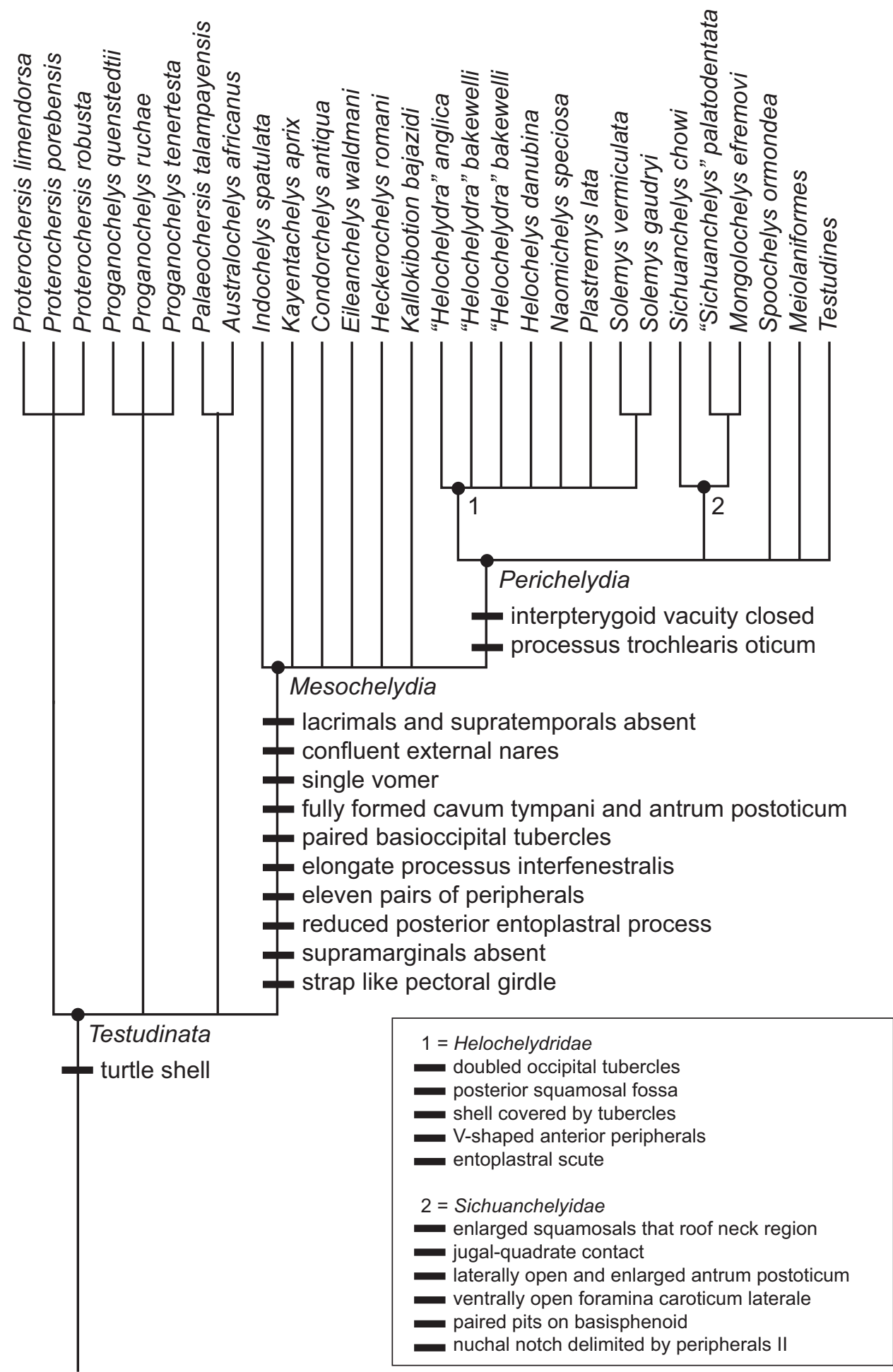

FIgure 3. A phylogenetic hypothesis of Mesozoic stem testudinates, with select diagnostic characters for the most important clades. 
once again notably absent from marine settings. Given that terrestrial turtles are plausibly found in any of these depositional settings, I am cautious about inferring semiaquatic to aquatic habitat preference of these turtles (contra Anquetin et al. 2009; Marmi et al. 2009). The deposition settings of basal turtles are nevertheless broadly consistent with these animals being continental, but an unambiguous terrestrial signal is nevertheless apparent in the Triassic.

The ecology of Mesozoic basal turtles can furthermore be assessed by reference to their skeletal morphology. Triassic representatives once again show a consistent terrestrial signal by having notably stout limbs with short hands and feet, osteoderms, and tail clubs (e.g., Rougier et al. 1995; Joyce and Gauthier 2004; Joyce et al. 2009), but the signal is mixed once again among Jurassic and Cretaceous stem turtles. Complete fore- and hind limbs have so far only been reported for the sichuanchelyid Mongolochelys efremovi (Suzuki and Chinzorig 2010; pers. obs. of material held at PIN) whereas complete hind limbs are known for the helochelydrid Naomichelys speciosa (Joyce et al. 2014). The hands and feet of these animals are more gracile and possess an expanded digital count relative to those of their Triassic relatives, but are nevertheless consistent with terrestrial habitat preferences (Joyce and Gauthier 2004). Osteoderms appear to be broadly present among helochelydrids (Barrett et al. 2002; Joyce et al. 2014), and are therefore consistent with a terrestrial signal as well. The available skeletal morphology of Mesozoic basal testudinates is therefore more consistent with terrestrial habitat preferences, but significant portions of the tree are not sampled, particularly various Jurassic representatives.

The histology of turtle bone has emerged in the last decade as an alternative source of paleoecological data that can even utilize fragmentary specimens to retrieve meaningful insights. This research program has led to the conclusion that the basal Triassic testudinates Proganochelys quenstedtii and Proterochersis robusta have a shell bone histology consistent with terrestrial habitat preferences, that most Jurassic stem turtles, in particular Condorchelys antiqua, Eileanchelys waldmani, and Heckerochelys romani, show aquatic adaptations (Scheyer et al. 2014; Cerda et al. 2016), but that derived stem turtles, such as solemydids and meiolaniforms, show terrestrial adaptations again
(Sterli, de la Fuente, and Cerda 2013; Scheyer et al. 2015). These conclusions are broadly consistent with the sedimentological and postcranial anatomy discussed above. However, given that the relationships of basal turtles still remain partially unresolved and that sampling is poor, it remains unclear if the stem turtle lineage is terrestrial, but gave rise to groups with aquatic specializations, or if the ecological preferences of the stem turtle lineage flip-flopped during its evolution.

In contrast to the habitat preferences, only little is known about the dietary preferences of basal testudinates, in part because little complete cranial material is available. All basal representatives, in particular as Condorchelys antiqua, Eileanchelys waldmani, Heckerochelys romani, Kayentachelys aprix, Proganochelys quenstedtii, and "Sichuanchelys" palatodentata, have narrow jaws and their diet is therefore best interpreted as unspecialized. However, meiolaniids and Mongolochelys efremovi possess multiple rows of low, serrated accessory ridges in their jaws that are broadly consistent with herbivorous lifestyles in extant turtles (Sterli 2015; Foth et al. in press). On the other hand, helochelydrids have expanded flat triturating surfaces more consistent with durophagous dietary preferences. However, given that the remaining postcranial anatomy is more consistent with terrestrial habitat preferences (see above), it remains unclear what hard-shelled foodstuffs these turtles may have found on land (Joyce et al. 2011, 2014).

\section{Paleobiogeography}

The origin of turtles has been contentiously debated for more than two centuries (see Joyce 2015 for more recent summary) and the fossil record has therefore been scrutinized intensively for informative remains. A number of purported turtles, particularly from the Permian to Triassic, have since been shown to be non-testudinate in name. Among named taxa, these include Archaeochelys pougeti from the Permian of France (Bergounioux 1938), Chelyzoon latum, Chelyzoon blezingeri, and Priscochelys hegnabrunnensis from the Middle Triassic of Germany (Huene 1902; Karl 2005), and Arctosaurus osborni, Entoplastrites nuertingensis, Saurischiocomes keuperinus, and Saurodesmus robertsoni from the Late Triassic of Canada, Germany, and the United Kingdom, respectively (Adams 1875; Seeley 1891; Kuhn 


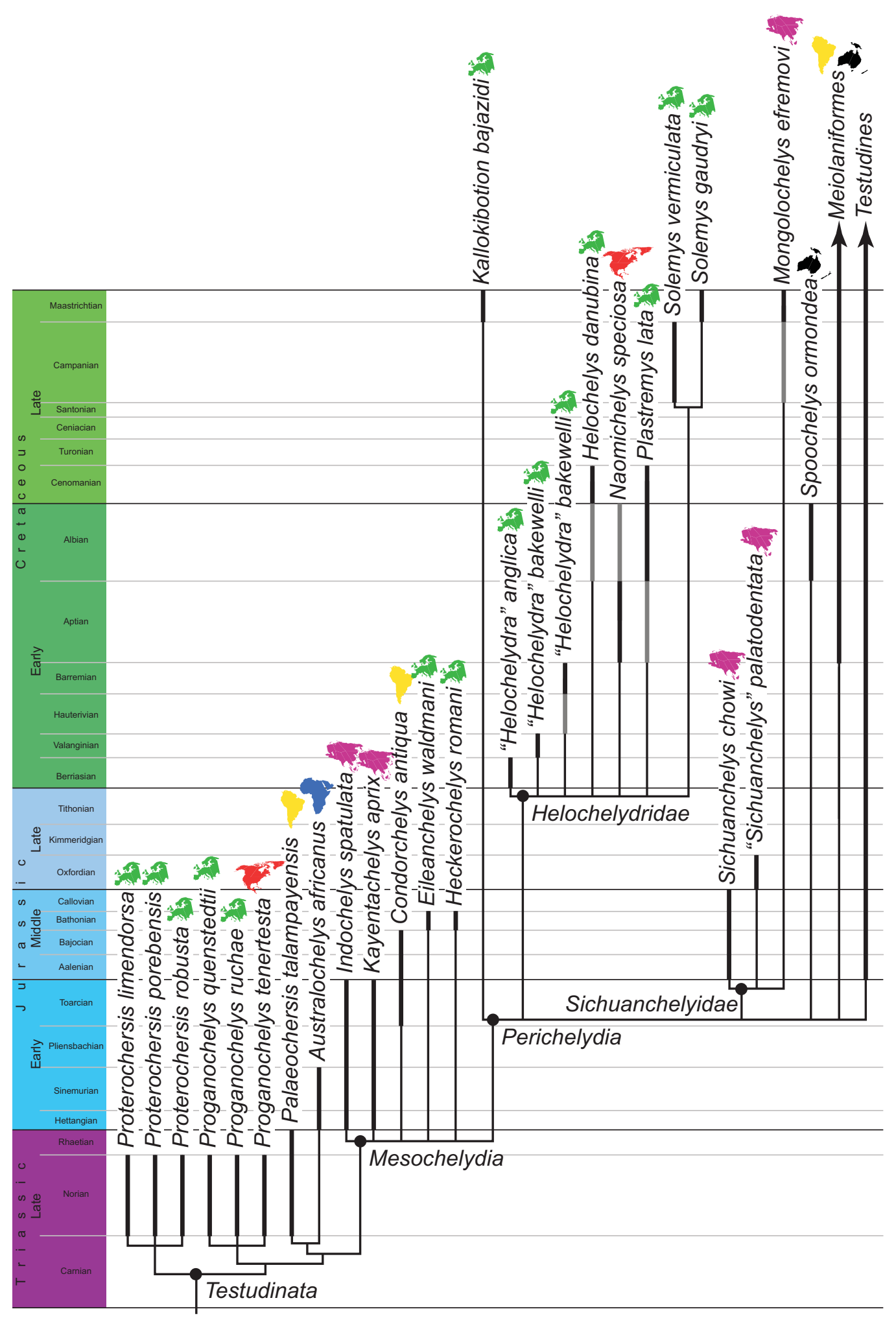

FIGURE 4. The stratigraphic and biogeographic distribution of valid Mesozoic stem turtles. Black lines indicate temporal distribution based on type material. Gray lines indicate temporal distribution based on referred material. 
1939; Huene 1956). The nonturtle nature of these fossils is briefly discussed below (see Systematic Paleontology). Huene (1902) reported additional, unnamed fragments from the Late Triassic of Germany and France, but these have all since been discredited (Jaekel 1914, 1915-1916; Kuhn 1941).

The earliest known unambiguous turtles are from the Late Triassic (Norian) and already have a global distribution. Norian turtle remains include Proganochelys quenstedtii, Proterochersis limendorsa, and Proterochersis robusta from northern and southern Germany (e.g., Baur 1887; Quenstedt 1889; Fraas 1899, 1913; Jaekel 1914, 1915-1916; Gaffney 1990; Karl and Tichy 2000; Joyce, Schoch et al. 2013; Szczygielski and Sulej 2016), Proganochelys ruchae from Phetchabun Province, Thailand (Broin et al. 1982; Broin 1984), Palaeochersis talampayensis from La Rioja Province, Argentina (Rougier et al. 1995; Sterli et al. 2007), Proganochelys tenertesta from New Mexico, USA (Lucas et al. 2000; Joyce et al. 2009), Proterochersis porebensis from the Silesian Voivodeship, Poland (Szczygielski and Sulej 2016), and Proganochelys indet. from Sermersooq, Greenland (Jenkins et al. 1994). Additional, indeterminate remains have recently been reported from the Norian to Rhaetian of Argentina (Martínez et al. 2015). Although some taxonomic clustering is apparent in the northern versus southern continents (e.g., Rougier et al. 1995), sampling is still low, especially in the south, and robust biogeographic patterns can therefore not be established at the moment (Joyce et al. 2016).

The Early Jurassic turtle record is relatively poor and typically restricted to single localities. All more complete turtle remains, however, have been identified as stem turtles. Early Jurassic turtles include Australochelys africanus from the Hettangian/Sinemurian (i.e., Hettangian or Sinemurian) of Orange Free State, South Africa (Gaffney and Kitching 1994), Condorchelys antiqua from the Toarcian-Bajocian of Chubut, Argentina (Sterli 2008; Sterli and de la Fuente 2010; Cerda et al. 2016), Indochelys spatulata from Maharashtra State, India (Datta et al. 2000), and Kayentachelys aprix from Arizona, USA (Gaffney et al. 1987; Sterli and Joyce 2007; Gaffney and Jenkins 2010). I hereby identify the purported isolated costal of a thalassemydid turtle from the Early Jurassic (Sinemurian) of Bavaria, Germany (Schleich 1984), as an indeterminate testudinate. Additional remains have otherwise been reported from the Early Jurassic of Germany (Theodori 1831; Münster 1834) and India (Nath et al. 2002), but none of these remains are figured and the German material now appears to be lost.

A number of studies have concluded in the last decade that the turtle crown is likely Middle Jurassic in age (e.g., Danilov and Parham 2008; Anquetin et al. 2009; Joyce, Parham, et al. 2013). However, given that the vast majority of turtle fossils are fragmentary, it is often difficult to distinguish between crown and stem turtles. Although closer examination revealed the majority of specimens from Asia and Europe to be associated with the crown (e.g., Tong et al. 2002; Scheyer and Anquetin 2008; Rabi et al. 2010, 2014; Tong, Danilov, Ye, Ouyang, and Peng 2012; Tong, Danilov, Ye, Ouyang, Peng, and Li 2012; Rabi, Zhou, et al. 2013), two named taxa have been revealed to be basal mesochelydians, in particular Eileanchelys waldmani from the Bathonian of Scotland, United Kingdom (Anquetin et al. 2009; Anquetin 2010), and Heckerochelys romani from the Bathonian of Moscow Oblast, Russia (Sukhanov 2006). Additional, fragmentary remains have been reported from the Middle Jurassic of Morocco, but these are too incomplete to allow identification beyond Testudinata (Haddoumi et al. 2016).

The freshwater aquatic habitat of crown turtles splits into three during the Middle Jurassic and each landmass, Asia, Euramerica, and Gondwana, vicariantly develops its own turtle fauna, Pan-Cryptodira, Paracryptodira, and Pan-Pleurodira, respectively. Three basal turtle lineages mimic this development, although it remains unclear if this pattern is caused by vicariance as well (Joyce et al. 2016). The oldest remains of the Asian clade Sichuanchelyidae are Sichuanchelys chowi from the Middle Jurassic Sichuan, China (Ye and Pi 1997; Danilov and Parham 2008; Tong, Danilov, Ye, Ouyang, and Peng 2012), followed by "Sichuanchelys" palatodentata from the Late Jurassic (Oxfordian) of Xinjiang, China (Brinkman et al. 2013; Joyce et al. 2016). The last representative of the sichuanchelyid lineage is Mongolochelys efremovi from the Late Cretaceous (Campanian-Maastrichtian) of Mongolia (Khosatzky 1997; Suzuki and Chinzorig 2010), indicating the presence of an extensive sichuanchelyid ghost lineage that spans much of the Cretaceous. 
The basal turtle clade Helochelydridae (= Solemydidae) is restricted to Euramerica (Nopcsa 1928a; Lapparent de Broin and Murelaga 1996; Hirayama et al. 2000; Joyce et al. 2011, 2016). The earliest evidence for this lineage is a single, diagnostic fragment from the Late Jurassic (Tithonian) of England (Joyce et al. 2011). A partial carapace from Late Jurassic of Poland was initially interpreted as belonging to the helochelydrid lineage as well (Borsuk-Białynicka and Młynarski 1968), but similarities are more apparent with plesiochelyids (J. Anquetin, pers. comm., 2016) and this fossil is therefore disregarded herein. The early to "mid" Cretaceous (Berriasian to Cenomanian) European helochelydrid record consists of the Berriasian "Helochelydra" anglica from England (Lydekker 1889b), the Berriasian or Valanginian "Helochelydra" bakewelli from England (Mantell 1827, 1833; Lydekker 1889b; Joyce et al. 2011), the Barremian Helochelydra nopcsai from England (Lydekker and Boulenger 1887; Lydekker 1889b; Nopcsa 1928a; Lapparent de Broin and Murelaga 1999; Sweetman and Insole 2010; Joyce et al. 2011), to which I here refer fragments from the Hauterivian to Barremian of France (Néraudeau et al. 2012) and from the Barremian to Albian of Spain (Pérez García 2009; Pérez-García et al. 2012, 2013; Scheyer et al. 2015), the Barremian Helochelys danubina from the Albian of England (Joyce et al. 2011) and Germany (Meyer 1854, 1855) to which I here refer additional fragments from the Cenomanian of France (Vullo et al. 2010) and Spain (Torices et al. 2012), and Plastremys lata from the Barremian to Cenomanian of England (Seeley 1869; Lydekker 1889b; Parkinson 1881; Andrews 1920) and Spain (Bergounioux 1957; Canudo, Cobos, et al. 2005), to which I here refer fragments from France (Vullo et al. 2010). Less diagnostic fragments have otherwise been reported from the Berriasian to Valanginian of England (Owen 1842, 1878; Joyce et al. 2011). Lapparent de Broin (2001) listed Trachyaspis sactaecrucis from the Valanginian of Switzerland (Pictet and Campiche 1858-1860) as a potential helochelydrid, but I find the sculpturing and well-developed rib heads untypical for the group and therefore disregard these remains herein. After a hiatus, the helochelydrid record continues with the Campanian Solemys vermiculata from Spain (Astibia et al. 1987; Jiménez Fuentes 1992; Lapparent de Broin and Murelaga 1996, 1999; Pérez García 2009; Scheyer et al. 2015) and the Maastrichtian Solemys gaudryi from France (Matheron 1869; Lapparent de Broin and Murelaga 1996). Numerous fragmentary remains from the Campanian and Maastrichtian of France (Le Loeuff 1991; Tong et al. 1993; Lapparent de Broin and Murelaga 1999) and Spain (Jiménez Fuentes 1992; Murelaga et al. 1998; Lapparent de Broin and Murelaga 1999; Pereda-Suberbiola et al. 1999; Canudo, Infante, and Murelaga 2005; Murelaga and Canudo 2005; Murelaga et al. 2005; Marmi et al. 2009) are only referable to Solemys indet. No helochelydrids have been reported from the Tertiary of this continent. The Late Cretaceous (Santonian to Maastrichtian) of Austria (Seeley 1881; Rabi, Vremir, and Tong 2013) and Romania (Nopcsa 1923a, 1923b; Rabi, Vremir, and Tong 2013; Grellet-Tinner and Codrea 2015) otherwise produced material representing the lineage of Kallokibotion bajazidi, but no clear relationships are currently apparent with the helochelydrids from the same continent. Putative remains referable to the Kallokibotion lineage have furthermore been reported from the Paleocene of France (Broin 1977; Lapparent de Broin 2001), but this material has not been figured to date and this claim can therefore not be substantiated.

The North American helochelydrid record is restricted to Naomichelys speciosa, which has been reported from the Aptian to Cenomanian of Maryland (Kranz 1998), Montana (Hay 1908; Ostrom 1970; Joyce et al. 2011; Oreska et al. 2013), Nevada (Bonde et al. 2008), Texas (Jacobs et al. 1991; Scheyer and Anquetin 2008; Joyce et al. 2014; Scheyer et al. 2015), Utah (Joyce et al. 2011), and Wyoming, USA (Oreska et al. 2013). Additional, fragmentary material has otherwise been reported from the Turonian of British Columbia, Canada (Rylaarsdam et al. 2006), the Turonian to Santonian of Utah (Joyce et al. 2011), the Santonian or Campanian of Alberta, Canada (Brinkman 2003; Joyce et al. 2011), and the Campanian of Alberta (Peng et al. 2001; Scheyer and Anquetin 2008; Scheyer et al. 2015; Naomichelys speciosa of Joyce et al. 2011), Montana (Joyce et al. 2011), New Mexico, USA (Joyce et al. 2011; Lichtig and Lucas 2015), Utah (Joyce et al. 2011), and Wyoming (Demar and Breithaupt 2006), but I here refer all to Naomichelys indet. (contra Joyce et al. 2011) as it is unreasonable to speculate that a single species existed throughout the entire Cretaceous. 


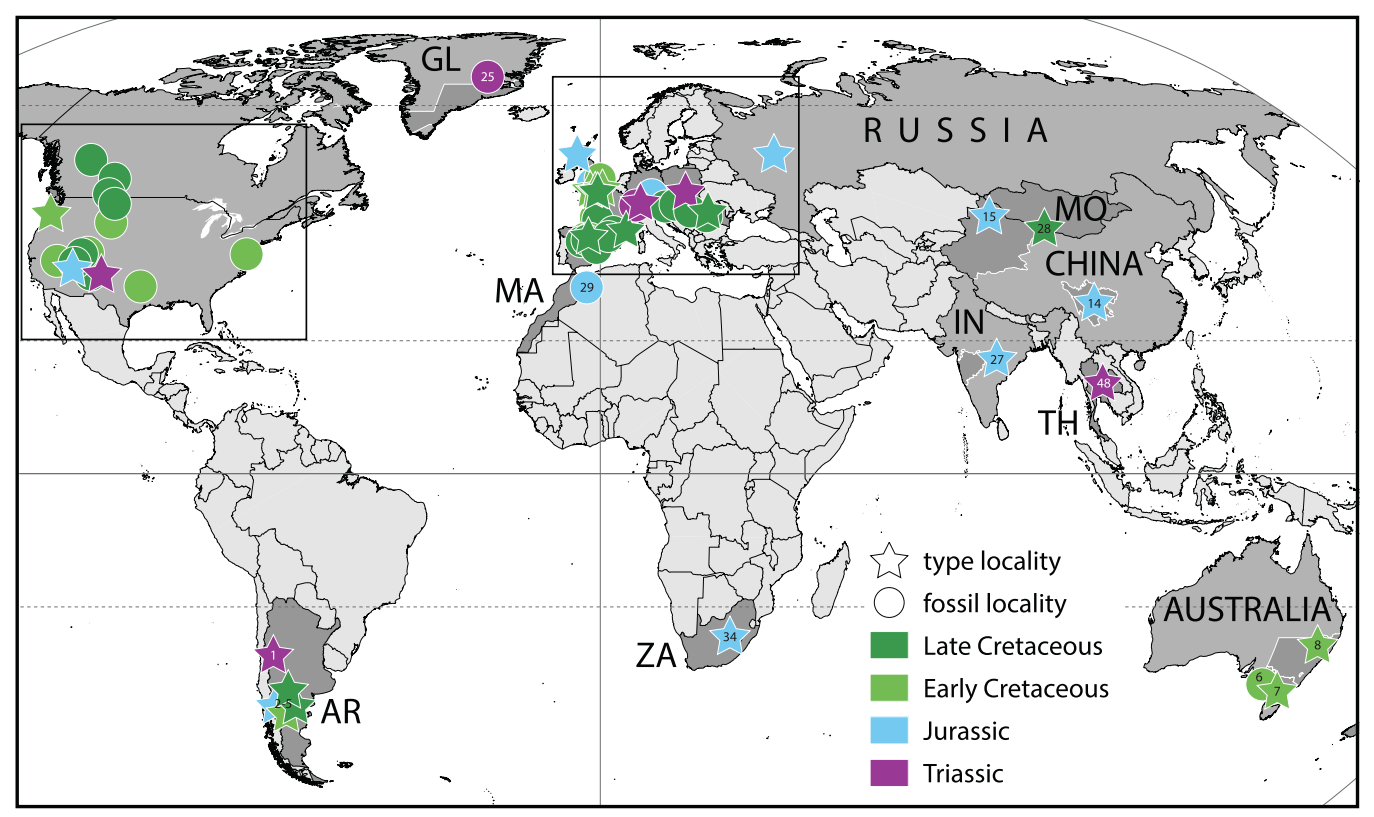

FiguRE 5. The global geographic distribution of Mesozoic stem turtles. Stars mark the type localities of valid taxa. Locality numbers are cross-listed in Appendix 3. The two boxes highlight sections enlarged in Figures 6 and 7. Abbreviations: AR, Argentina; GL, Greenland; IN, India; MA, Morocco; MO, Mongolia; TH, Thailand; ZA, South Africa.

The third basal turtle lineage that diversified in concert with crown turtles is Meiolaniformes, which has a geographic range in southern Gondwana that coincides with that of chelid pleurodires (Sterli and de la Fuente 2013; Joyce et al. 2016). The Cretaceous to Holocene biogeography of this group is discussed in detail in Sterli (2015), but the Cretaceous representatives are listed herein for completeness (Appendix 3, Figure 5). An additional basal turtle from the southern continents, but with uncertain affinities, is Spoochelys ormondea from the Early Cretaceous (Albian) of New South Wales, Australia (Smith and Kear 2013). I here interpret Chelycarapookus arcuatus from the Early Cretaceous of Victoria, Australia (Warren 1969), as an indeterminate basal turtle.

\section{Systematic Paleontology}

\section{Valid Taxa}

See Appendix 4 for the hierarchical taxonomy of basal Mesozoic turtles used in this work.

Testudinata Joyce et al., 2004

Phylogenetic definition. Following Joyce et al. (2004), the name Testudinata is referred to the clade arising from the first pan- testudine with a complete turtle shell that is homologous with the shell developed in the extant turtle Chelonia mydas (Linnaeus, 1758). Following new advances in the understanding of the formation of this complex anatomical structure (Burke 1989; Lyson, Bever, et al. 2013; Lyson, Bhullar, et al. 2013), the turtle shell is here defined as the interaction of the ribs, vertebrae, shoulder girdle, and gastralia with the dermis to form a set of bony elements (i.e., neurals, costals, peripherals, and the nuchal for the carapace, and epi-, hyo-, meso-, hypo-, xiphiplastra, and the entoplastron for the plastron), that suture together to form a structure that surrounds much of the thorax of the animal.

Diagnosis. In addition to its defining characteristic, the turtle shell, representatives of Testudinata are currently diagnosed relative to more basal pan-testudines such as Odontochelys semitestacea Li et al., 2008 through the absence of dentary, maxillary, and premaxillary teeth.

\section{Australochelys africanus Gaffney and Kitching, 1994}

Taxonomic history. Australochelys africanus Gaffney and Kitching, 1994 (new species).

Type material. BP 1/4933 (holotype), a near-complete skull and associated shell fragments (Gaffney and Kitching 1994, figs. 1, 2; Gaffney and Kitching 1995, figs. 1-9, 12-18, 24).

Type locality. Bormansdrift locality, town of Clocolan, Orange Free State, South Africa (Figure 5); Upper Elliot Formation, 
Hettangian/Sinemurian; Early Jurassic (Gaffney and Kitching 1994).

Referred material and range. No specimens have been referred to date.

Diagnosis. Australochelys africanus can be diagnosed as a representative of Testudinata by the presence of a turtle shell and by the lack of premaxillary and maxillary teeth. Within Testudinata, Australochelys africanus is most easily distinguished from Proganochelys quenstedtii and Palaeochersis talampayensis by the presence of a large fossa nasalis and a large lacrimal foramen and from representatives of Mesochelydia by lacking a fully developed cavum tympani and antrum postoticum.

Comments. Australochelys africanus is based on a relatively complete skull and associated shell fragments from the Early Jurassic of South Africa (Gaffney and Kitching 1994). The fossil was initially announced as the oldest known African turtle in a short contribution in a high-impact journal (Gaffney and Kitching 1994) but soon after described in great detail (Gaffney and Kitching 1995). The skull is highly fractured and partially eroded, and only few anatomical details are therefore clearly visible. The validity of this taxon is nevertheless not controversial. A number of characters distinguish Australochelys africanus from Palaeochersis talampayensis or Proganochelys quenstedti, but I here list the single autapomorphy highlighted by Sterli et al. (2007) for this taxon. Gaffney and Kitching $(1994,1995)$ compiled a list of characters that allow hypothesizing that Australochelys africanus is more derived relative to Proganochelys quenstedtii, but still outside Mesochelydia (Casichelydia of Gaffney and Kitching 1994, 1995), and all subsequent global analyses have agreed with that conclusion (e.g., Rougier et al 1995; Hirayama et al. 2000; Gaffney et al. 2007; Joyce 2007; and all derivative analyses). Australochelys africanus is placed as sister to the South American Palaeochersis talampayensis in some analyses to form a basal clade of Gondwanan turtles (e.g., Rougier et al. 1995; Sterli et al. 2007), but others do not support this arrangement (e.g., Gaffney et al. 2007; Joyce 2007).

\section{Palaeochersis talampayensis Rougier et al., 1995}

Taxonomic history. Palaeochersis talampayensis Rougier et al., 1995 (new species); Paleochersis talampayensis Meylan 1996 (incorrect spelling of genus name).

Type material. PULR 68 (holotype), a relatively complete, though crushed skeleton (Rougier et al. 1995, figs. 1, 2; Sterli et al. 2007, figs. 2, 4, 5, 7-11, 12a-t, pls. 1-3, 7-13, 14a-t).

Type locality. Provincial Park Talampaya, La Rioja Province, Argentina (Figure 5); Los Colorados Formation, Norian, Late Triassic (Rougier et al. 1995).

Referred material and range. Late Triassic (Norian) of type locality, La Rioja Province, Argentina (Rougier et al. 1995).

Diagnosis. Palaeochersis talampayensis can be diagnosed as a representative of Testudinata by the full list of characters listed for that clade above. Among a long list of features, Palaeochersis talampayensis is most readily distinguished from Australochelys africanus by having a smaller nasal cavity and smaller lacrimal foramen, from Proganochelys spp. by lacking vomerine teeth, having sutured basipterygoid and paroccipital articulations, a substantial contribution of the quadratojugal to the enlarged cavum tympani, only minor gular projections, and by lacking osteoderms that cover the neck, tail, or limbs, from Proterochersis spp. by exhibiting anterior supramarginals and by lacking postanal scutes, and from representatives of Mesochelydia by the full suite of characters listed below for that clade.

Comments. Although vertebrate localities are not uncommon in the Late Triassic of South America, only a single quarry in La Rioja Province has yielded up to 17 turtle skeletons (Rougier et al. 1995; Sterli et al. 2007). The sediment that encases these rare fossils is extremely hard and only three specimens have therefore been removed from the encasing rock to date, but most anatomical regions are represented by at least one specimen. A preliminary description was provided by Rougier et al. (1995), but greatly expanded upon by Sterli et al. (2007). Although it is unfortunate that the anatomy of many anatomical regions remains unclear due to a lack of preservation, the validity of this turtle is not controversial. A number of terrestrial features, such as osteoderms or a tail club, are lacking in this species that are apparent in Proganochelys quenstedtii, but the limb anatomy suggests terrestrial habitat preferences (Sterli et al. 2007). Although many more characters could have been listed above to diagnose Palaeochersis talampayensis, I here only list those highlighted as autapomorphic by Sterli et al. (2007). Phylogenetic analyses consistently place Palaeochersis talampayensis in a position more derived than Proganochelys quenstedtii, but outside of Mesochelydia (Rougier et al. 1995; Hirayama et al. 2000; Gaffney et al. 2007; Joyce 2007; Sterli et al. 2007; and all derivative analyses). Palaeochersis talampayensis is placed as sister to Australochelys africanus in some analyses to form a Gondwanan turtle clade (e.g., Rougier et al. 1995; Sterli et al. 2007), but other analyses do not retrieve this arrangement (e.g., Gaffney et al. 2007; Joyce 2007).

\section{Proganochelys Baur, 1887}

Type species. Proganochelys quenstedtii Baur, 1887.

Diagnosis. Proganochelys can be diagnosed as a representative of Testudinata by the full list of characters listed for that clade above. Among a long list of features, representatives of Proganochelys are most readily distinguished from Australochelys africanus by having a smaller nasal cavity and smaller lacrimal foramen, from Palaeochersis talampayensis by having vomerine teeth, lacking sutured basipterygoid and paroccipital articulations, by lacking a substantial contribution of the quadratojugal to the enlarged cavum tympani, by exhibiting well-developed gular and extragular projections, and by exhibiting osteoderms that cover the neck, tail, or limbs, from Proterochersis spp. by having a flatter shell, exhibiting a full row of supramarginals and large epiplastral processes that contacted the carapace, and by lacking a sutured pelvis and postanal scutes, and from representatives of Mesochelydia by the full suite of characters listed for that clade below. 




FIGURE 6. The geographic distribution of Mesozoic stem turtles from Europe. Stars mark the type localities of valid taxa. Locality numbers are cross-listed in Appendix 3. Abbreviations: AT, Austria; DE, Germany; HU, Hungary; UK, United Kingdom.

Comments. In addition to the three species referred herein, I confirm the plausible placement of the material from Greenland in Proganochelys based on the presence of well-developed gular projections (Jenkins et al. 1994).

\section{Proganochelys quenstedtii \\ Baur, 1887}

(= Psammochelys keuperina Quenstedt, 1889 = Stegochelys dux Jaekel, 1914)

Taxonomic history. Proganochelys quenstedtii Baur, 1887 (new species); Proganochelys quenstedti Lydekker 1889b (incorrect spelling of species epithet); Proganochelys quenstedtii = Psammochelys keuperina Quenstedt 1889 (objective senior synonym); Proganochelys quenstedt $i=$ Psammochelys keuperina $=$ Stegochelys dux Gaffney 1985 (senior synonym and incorrect spelling of species epithet).

Type material. GPIT RE/09396 (holotype), the steinkern of a shell (Quenstedt 1889, pls. 1, 2; Fraas 1899, pl. 8; Gaffney 1990, fig. 104).
Type locality. Neuenhaus (= Häfner-Neuhausen), Baden-Württemberg, Germany (Figure 6); Löwenstein Formation (= weisser Keupersandstein of Quenstedt 1889), Norian, Late Triassic (Villinger 2002; Geyer et al. 2011).

Referred material and range. Late Triassic (Norian) Löwenstein and Trossingen Formations of Trossingen and Aixheim, BadenWürttemberg, Germany (Fraas 1899; Huene 1926; Parsons and Williams 1961; Gaffney and Meeker 1983; Gaffney 1985, 1990); Late Triassic (Norian) Trossingen Formation of Halberstadt, Saxony-Anhalt, Germany (Jaekel 1914, 1915-1916).

Diagnosis. Proganochelys quenstedtii can be diagnosed as a representative of Testudinata and Proganochelys by the full list of characters listed for those clades above. Proganochelys quenstedtii can be differentiated from Proganochelys ruchae by the presence of more anteriorly oriented extragular projections and from Proganochelys tenertesta by the presence of rounded neck osteoderms.

Comments. Proganochelys quenstedtii is based on a steinkern from Neuenhaus, a village located between Stuttgart and 
Tübingen (Baur 1887, 1888). The same specimen also serves as the holotype of Psammobates keuperina (Quenstedt 1889) and these two taxa are therefore objective synonyms. Quenstedt (1889) noted that the holotype originated from white Keuper sandstone (= weisser Keupersandstein), a term not in general use nowadays. The most recent regional geological map (Villinger 2002), however, indicates that the Löwenstein Formation (formerly Stubensandstein) crops out in the area surrounding the village of Neuenhaus. The holotype is therefore likely Norian in age (Geyer et al. 2011). The holotype is not particularly informative, but it is at least fully consistent in its morphology with rich referred material from the nearby (approximately $60 \mathrm{~km}$ ) quarries of Trossingen and Aixheim and from the significantly more distant quarries (approximately $450 \mathrm{~km}$ ) of Halberstadt, which also serve as the type locality of Stegochelys dux (Jaekel 1914). As noted above, the holotype of Proganochelys quenstedtii likely originated from the Löwenstein Formation, whereas the specimens from Trossingen and Halberstadt were quarried from the overlying Trossingen Formation (Gaffney 1990). However, given that the fossils from these quarries are still poorly dated and that lithostratigraphic units are not synchronous, these differences in depositional settings are likely of no relevance. I therefore find the proposed synonymy of Gaffney $(1985,1990)$ to be unproblematic. For differences between the Trossingen and Halberstadt material, please refer to Gaffney (1990).

Proganochelys quenstedtii is arguably the most importan Triassic turtle worldwide, because nearly all aspects of its skeletal morphology are preserved. Gaffney (1990) carefully summarized all previous research pertaining to this species and provided the single most detailed and informative description available for any fossil turtle to date. This work serves at the basis and inspiration of nearly all subsequent work in fossil turtle paleontology, especially work pertaining to the postcranial anatomy of turtles, and I therefore refer the reader to this monumental accomplishment for all questions pertaining to this taxon. Kordikova (2002) provided an alternative interpretation of the skull that differs through the recognition of numerous bones otherwise lost in crown turtles, in particular the ectopterygoids, postfrontals, postparietals, and tabulars, but it appears that most researchers favor the more reasonable reconstructions provided by Gaffney (1990). Joyce, Schoch, and Lyson (2013) otherwise suggested that Proganochelys quenstedtii had a scapular process that was oriented vertically, not anterodorsally as reconstructed by Gaffney (1990), and Werneburg et al. (2015) clarified that Proganochelys quenstedtii likely possessed only two neck spines, not a full set of six to eight, as suggested by the reconstructions of Gaffney (1990).

Proganochelys quenstedtii has featured in virtually every phylogenetic analysis of basal turtles in the last decades (e.g. Gaffney et al. 1991; Gaffney 1996; Hirayama et al. 2000; Gaffney et al. 2007; Joyce 2007; and all subsequent analyses based on either of these) and there is full agreement that this is one of the most basal turtles known.

Proganochelys quenstedtii is only found in continental sediments and in association with the terrestrial dinosaurs and notably lacking from all aquatic assemblages (Joyce et al. 2009). The shell bone histology is comparable to that of extant tortoises (Scheyer and Sander 2007) and the presence of osteoderms, a tail club, and short limbs with strong claws are finally inconsis- tent with aquatic habitats (Joyce and Gauthier 2004). This important stem turtle therefore was most likely terrestrial. Three-dimensional modeling of the neck vertebrae of Proganochelys quenstedtii revealed that this species could not retract its neck within the shell like modern turtles do, but that it was nevertheless able to protect itself by ventrolaterally tucking its head below the shell (Werneburg et al. 2015).

\section{Proganochelys ruchae Broin, 1984}

Taxonomic history. Proganochelys ruchae Broin, 1984 (new species).

Type material. DMR TF1440-6 (holotype), a partial anterior plastral lobe consisting of parts of left epi-, ento-, and hyoplastron (Broin 1984, pl. 1.1).

Type locality. $2 \mathrm{~km}$ north of the highway between the towns of Chum Phae and Lom Sak, Phetchabun Province, Thailand (Figure 5); Huai Hin Lat Formation, Norian, Late Triassic (Broin 1984).

Referred material and range. Late Triassic (Norian) Huai Hin Lat Formation of Phetchabun Province, Thailand (Broin et al. 1982; Broin 1984).

Diagnosis. Proganochelys ruchae can be diagnosed as representative of Testudinata by the presence of a fully formed shell and as a representative of Proganochelys by the presence of welldeveloped gular projections. Proganochelys ruchae can be differentiated from Proganochelys quenstedtii by having more laterally oriented extragular projections.

Comments. Proganochelys ruchae is based on highly fragmentary material from the Late Triassic (Norian) of Thailand that is somewhat challenging to interpret (Broin et al. 1982; Broin 1984). The material is nevertheless highly significant, as it remains the only testudinate material from the Late Triassic of all of Asia described to date. Broin (1984) highlighted that the Thai material most resembles the roughly coeval Proganochelys quenstedtii from Germany by possessing two pairs of anterior plastral tuberosities and well-developed dorsal epiplastral processes, though notable differences are apparent to the size and orientation of these processes. Although some additional material has since been described from the Late Triassic worldwide (Rougier et al. 1995; Sterli et al. 2007; Joyce et al. 2009; Szczygielski and Sulej 2016), these observations still hold true. I therefore agree with Broin's (1984) original assessments, but anticipate the discovery of more complete material.

\section{Proganochelys tenertesta \\ (Joyce et al., 2009) comb. nov.}

Taxonomic history. Chinlechelys tenertesta Joyce et al., 2009 (new species).

Type material. NMMNH P-16697 (holotype), a partial skeleton consisting of the central portion of the carapace, a partial left hypoplastron, a posterior costal, portions of the bridge, a neck 




FIGURE 7. The geographic distribution of Mesozoic stem turtles from North America. Stars mark the type localities of valid taxa. Locality numbers are cross-listed in Appendix 3. Abbreviations: AB, Alberta; AZ, Arizona; BC, British Columbia; MD, Maryland; MT, Montana; NM, New Mexico; NV, Nevada; TX, Texas; UT, Utah; WY, Wyoming.

spine, and isolated osteoderms (Lucas et al. 2000, fig. 2a, b, h, i; Joyce et al. 2009, figs. 1, 2).

Type locality. Ruvuelto Creek, Quay County, New Mexico, USA (Figure 7); Bull Canyon Formation, Chinle Group, Norian, Late Triassic (Joyce et al. 2009).

Referred material and range. No specimens have been referred to date.

Diagnosis. Proganochelys tenertesta can be diagnosed as representative of Testudinata by the presence of a fully formed shell and as a representative of Proganochelys by the presence of neck osteoderms. Proganochelys tenertesta can be differentiated from Proganochelys quenstedtii by having more angular neck osteoderms.

Comments. Triassic turtles remain elusive in North America despite the prevalence of extensive and well-sampled outcrops of sediments with rich terrestrial faunas. The turtle remains originally reported by Lucas et al. (2000) and Joyce et al. (2009) from the Norian of New Mexico serve as the holotype of Proganochelys tenertesta and remain the only reported turtle remains from the Triassic of North America. In addition to poorly preserved shell remains, the type specimen includes a beautifully preserved cervical spine that greatly resembles those reported from Proganochelys quenstedtii (Lucas et al. 2000). A more detailed analysis later revealed that the specimens include the well-preserved central portion of the carapace consisting of at least two dorsal vertebrae and adjacent portions of the ribs, neurals, and costals, a partial left hypoplastron, and portions of the right posterior costals and associated ribs remains and peripherals, in addition to numerous unidentifiable fragments (Joyce et al. 2009).

Paleontologists have historically supported the hypothesis that turtles derive from basal amniotes that were covered by osteoderms and that these bones eventually connected to the underlying portions of the endoskeleton. This conclusion was more recently falsified through the discovery of the intermediate, Late Triassic stem turtle Odontochelys semitestacea (Li et al. 2008) coupled with the realization that the Permian Eunotosaurus africanus is an even more basal stem turtle (Lyson et al. 2010). Joyce et al. (2009) originally concluded that Proganochelys tenertesta is the most basal known turtle on the basis of the observation that its dorsal ribs were oriented vertically, the presumed basal condition for amniotes, and a perceived separation of the ribs from the overlying metaplastic portion of the carapace. Although Joyce et al. (2009) appeared in print in 2009, 
it was accepted for publication long before the appearance of $\mathrm{Li}$ et al. (2008), which cast an entirely new light on the specimen. I have since been able to study the Trossingen material of Proganochelys quenstedtii again and now find the listed differences to be of less significance, as Proganochelys quenstedtii also possesses thin, vertically oriented ribs. The shell therefore lacks any features that would allow evaluating the phylogenetic position of Proganochelys tenertesta relative to Proganochelys quenstedtii. However, given that neck spines are lacking in Odontochelys semitestacea and all other known Triassic turtles to the exception of Proganochelys quenstedtii (Sterli et al. 2007; Szczygielski and Sulej 2016), it is now more prudent to postulate that neck spines are a derived feature shared by Proganochelys tenertesta and Proganochelys quenstedtii, although differences are nevertheless apparent in the morphology of these spines. therefore here confirm the validity of the New Mexico turtle, but refer it to Proganochelys.

\section{Proterochersis Fraas, 1913}

Type species. Proterochersis robusta Fraas, 1913.

Diagnosis. Proterochersis can be diagnosed as a representative of Testudinata by the full list of characters listed for that clade above. Within Testudinata, representatives of Proterochersis are most readily distinguished from Palaeochersis talampayensis by having a higher domed shell with a sutured pelvis, by lacking anterior supramarginals, and the presence of postanal scutes, from Proganochelys spp. by exhibiting a higher domed shell, a sutured pelvis, a partial row of supramarginals, large epiplastral processes that do not contact the carapace dorsally, and postanal scutes, and from representatives of Mesochelydia by the full suite of characters listed for that clade below. Proterochersis spp. cannot be distinguished from Australochelys africanus for the moment, as there is no overlap in the preserved portions of the skeleton.

\section{Proterochersis limendorsa \\ (Szczygielski and Sulej, 2016) comb. nov.}

Taxonomic history. Keuperotesta limendorsa Szczygielski and Sulej, 2016 (new species).

Type material. SMNS 17757 (holotype), a partial skeleton consisting of part of the carapace, most of the plastron, the pelvis, the right scapulocoracoid, and parts of the vertebral column associated with the shell (Joyce, Schoch, and Lyson 2013, figs. 1, 2; Szczygielski and Sulej 2016, figs. 9, 10i, 1, m).

Type locality. Rudersberg, Baden-Württemberg, Germany (Figure 6); lower Löwenstein Formation, Norian, Late Triassic (Joyce, Schoch, and Lyson 2013; Szczygielski and Sulej 2016).

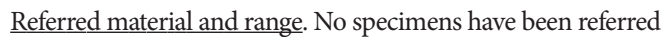
to date.

Diagnosis. Proterochersis limendorsa can be diagnosed as a representative of Testudinata and Proterochersis by the full list of characters listed for those clades above. Proterochersis limendorsa is most notably distinguished from Proterochersis porebensis and Proterochersis robusta by lacking supernumerary anterior marginals, and by exhibiting serrated anterior marginals, a narrow contact between the cervical and marginal I, an anteromedially sloping lateral sulcus of vertebral I, thickened carapacial bones near the posterior margins of vertebrals II-IV, and a mobile cervical VIII.

Comments. Like so many other taxa from the Late Triassic (Norian) of Germany, Proterochersis limendorsa is based on a partial shell (SMNS 17757) from Rudersberg, near Stuttgart, Germany, preserved as a steinkern with attached plastron. The specimen had languished in the collections of the SMNS for many decades until preparation exposed the right scapulocoracoid, the anterior parts of the thoracic column, and the pelvis with associated sacrum within the steinkern. Given that the anatomy of Proterochersis robusta was so poorly documented in the literature, Joyce, Schoch, and Lyson (2013) described the girdles and vertebral column of SMNS 17757 and utilized the resulting information to conclude that Proterochersis robusta indeed possesses a sutured pelvis like a pleurodire, but nevertheless exhibits enough plesiomorphic characters to place it far outside crown group Testudines. The preliminary review by Szczygielski and Sulej (2016) of all turtle material from the lower Löwenstein Formation of Germany yielded the surprising conclusion that SMNS 17757 is systematically different from all other specimens, including the holotype of Proterochersis robusta. Among others, SMNS 17757 exhibits serrated anterior marginals, lacks a supernumerary anterior marginal, possesses an extremely narrow contact between the cervical and marginal I, an anterolateral contact of vertebral I with pleural I, and a lack of sutural attachment of cervical vertebra VIII with the shell. Although a more thorough description of Proterochersis robusta is still outstanding, I am overall convinced by this extensive list of characters and therefore agree that Proterochersis limendorsa is a valid taxon. However, given that Szczygielski and Sulej (2016) find that Proterochersis limendorsa is sister to the German Proterochersis robusta and the Polish Proterochersis porebensis, I see little value in placing this species in its own genus and therefore refer it to Proterochersis as well.

\section{Proterochersis porebensis} Szczygielski and Sulej, 2016

Taxonomic history. Proterochersis porebensis Szczygielski and Sulej, 2016 (new species).

Type material. ZPAL V.39/48 (holotype), a partial skeleton consisting of a near-complete shell, left scapulocoracoid, pelvis, and partial right femur (Szczygielski and Sulej 2016, figs. 3a-d, g, h, i, $4 a-e, h, i)$.

Type locality. Poręba, Silesian Voivodeship, Poland (Figure 6); Zbaszynek Beds, Norian, Late Triassic (Szczygielski and Sulej 2016).

Referred material and range. Late Triassic (Norian) of type locality, Silesian Voivodeship, Poland (referred material of Szczygielski and Sulej 2016).

Diagnosis. Proterochersis porebensis can be diagnosed as a representative of Testudinata and Proterochersis by the full list of 
characters listed for those clades. Proterochersis porebensis can be distinguished from Proterochersis limendorsa by lacking serrated marginals, and by exhibiting supernumerary anterior marginals, a broad contact of the cervical with the adjacent marginals, a transverse-oriented lateral sulcus of vertebral I, evenly thin carapacial bones, and an immobilized cervical VIII, and from Proterochersis robusta most notably by having a lower shell with a more triangular caudal notch.

Comments. Sulej et al. (2012) recently announced a Late Triassic fauna from southern Poland that includes rich turtle material referable to Proterochersis. The locality is unique in Europe in that is not only yielded more than 200 partial to complete shells, but also remains of the pectoral and pelvic girdles, parts of the vertebral column, and isolated limb bones. Szczygielski and Sulej (2016) described the new turtle material in more detail and named a new species, Proterochersis porebensis. Given that the morphology of the German Proterochersis material had not been reevaluated in more than a century, despite new specimens that had been collected over the course of the last decades, Szczygielski and Sulej (2016) furthermore briefly reviewed the German material to provide a more robust comparative basis for the description of the Polish material. This review concluded that Proterochersis intermedia and Murrhardtia staeschei are junior synonyms of Proterochersis robusta (see Murrhardtia staeschei and Proterochersis intermedia below), that a recently described specimen (Joyce, Schoch, and Lyson 2013) actually represents a new species (see Proterochersis limendorsa above), and that the Polish material represents a new species, Proterochersis porebensis. Szczygielski and Sulej (2016) identify two morphotypes within the Polish material, a smaller morphotype with a midline keel and lacking anterior and posterior plastral projections and a larger morphotype lacking a midline keel but with pronounced anterior and posterior plastral projections, but attributed these differences to ontogenetic variation. A phylogenetic analysis of basal turtles reveals that Proterochersis porebensis is more closely related with Proterochersis robusta than Proterochersis limendorsa and that Proterochersis is the most basal clade of Testudinata (Szczygielski and Sulej 2016). The diagnostic differences between the Polish Proterochersis porebensis and the German Proterochersis robusta are rather minute, but given that the German material still remains poorly described, I find it difficult to evaluate the listed differences. Even if these differences are considered to be significant, it is unclear if these two taxa might represent chronotaxa, as the German material is poorly dated.

\section{Proterochersis robusta Fraas, 1913 (= Proterochersis intermedia Fraas, 1913 = Murrhardtia staeschei Karl and Tichy, 2000)}

Taxonomic history. Proterochersis robusta Fraas, 1913 (new species); Proterochersis robusta $=$ Proterochersis intermedia Mlynarski 1976 (senior synonym); Proterochersis robusta $=$ Proterochersis intermedia $=$ Murrhardtia staeschei Szczygielski and Sulej 2016 (senior synonym).

Type material. SMNS 12777 (holotype), the steinkern of a shell with plastron and right pelvis (Fraas 1913, pls. 3, 4; Szczygielski and Sulej 2016, fig. 10g, j, h, k).
Type locality. Rudersberg, Baden-Württemberg, Germany (Fraas 1913; Figure 6); lower Löwenstein Formation, Norian, Late Triassic (Szczygielski and Sulej 2016).

Referred material and range. Late Triassic (Norian), lower Löwenstein Formation, central Baden-Württemberg, Germany (referred material of Szczygielski and Sulej 2016).

Diagnosis. Proterochersis robusta can be diagnosed as a representative of Testudinata and Proterochersis by the full list of characters listed for those clades. Proterochersis robusta can be distinguished from Proterochersis limendors a by lacking serrated marginals, and by exhibiting supernumerary anterior marginals, a broad contact of the cervical with the adjacent marginals, a transverse-oriented lateral sulcus of vertebral I, evenly thin carapacial bones, and an immobilized cervical VIII, and from Proterochersis porebensis most notably by having a higher domed shell with a more rounded caudal notch.

Comments. Proterochersis robusta is based on a poorly preserved shell from the lower Löwenstein Formation near Rudersberg, Germany (Fraas 1913). The specimen only preserves part of the plastron and the internal imprint of the carapace, but nevertheless clearly reveals sufficient detail to easily distinguish it from Proganochelys quenstedtii, which had only been described a few years earlier based on a steinkern from the upper Löwenstein Formation of nearby Neuenhaus, Germany. However, given that several complete skeletons were soon after found that were attributable to Proganochelys quenstedtii, P. robusta received little attention, even though it objectively was the world's oldest turtle for at least a century. Fraas (1913) named yet another fossil turtle from the same strata, $P$. intermedia, based on a flattened steinkern, but this taxon was recently synonymized firmly with P. robusta (Szczygielski and Sulej 2016; see below).

A number of new, often partial specimens were collected from the lower Löwenstein Formation in the area surrounding Stuttgart over the course of the decades, but only some of these have been described. Broin (1984) figured part of a specimen that had been found near Lorch, Germany, in her description of a new turtle from the Triassic of Thailand and this specimen was recently confirmed to be attributable to P. robusta (Szczygielski and Sulej 2016). Another specimen, this time from nearby Murrhardt, was utilized by Gaffney $(1986,1990)$ as the basis of his reconstruction of the shell of P. robusta. The specimen is among the best preserved from the lower Löwenstein Formation, but its morphology, at least as apparent from photographs, must be viewed with caution, as significant portions of the shell have been reconstructed for exhibit purposes. Karl and Tichy (2000) described a new species, Murrhardtia staeschei, based on yet another specimen from Murrhardt and also referred the well-preserved shell first figured by Gaffney $(1986,1990)$ to this taxon. Given that Fraas (1913) provided a highly imaginative shell reconstruction of $P$. robusta that lacked much factual basis, Gaffney et al. (2006) speculated that Karl and Tichy (2000) were fooled to believe that they had found a new species through the fantastic reconstructions of Fraas (1913), a conclusion confirmed by Szczygielski and Sulej (2016). Joyce, Schoch, and Lyson (2013) described yet another specimen, this time from Stuttgart, Germany, under the name P. robusta, but the more recent analysis of Szczygielski and Sulej (2016) concludes that it represents a new species, $P$. limendorsa (see above). Szczygielski 
and Sulej (2016) referred additional specimens from the greater Stuttgart region to P. robusta but none of these are figured or explicitly described. The morphology of this taxon therefore still remains poorly documented.

\section{Mesochelydia \\ New Clade Name}

Phylogenetic definition. The name Mesochelydia is herein referred to the clade that arises from the most recent common ancestor of Condorchelys antiqua Sterli, 2008, Eileanchelys waldmani Anquetin et al., 2009, Heckerochelys romani Sukhanov, 2006, and Kayentachelys aprix Gaffney et al., 1987.

Diagnosis. Representatives of Mesochelydia are currently diagnosed relative to more basal testudinates most notably by lacking lacrimals, lacrimal ducts, and supratemporals, and by exhibiting confluent external nares, a single vomer, a fully formed cavum tympani and antrum postoticum, a pair of basioccipital tubercles, a processus interfenestralis, a carapace that only consists of eleven pairs of peripherals, a reduced posterior entoplastral process, absence of supramarginal scutes, and a pectoral girdle consisting of three straplike processes that are only connected by minor bony webs.

Comments. The stem lineage of turtles is now understood to consist of a diverse assemblage of fossil forms that documents the significant morphological gap between the most basal testudinates from the Late Triassic and crown Testudines. Given that the better understood Early to Middle Jurassic turtles already display a morphology quite distinct from their more basal cousins, I find it useful to give a name to the clade they form. The name Mesochelydia is formed by combining the prefix "meso-" (Greek for intermediate) with "chelydia" (derived from the Greek word chelys for turtle). This name had originally been proposed by Zangerl (1969) to unite an eclectic group of turtles consisting of paracryptodires, meiolaniids, and pleurodires that he felt to exhibit an intermediate level of evolutionary organization to the shell, a classification that was mostly ignored by subsequent authors. The clade named herein only shares its name with this polyphyletic grouping.

\section{Condorchelys antiqua Sterli, 2008}

Taxonomic history. Condorchelys antiqua Sterli, 2008 (new species).

Type material. MPEF PV1152 (holotype), a basicranium (Sterli 2008, fig. 1a, b; Sterli and de la Fuente 2010, figs. 2e, f, 3a, b).

Type locality. Queso Rallado locality, $5.5 \mathrm{~km}$ west of the village of Cerro Cóndor, Chubut Province, Argentina (Figure 5); Cañadón Asfalto Formation (Sterli 2008), Toarcian-Bajocian, Early to Middle Jurassic (Cúneo et al. 2013; Cerda et al. 2016).

Referred material and range. Early to Middle Jurassic (Toarcian-Bajocian) of type locality, Chubut Province, Argentina (Sterli 2008; Sterli and de la Fuente 2010; Cerda et al. 2016).

Diagnosis. Condorchelys antiqua can be diagnosed as a representative of Testudinata and Mesochelydia by the full list of char- acters listed for those clades above. Condorchelys antiqua can be distinguished from Eileanchelys waldmani by the presence of a less developed antrum postoticum, a less distinct processus interfenestralis, and absence of a peripheral gutter, from Heckerochelys romani by a less developed antrum postoticum, a more ventrally oriented basipterygoid joint, lack of a posterior projection of the external pterygoid process, and absence of shell sculpturing and fontanelles, from Indochelys spatulata in having narrower suprapygals, from Kayentachelys aprix in the absence of pterygoid teeth and lack of a posterior projection of the external pterygoid process, and from representatives of Perichelydia by the presence of an open interpterygoid vacuity and the absence of a processus trochlearis oticum.

Comments. All available material referable to Condorchelys antiqua has been recovered from a single quarry in Chubut Province, Argentina (Sterli 2008; Sterli and de la Fuente 2010; Cerda et al. 2016). Sterli (2008) only briefly announced the species, but Sterli and de la Fuente (2010) soon after described all then available material in greater detail. Cerda et al. (2016) more recently provided an analysis of the bone histology of this turtle and concluded that an aquatic habitat preference was better supported by this source of data. The quarry was initially dated as Middle to Late Jurassic (Sterli 2008), but more recent radiometric analyses yielded an Early to Middle Jurassic (Toarcian-Bajocian) age (Cúneo et al. 2013; Cerda et al. 2016). Although much of the skeleton is not preserved and the available material heavily crushed, the validity of this species is not controversial. Phylogenetic analysis consistently places Condorchelys antiqua at a similar level with Kayentachelys aprix more derived than all named Triassic turtles, but clearly outside crown group Testudines (Sterli 2008; Sterli and de la Fuente 2010; Sterli, Pol, and Laurin 2013; and all derivative analyses).

\section{Eileanchelys waldmani Anquetin et al., 2009}

Taxonomic history. Eileanchelys waldmani Anquetin et al., 2009 (new species).

Type material. NMS G.2004.31.15 (holotype), the posterior portions of a skull (Anquetin et al. 2009, fig. 1; Anquetin 2010, figs. 3, 4); NMS G.2004.31.16a-f (paratypes), an aggregation of up to six skeletons in a single block that once included the holotype (Anquetin et al. 2009, fig. 2, suppl. fig. 1; Anquetin 2010, figs. 2, $5-7,9-12,15 \mathrm{~g}, \mathrm{~h}, \mathrm{~m}-\mathrm{r})$.

Type locality. Cladach a'Ghlinne, Isle of Skye, Highland, Scotland, United Kingdom (Figure 5); Kilmaluag Formation, Bathonian; Middle Jurassic (Anquetin et al. 2009).

Referred material and range. Middle Jurassic (Bathonian) of type locality, Isle of Skye, United Kingdom (type locality) (Anquetin 2010).

Diagnosis. Eileanchelys waldmani can be diagnosed as a representative of Testudinata and Mesochelydia by the full list of characters listed for those clades above. Eileanchelys waldmani can be distinguished from Condorchelys antiqua by the presence of a better developed antrum postoticum, a more distinct processus interfenestralis, and presence of a peripheral gutter, from Heckerochelys romani by the presence of a peripheral gutter and 
absence of shell sculpturing and fontanelles, from Indochelys spatulata by exhibiting a midline contact of the epiplastra, from Kayentachelys aprix in the presence of a well-developed antrum postoticum, a slender processus interfenestralis, a peripheral gutter, and lack of a midline contact of the epiplastra, and from representatives of Perichelydia by the presence of an open interpterygoid vacuity and the absence of a processus trochlearis oticum.

Comments. Eileanchelys waldmani is primarily based on a block of matrix that holds up to six, partially intermixed turtle skeletons from the Middle Jurassic of Scotland (Anquetin et al. 2009). Anquetin (2010) provided a detailed morphological analysis of all available material, but many aspects remain difficult to interpret, as the available material is highly fractured and still remains in a block. There is no doubt, however, that this is a valid taxon. Anquetin et al. (2009) used information obtained from the depositional system to conclude that Eileanchelys waldmani was aquatic, a conclusion that was soon after supported by histological data (Scheyer et al. 2014). Phylogenetic analyses routinely retrieve Eileanchelys waldmani in close association with various other Early to Middle Jurassic turtles along the stem lineage of crown Testudines (e.g., Anquetin et al. 2009; Anquetin 2012; Sterli, Pol, and Laurin 2013; Zhou and Rabi 2015).

Heckerochelys romani Sukhanov, 2006

Taxonomic history. Heckerochelys romani Sukhanov, 2006 (new species).

Type material. PIN 4561-1 (holotype), a partial shell consisting of seven peripherals, three costals, two neurals, and the epiplastra and entoplastron (Sukhanov 2006, fig. 2b, c, e).

Type locality. Peski locality, Kolomna District, Moscow Oblast, Russia (Figure 6); Bathonian, Middle Jurassic (Sukhanov 2006; Gordenko 2008).

Referred material and range. Middle Jurassic (Bathonian) of type locality, Moscow Oblast, Russia (type locality) (Sukhanov 2006).

Diagnosis. Heckerochelys romani can be diagnosed as a representative of Testudinata by the full list of characters listed for that clade above and of Mesochelydia by lacking lacrimals and lacrimal ducts, and supratemporals, a single vomer, a fully formed cavum tympani and antrum postoticum, a pair of basioccipital tubercles, a processus interfenestralis, a reduced posterior entoplastral process, and a pectoral girdle consisting of three straplike processes that are only connected by minor bony webs. Heckerochelys romani can be distinguished from all other basal mesochelydians by exhibiting a flat basicranium joint, shell fontanelles, and crenulated shell sculpturing. It can furthermore be distinguished from Condorchelys antiqua by the presence of a better developed antrum postoticum, a posterior projection of the external pterygoid process, and a more distinct processus interfenestralis, from Eileanchelys waldmani by the absence of a peripheral gutter, from Indochelys spatulata by exhibiting a midline contact of the epiplastra, from Kayentachelys aprix in lacking pterygoid teeth, a well-developed antrum postoticum, a slender processus interfenestralis, and a midline contact of the epiplastra, and from representatives of Perichelydia by the pres- ence of an open interpterygoid vacuity and the absence of a processus trochlearis oticum.

Comments. Heckerochelys romani is unique among Mesozoic turtles by being based on hundreds of exquisitely preserved elements, often partially articulated specimens, that were collected from a fissure fill (V. Sukhanov, pers. comm. 2011). The type description is relatively brief and only includes figures for the most important specimens, and many questions therefore remain regarding the anatomy of this important turtle. However, given the isolated nature of this taxon and the quality of the preserved material, the validity of Heckerochelys romani is not controversial. Phylogenetic analysis usually places this taxon along the turtle stem lineage in close affinity with other Early to Middle Jurassic turtles (e.g., Sukhanov 2006; Anquetin 2012; Sterli, Pol, and Laurin 2013; Zhou and Rabi 2015). The relatively derived nature of the skull, the pleurosternid-like surface sculpturing, combined with biogeographic considerations (Joyce et al. 2016), however, allow me to speculate that this taxon may eventually be shown to be the most basal representative of the paracryptodiran lineage, in which case this species is misplaced in this contribution.

\section{Indochelys spatulata Datta et al., 2000}

Taxonomic history. Indochelys spatulata Datta et al., 2000 (new species).

Type material. GSI 20380 (holotype), a relatively complete shell (Datta et al. 2000, figs. 3, 4)

Type locality. Kota, north of Sironcha, Maharashtra State, India (Figure 5); Kota Formation, Early Jurassic (Datta et al. 2000).

Referred material and range. No specimens have been referred to date.

Diagnosis. Indochelys spatulata can be diagnosed as a testudinate by the presence of a fully formed shell and as a mesochelydian by the reduction of the number of shell elements and the absence of supramarginals. Indochelys spatulata can be distinguished from Condorchelys antiqua and Kayentachelys aprix by exhibiting broader suprapygals, from Eileanchelys waldmani and Heckerochelys romani by the absence of a midline contact of the epiplastra, and from all perichelydians through the absence of a midline contact of the epiplastra.

Comments. Indochelys spatulata is based on a single shell from the Early Jurassic Kota Formation of Maharashtra State, India (Datta et al. 2000). An additional shell had been reported from the same formation in neighboring Telangana State (Nath et al. 2002), but I am unaware of this specimen having been described. The shell of Indochelys spatulata provides sufficient information to allow phylogenetically placing it at a position more derived than all named Triassic turtles, but clearly outside crown Testudines (Sterli 2008; Anquetin 2012; and derivative analyses). A reanalysis of turtles from the Kota Formation is likely to yield additional insights into the anatomy of this important turtle. 
Kayentachelys aprix Gaffney et al., 1987

Taxonomic history. Kayentachelys aprix Gaffney et al., 1987 (new species).

Type material. MNA V1558 = MCZ 8913 (holotype), a crushed, partial skull (Sterli and Joyce 2007, fig. 3; Gaffney and Jenkins 2010, figs. 3, 4).

Type locality. Gold Springs, Adeii Eechii Cliffs, Coconino County, Arizona, USA (Figure 7); Kayenta Formation, Early Jurassic (Gaffney et al. 1987).

Referred material and range. Early Jurassic of Gold Springs (type locality) and Willow Springs, Kayenta Formation, Arizona, USA (Gaffney et al. 1987; Sterli and Joyce 2007; Gaffney and Jenkins 2010).

Diagnosis. Kayentachelys aprix can be diagnosed as a representative of Testudinata and Mesochelydia by the full list of characters listed for those clades. Kayentachelys aprix can be distinguished from Condorchelys antiqua in the presence of pterygoid teeth and of a posterior projection of the external pterygoid process, from Eileanchelys waldmani and Heckerochelys romani in the presence of pterygoid teeth, a poorly developed antrum postoticum, a low processus interfenestralis, and the lack of a midline contact of the epiplastra, from Indochelys spatulata in having narrower suprapygals, and from representatives of Perichelydia by the presence of an open interpterygoid vacuity and the absence of a processus trochlearis oticum.

Comments. Kayentachelys aprix is based on a rich assemblage of fossils collected at two nearby Early Jurassic localities in Arizona USA (Gaffney et al. 1987). The species was introduced to the world in a brief communication in a high-impact journal (Gaffney et al. 1987), but a full description of the available material did not follow afterwards. Although the available material from Arizona consists of hundreds of specimens ranging from isolated shell pieces to near-complete skeletons, the vast majority of material, which is distributed in four museums across the United States, is fragmentary, or badly crushed, or thickly encrusted by iron oxides, or a combination thereof. The interpretation of the available material is therefore difficult and it is not surprising that two differing accounts were published in short succession regarding the cranial anatomy of this taxon (Sterli and Joyce 2007; Gaffney and Jenkins 2010). The postcranial anatomy remains undescribed to date, even though most elements are preserved.

Kayentachelys aprix is at the center of a debate regarding the phylogeny of Mesozoic turtles. This turtle was initially introduced as the world's oldest stem cryptodire (Gaffney et al. 1987), but most analyses now agree that it has an intermediate position along the turtle stem lineage (see Phylogenetic Relationships above). For competing views, please see Gaffney and Jenkins (2010) versus Joyce and Sterli (2012).

\section{Perichelydia \\ New Clade Name}

Phylogenetic definition. The name Perichelydia is herein informally referred to the clade that arises from the most recent com- mon ancestor of Meiolania platyceps Owen, 1886, Helochelydra nopcsai Lapparent de Broin and Murelaga, 1999, Sichuanchelys chowi Ye and $\mathrm{Pi}, 1997$, and the extant turtle Testudo graeca Linnaeus, 1758.

Diagnosis. Representatives of Perichelydia are currently diagnosed relative to more basal testudinates by the absence of an open interpterygoid vacuity and the presence of a processus trochlearis oticum.

Comments. In the majority of recent phylogenies, helochelydrids, meiolaniforms, sichuanchelyids, and crown turtles form a clade that is more derived relative to all named Triassic to Early Jurassic turtles. Although the exact interrelationship of these taxa remains unstable, I find it useful to name this clade Perichelydia. In contrast to Mesochelydia, the diagnosis is relatively short, as only few characters unambiguously distinguish perichelydians from more basal turtles. The name Perichelydia is formed by combining the prefix "peri-" (Greek for around) with "chelydia" (derived from the Greek word chelys for turtle) in allusion to the fact that this clade of turtles closely "surrounds" crown Testudines.

\section{Helochelydridae Nopcsa, 1928a}

Phylogenetic definition. Following Joyce et al. (2016), the name Helochelydridae is herein referred to the clade that includes all turtles more closely related to Helochelys nopcsai Lapparent de Broin and Murelaga, 1999, than to Meiolania platyceps Owen, 1886, Sichuanchelys chowi Ye and Pi, 1997, or any extant turtle.

Diagnosis. Among others, representatives of Helochelydridae are currently differentiated relative to other perichelydians by the presence of a secondary pair of occipital tubercles that are formed by the pterygoids, a triangular fossa that is formed by the squamosal at the posterior margin of the skull, a shell covered by a surface texture consisting of distinct tubercles, Vshaped anterior peripherals, and the presence of an entoplastral scute.

Comments. Although a number of helochelydrid remains had been reported throughout the late 19th to early 20th century, Nopcsa (1928a) was the first to explicitly unite all then known taxa under the name Helochelydrinae (see Introduction above). The same publication includes the naming of a new helochelydrid, Helochelydra, but, strangely, no species was referred to this genus. Following the rules of the ICZN (1999), genus names that were formed prior to 1930 do not have to include a type species. Nopcsa (1928a) therefore established an available genus name, and by extension an available family group taxon, Helochelydrinae. However, given that Nopcsa's (1928a) description is relatively poor, clear figures are lacking, doubt was nevertheless warranted regarding the morphology and taxonomic affinities of his taxon. Lapparent de Broin and Murelaga (1996) highlighted this ambiguity and created a new name, Solemydidae, to unite the same group as Nopcsa (1928a) did, though to the exclusion of Helochelydra. Soon after, Lapparent de Broin and Murelaga (1999) clarified any taxonomic ambiguity surrounding Helochelydra by providing descriptions of key features apparent in the type specimen, by creating a new species that they fittingly named Helochelydra nopcsai, and by referring Helochely- 
dra nopcsai to Solemydidae. However, they failed to note at this point that any family group taxon typified by Helochelydra has priority over any family group taxon typified by Solemys, regardless of its rank at which they were created (ICZN 1999). Although it is unfortunate that the name Solemydidae was consistently applied to the group initially named by Nopcsa (1928a), it is not too late to correct this nomenclatural muddle. I therefore here follow Joyce et al. (2016) by utilizing the name Helochelydridae. The "family" ending was simply chosen for aesthetic reasons.

\section{Helochelydra Nopcsa, 1928a}

Type species. Helochelydra nopcsai Lapparent de Broin and Murelaga, 1999.

Comments. With exception of the type species, Helochelydra nopcsai, all other taxa are only referred to Helochelydra for a lack of justifiable taxonomic alternatives beyond the creation of more genera. This ambiguity is highlighted through the use of quotation marks. I therefore furthermore do not provide a formal diagnosis for Helochelydra.

\section{"Helochelydra" anglica (Lydekker, 1889b)}

Taxonomic history. Platychelys anglica Lydekker, 1889b (new species); Helochelydra anglica Milner 2004 (new combination); Compsemys anglica Joyce et al. 2011 (new combination).

Type material. BMNH 48357 (holotype), left posterolateral portion of a carapace (Lydekker 1889b, fig. 49).

Type locality. Durdlestone Bay, Dorset, United Kingdom (Lydekker 1889b; Figure 6); Purbeck Limestone Group, Berriasian, Early Cretaceous (Joyce et al. 2011).

Referred material and range. Early Cretaceous (Berriasian), Dorset, United Kingdom (referred material of Joyce et al. 2011).

Diagnosis. "Helochelydra" anglica is diagnosed as a helochelydrid by the presence of a shell surface texture consisting of tubercles. "Helochelydra" anglica can be distinguished from Helochelydra nopcsai, Helochelys danubina, and Naomichelys speciosa by lacking tubercles that easily dislocate from the shell surface, and from Plastremys lata and Solemys spp. by lacking tubercles that coalesce. A rigorous differentiation is currently not possible relative to "Helochelydra" bakewelli beyond temporal considerations (see Comments below).

Comments. Lydekker (1889b) described "Helochelydra" anglica (his Platychelys anglica) based on the posterior portions of a juvenile carapace from the Early Cretaceous (Berriasian) of southern England. Although its attribution to the pleurodiran taxon Platychelys should have drawn considerable attention, it appears that this species was mostly ignored over the course of the following century. In his review of the turtles of the Purbeck Limestone Group, Milner (2004) clarified that Platychelys anglica is not a pleurodire, but rather shows helochelydrid characteristics, in particular the shell sculpturing so typical of the group. Milner (2004) therefore assigned anglica to the English helochelydrid genus Helochelydra. Milner (2004) furthermore assigned numerous shell fragments from the Purbeck Limestone Group to this species, but given that these do not overlap in any anatomical region, it must be emphasized that these were referred using stratigraphic reasoning and similarity in shell sculpture and may therefore represent a chimera.

Joyce et al. (2011) noted that shell sculpturing perhaps allows recognizing two taxa with tubercles in the Early Cretaceous of England (Berriasian-Valanginian): a taxon with lower tubercles, as in the type specimens of the Berriasian Platychelys anglica and Valanginian Trionyx bakewelli, and a taxon with high tubercles that easily dislocate, similar to those in the much younger Helochelydra nopcsai. And given that the low sculpturing of Platychelys anglica and Trionyx bakewelli generally resembles that of the North American turtle Compsemys victa Leidy, 1856, Joyce et al. (2011) provocatively referred both to Compsemys to highlight the possibility that they actually may represent a basal paracryptodire.

The subsequent description of an articulated shell of the helochelydrid Naomichelys speciosa from the Early Cretaceous of North America (Joyce et al. 2014) more recently provided many novel insights into the anatomy of a single helochelydrid specimen and a meaningful comparative basis. As far as I can tell, all fragmentary material from the early Early Cretaceous (Berriasian-Valanginian) of the United Kingdom broadly agrees with Naomichelys speciosa in its morphology. In addition to the shell sculpturing consisting of raised tubercles, notable characters include the presence of a raised midline keel (apparent in the holotype of "Helochelydra" anglica), the presence of short, but wide extragulars (BMNH 3598, typically assigned to "Helochelydra" bakewelli), lack of an anal notch (BMNH 2275, typically assigned to "Helochelydra" bakewelli), a well-developed, upturned lip along the lateral rims of the anterior and posterior plastral lobe with external sculpturing developed on the visceral side of the shell (BMNH 2275, 3598), and a pectoral scute that does not lap onto the entoplastron (BMNH 46325, referred to "Helochelydra" anglica). Although a phylogenetic analysis would likely reveal many of these characters to be plesiomorphic, I suspect that several are apomorphic and therefore useful in diagnosing helochelydrids relative to other turtles, including basal paracryptodires such as Compsemys victa. Given that the phylogenetic relationships among European helochelydrids remains far from resolved, I find it appropriate to place anglica and bakewelli in Helochelydra, as originally proposed by Milner (2004), but to highlight taxonomic uncertainty through the use of quotation marks.

Differences between "Helochelydra" anglica and "Helochelydra" bakewelli (see below) are minute. Indeed, given that so little is known about the anatomy of both taxa, they are only diagnosed by minor differences in their sculpturing. It is therefore highly plausible that they actually represent a single species, or two adjacent chronospecies, "Helochelydra" anglica being slightly older than "Helochelydra" bakewelli.

\section{"Helochelydra" bakewelli Mantell, 1833 lectotype designation}

Taxonomic history. Trionyx bakewelli Mantell, 1833 (new species); Tretosternum bakewelli $=$ Tretosternum punctatum $=$ Peltochelys duchastelli Lydekker and Boulenger 1887 (senior synonym, new combination, incorrect spelling of genus name); Helochelydra bakewelli Milner 2004 (new combination); Compsemys bakewelli Joyce et al. 2011 (new combination). 
Type material. BMNH 2265 (lectotype), an isolated costal (Mantell 1827, pl. 4.1; Mantell 1833, p. 255; Joyce et al. 2011, fig. 3a). The whereabouts of the paralectotypes is unknown.

Type locality. Cuckfield, West Sussex, United Kingdom (Mantell 1833; Figure 6); Cuckfield Stone, Grinstead Clay Member, Tunbridge Wells Sand Formation, Wealden Group, Valanginian, Early Cretaceous (Joyce et al. 2011).

Referred material and range. Early Cretaceous (Valanginian) of the Hastings Subgroup, East and West Sussex (Joyce et al. 2011).

Diagnosis. "Helochelydra" bakewell is diagnosed as a helochelydrid by the presence of a shell surface texture consisting of tubercles. "Helochelydra" bakewelli can be distinguished from Helochelydra nopcsai, Helochelys danubina, and Naomichelys speciosa by lacking tubercles that easily dislocate from the shell surface, and from Plastremys lata and Solemys spp. by lacking tubercles that coalesce. A rigorous differentiation is currently not possible relative to "Helochelydra" anglica beyond temporal considerations (see "Helochelydra" anglica above).

Comments. "Helochelydra" bakewelli was originally based on a small assortment of fossils from the Early Cretaceous (Valanginian) of southern England (Mantell 1833). In addition to a figured costal, the syntype series also consisted of "portions of the sternum or plastron, and some of the scales belonging to this species" (Mantell 1833: p. 256). I am only aware of the whereabouts of the costal and therefore designate it as the lectotype herein.

A number of fragmentary shell remains from the type section have been attributed to "Helochelydra" bakewelli over the decades (e.g., Lydekker 1889b; Joyce et al. 2011), but the anatomy of the species remains poorly understood. Lydekker and Boulenger (1887) believed "Helochelydra" bakewelli to be synonymous with the roughly coeval Belgian taxon Peltochelys duchastelli Dollo, 1884 for reasons that are extremely difficult to parse out, but that are barely worth the effort, as the conclusions of Lydekker and Boulenger (1887) are drawn from an eclectic assortment of specimens that now are understood to have little to do with "Helochelydra" bakewelli (also see Milner 2004). The partial plastron of "Helochelydra" bakewell figured by Lydekker (1889b, p. 139) seems to confirm the assertion of Lydekker and Boulenger (1887) that this species possesses fused gular scutes, just like Peltochelys duchastelli (Meylan 1988), but my personal observations of this specimen, BMNH 3598, indicate that the proportions of this specimen are heavily distorted in this figure and that there is no indication of fused gulars.

At present, only minor differences in shell sculpturing distinguish the Barremian "Helochelydra" anglica from the Valanginian "Helochelydra" bakewelli. It is therefore highly possible that these taxa are synonymous or represent chronospecies. For a discussion regarding the referral of bakewelli to "Helochelydra," please see "Helochelydra" anglica (above).

\section{Helochelydra nopcsai}

Lapparent de Broin and Murelaga, 1999

Taxonomic history. Helochelydra nopcsai Lapparent de Broin and Murelaga, 1999 (new species).
Type material. BMNH R171 (holotype), substantial portions of a highly fragmented shell with limb and girdle elements (Nopcsa 1928a, figs. 7, 8; Lapparent de Broin and Murelaga 1999, fig. 14a; Milner 2004, fig. 10a; Joyce et al. 2011, fig. 3c).

Type locality. Isle of Wight, United Kingdom (Figure 6); Wessex Formation, Wealden Group, Barremian, Early Cretaceous (Joyce et al. 2011).

Referred material and range. Early Cretaceous (Barremian), Wessex Formation, Isle of Wight, United Kingdom (Lapparent de Broin and Murelaga 1999; Sweetman and Insole 2010; Joyce et al. 2011); Early Cretaceous (Hauterivian-Barremian), Nouvelle-Aquitaine, France (Néraudeau et al. 2012); Early Cretaceous (Barremian), Aragon (Pérez-García et al. 2013), Castile and León (Pérez-García et al. 2012), La Rioja (Pérez García 2009; Pérez-García et al. 2012), and Valencia, Spain (Scheyer et al. 2015).

Diagnosis. Helochelydra nopcsai can be diagnosed as a helochelydrid by the full list of characters listed for that clade above. Helochelydra nopcsai can be distinguished from Helochelydra "anglica" and "Helochelydra" bakewelli, Plastremys lata, and Solemys spp. by exhibiting a shell surface sculpture consisting of distinct tubercles that dislocate easily, and from Naomichelys speciosa by possessing pterygoids that fully cover the parabasisphenoid ventrally, a narrow symphyseal shelf, and an upright coracoid process. Only biogeographic and stratigraphic concerns currently distinguish Helochelydra nopcsai from Helochelys danubina.

Comments. Helochelydra nopcsai is based on a partial skeleton consisting of a fragmented shell and some girdle remains from the Early Cretaceous (Barremian) Wessex Formation of the Isle of Wight, England. Lydekker and Boulenger (1887) first mentioned the holotype under the name Tretosternum [sic] bakewelli, but Lydekker (1889b) soon after transferred the specimen to Tretosternum [sic] punctatum, likely because he believed Tretosternon bakewelli to have close affinities with Peltochelys duchastelli. Nopcsa (1928a) provided a brief description of this specimen, but the accompanying illustrations are poorly executed and photographs are lacking. Although Nopcsa (1928a) consistently noted similarities with somewhat younger Helochelydra danubina, he nevertheless established a new genus for this material, Helochelydra, though without a species, which is not problematic for genera established prior to 1930 (ICZN 1999). Although Lapparent de Broin and Murelaga (1999) established taxonomic clarity by naming a new species and by figuring the entoplastron, the type specimen essentially remains undescribed.

Sweetman and Insole (2010) recently reported the presence of isolated dermal armor with helochelydrid texturing (i.e., granicones) from the Wessex Formation of the Isle of Wight that is best assigned to Helochelydra nopcsai using stratigraphic arguments. Joyce et al. (2011) similarly described a near-complete helochelydrid skull and associated shell fragments from the general vicinity that are best assigned to Helochelydra nopcsai as well using stratigraphic and biogeographic concerns. Helochelydra nopcsai is therefore the best preserved helochelydrid taxon from Europe, though not necessarily the best described. The cranium is particularly important, as it helps clearly distinguish Helochely- 
dra nopcsai from the nearly coeval Naomichelys speciosa from North America.

Isolated shell fragments have been found in Cretaceous deposits throughout western Europe that often display a shell texture similar to Helochelydra nopcsai. Given that much of western Europe formed a more or less contiguous land mass during parts of the Cretaceous, I here refer all such fragments that correspond in their age to the deposits of the Isle of Wight to Helochelydra nopcsai, in particular specimens from the Hauterivian/Barremian of France (Néraudeau et al. 2012) and the Barremian of Spain (Pérez García 2009; Pérez-García et al. 2012, 2013; Scheyer et al. 2015). Fragments that are substantially older or younger are referred to Helochelydridae indet.

\section{Helochelys danubina Meyer, 1854}

Taxonomic history. Helochelys danubina Meyer, 1854 (new species).

Type material. A partial shell and a limb bone (holotype), now lost (Meyer 1855, pls. 17, 18; Joyce et al. 2011).

Type locality. Kelheim, Bavaria, Germany (Figure 6); Regensburger Grünsandstein Formation, Cenomanian, Late Cretaceous (Meyer 1854; Joyce et al. 2011).

Referred material and range. Early Cretaceous (Albian), Cambridge Greensand, Cambridge, United Kingdom (Joyce et al. 2011); Late Cretaceous (Cenomanian), Nouvelle-Aquitaine, France (Vullo et al. 2010); Late Cretaceous (Cenomanian), Castilla-La Mancha, Spain (Torices et al. 2012).

Diagnosis. Helochelys danubina can be diagnosed as a helochelydrid by the presence of a shell surface texture consisting of distinct tubercles. Helochelys danubina can be distinguished from Helochelydra "anglica" and "Helochelydra" bakewelli, Plastremys lata, and Solemys spp. by exhibiting a shell surface sculpture consisting of distinct tubercles that dislocate easily. Helochelys danubina can be distinguished from Naomichelys speciosa by having a shallower nuchal emargination, a deeper cervical scute, marginals that only cover half of the peripherals, and by lacking prepleural scutes. At present, the Cenomanian Helochelys danubina can only be separated from the Barremian Helochelydra nopcsai using temporal considerations.

Comments. Helochelys danubina is based on a partial shell from Late Cretaceous (Cenomanian) of southern Germany (Meyer $1854,1855)$ that was formerly held in a private collection, but now appears to be lost (Joyce et al. 2011). Among named helochelydrids, Helochelys danubina is most similar to the English Helochelydra nopcsai and the North American Naomichelys speciosa by having a shell that was covered by distinct tubercles that easily dislocate, but it was previously difficult to differentiate these taxa rigorously (Joyce et al. 2011). The recent description of the shell of Naomichelys speciosa revealed that this species has a deep nuchal notch, shallow cervical, broad marginals, and prepleural scutes, in contrast to Helochelys danubina, which has a shallow nuchal notch, a relatively deep cervical, narrow marginals that cover only half of the peripherals, and lacks prepleural scutes. These two species can therefore be distinguished easily. Until the available shell material of Helochelydra nopcsai has finally been described, it is only possible to diagnose Helochelys danubina relative to Helochelydra nopcsai using temporal considerations. Given that much of western Europe formed contiguous land masses during parts of the "mid" Cretaceous, or were only separated by narrow seas, Joyce et al. (2011) referred fragmentary material with the same shell texture from the Early Cretaceous (Albian) of the United Kingdom to Helochelys danubina using temporal considerations. Using the same rationale, I here furthermore refer fragmentary material from the Late Cretaceous (Cenomanian) of Nouvelle-Aquitaine, France (part of the material described by Vullo et al. 2010), and Castilla-La Mancha, Spain (Torices et al. 2012), to this species.

\section{Naomichelys speciosa Hay, 1908}

Taxonomic history. Naomichelys speciosa Hay, 1908 (new species).

Type material. AMNH 6136 (holotype), an isolated partial entoplastron (Hay 1908, pl. 40.2, 3).

Type locality. $40 \mathrm{~km}$ east of Pryor, Montana, USA (Hay 1908; Figure 7); Kootenai Formation, Aptian, Early Cretaceous (Joyce et al. 2011).

Referred material and range. Early Cretaceous (Aptian), Arundel Formation, Maryland (Kranz 1998); Early Cretaceous (Aptian) Cloverly Formation, Montana (Hay 1908; Ostrom 1970; Joyce et al. 2011; Oreska et al. 2013) and Wyoming (Oreska et al. 2013); Early Cretaceous (Aptian/Albian) Trinity Group, Texas (Jacobs et al. 1991; Scheyer and Anquetin 2008; Joyce et al. 2014; Scheyer et al. 2015); Early Cretaceous (Albian), Willow Tank Formation, Nevada (Bonde et al. 2008); "mid" Cretaceous (Albian-Cenomanian), Cedar Mountain Formation, Utah (Joyce et al. 2011).

Diagnosis. Naomichelys speciosa can be diagnosed as a helochelydrid by the full list of characters listed for that clade above. Naomichelys speciosa can be distinguished from Helochelydra "anglica" and "Helochelydra" bakewelli, Plastremys lata, and Solemys spp. by exhibiting a shell surface sculpture consisting of distinct tubercles that dislocate easily, from Helochelydra nopcsai by the exposed parabasisphenoid in ventral view, a broad symphyseal shelf, and a flattened coracoid process, and from Helochelys danubina by having a deeper nuchal emargination, a shallow cervical scute, marginals fully cover the peripherals, and prepleural scutes.

Comments. Naomichelys speciosa is the only helochelydrid named outside of Europe. The holotype, an isolated entoplastron, was originally reported to be from the Late Jurassic Morrison Formation (Hay 1908), but a recent reassessment of the type locality indicated that it originates from the Early Cretaceous (Aptian) Cloverly (or Kootenai) Formation (Joyce et al. 2011). Although the vast majority of North American helochelydrid finds are fragmentary (see below), a well-preserved nearcomplete skeleton from the Early Cretaceous (Aptian/Albian) of Texas documents nearly all parts of the skeleton. This specimen has languished undescribed in collections for many decades, but was recently described (Joyce et al. 2014). This specimen is the sole source of information regarding the phyloge- 
netic relationships of Naomichelys speciosa (e.g., Hirayama et al. 2000; Anquetin 2012; Joyce et al. 2016).

Over the course of the last century, turtle shell fragment have been reported all across North American that possess the characteristic helochelydrid sculpturing consisting of raised tubercles. These have variously been referred to Helochelydridae (= Solemydidae), Naomichelys sp., or Naomichelys speciosa. Joyce et al. (2014) recently summarized all figured or catalogued remains from North America and attributed all to Naomichelys speciosa. There is no reason to assume a priori that multiple species of helochelydrids must have populated North America during the late Early Cretaceous, especially as all major land masses producing fossils were then connected by land. I therefore still support the notion of assigning all available helochelydrid material from this time period to Naomichelys speciosa, even if fragments alone seldom warrant referral to a particular species (see a complete listing above). However, given that any more complete skeletal material from the Late Cretaceous of the continent will likely differ sufficiently to warrant naming a new species, I here more cautiously classify all fragments from this time interval as Naomichelys sp. This includes fragments from the Turonian Kaskapau Formation of British Columbia (Rylaarsdam et al. 2006), the Turonian-Santonian Straight Cliffs Formation (Joyce et al. 2011) and Tropic Shale of Utah (Albright et al. 2013), the Santonian-Campanian Milk River Formation of Alberta (Brinkman 2003; Joyce et al. 2011), and the Campanian Foremost Formation of Alberta (Peng et al. 2001; Scheyer and Anquetin 2008; Joyce et al. 2011; Scheyer et al. 2015), Wahweap Formation of Utah (Joyce et al. 2011) Mesaverde Formation of Wyoming (Demar and Breithaupt 2006), Menefee Formation of New Mexico (Joyce et al. 2011; Lichtig and Lucas 2015), and Two Medicine Formation of Montana (Joyce et al. 2011). Reports of helochelydrid material from North America that I have not been able to verify through published photographs or at least referred specimens include fragments from the Aptian/Albian Antlers Formation of Oklahoma (Cifelli et al. 1997), the Cenomanian Dunvegan Formation of Alberta (Larson et al. 2010), the Turonian Iron Spring Formation of Utah (Eaton et al. 2001), the Santonian Haslam Formation of British Columbia (Larson et al. 2010), and Campanian of Missouri, USA (Fix and Darrough 2004). These records are therefore not included in Appendix 3 or Figure 7.

\section{Plastremys lata Owen in Parkinson, 1881 (= Trachydermochelys rutteri Andrews 1920 = Trachyaspis turbulensis Bergounioux, 1957)}

Taxonomic history. Plastremys lata Owen in Parkinson, 1881 (new species); Trachydermochelys lata Andrews 1920 (new combination); Plastremys lata $=$ Trachydermochelys rutter $i=$ Trachyaspis turbulensis Joyce et al. 2011 (senior synonym).

Type material. BMNH R48 (holotype), a partial, disarticulated shell (not figured).

Type locality. Isle of Wight, United Kingdom (Owen in Parkinson 1881; Figure 6); Upper Greensand, Albian-Cenomanian, "mid" Cretaceous (Joyce et al. 2011).

Referred material and range. Early Cretaceous (Albian), Cambridge, United Kingdom (Trachydermochelys phlyctaenus of
Seeley 1869 and Lydekker 1889b); "mid" Cretaceous (AlbianCenomanian), Dorset, United Kingdom (Trachydermochelys rutteri of Andrews 1920); Early Cretaceous (Aptian), Aragon, Spain (Trachyaspis turbulensis of Bergounioux 1957; Late Cretaceous (Cenomanian), Nouvelle-Aquitaine, France (= Helochelydridae indet. of Vullo et al. 2010).

Diagnosis. Plastremys lata can be diagnosed as a helochelydrid by the presence of a shell surface texture consisting of distinct tubercles. Plastremys lata can be distinguished from all other helochelydrids by exhibiting a shell surface sculpture consisting of large, blunt tubercles that do not coalesce to form a vermiculated pattern.

Comments. Up to four names have been proposed for helochelydrid material from the "middle" Cretaceous of the United Kingdom and Spain characterized by low, rounded tubercles. Seeley (1869) initially listed a number of fragments from the Early Cretaceous (Albian) Cambridge Greensand under the name Trachydermochelys phlyctaenus, but he explicitly stated in the introduction to his book that the names he proposed were informal. Trachydermochelys phlyctaenus is therefore not available for nomenclatural considerations (Joyce et al. 2011, see below). Owen (in Parkinson 1881) soon after described a partial shell from the slightly younger (Aptian-Cenomanian) Upper Greensands of the Isle of Wight under the name Plastremys lata, but neither provided figures, nor a meaningful description, a fact soon after noted by Lydekker (1889b). Indeed, the type specimen of Plastremys lata remains unfigured, although Lapparent de Broin and Murelaga (1999) highlighted a few features they observed in this specimen. Given that Owen (in Parkinson 1881) explicitly lists characters that diagnose his taxon, his name must be considered available for nomenclatural considerations (ICZN 1999). A few decades later, Andrews (1920) described a relatively well-preserved shell from the Upper Greensands of Dorset, just across the strait from the Isle of Wight, under the name Trachydermochelys rutteri. Andrews (1920) explicitly mentioned having seen the material described by Owen (in Parkinson 1881) and referred it to Trachydermochelys, but failed to list characters that would differentiate his new taxon from Owen's. Bergounioux (1957) finally described Trachyaspis turbulensis on the basis of a partial carapace from the Early Cretaceous (Aptian) of Aragon, Spain, but failed to note any resemblances with previously described helochelydrid material from the rest of Europe. Joyce et al. (2011) recently suggested that these four taxa are synonymous, as they all originate from roughly the same time period throughout western Europe and display the same shell texture consisting of low tubercles. This decision is least controversial for Plastremys lata and Trachydermochelys rutteri, as they originate from same formation within neighboring counties. The much-needed reanalysis of the relevant type specimens is expected to further test this claim. The synonymy with Trachyaspis turbulensis is slightly more daring, as the Iberian Peninsula was not necessarily connected to Great Britain during this time period. Ongoing active fieldwork on the Iberian Peninsula combined with reanalysis of the holotype of Trachyaspis turbulensis, however, is expect to test this hypothesis as well. Canudo, Cobos, et al. (2005) explicitly compare a helochelydrid fragment from the Albian of Aragon, Spain, with Trachyaspis turbulensis and it is reasonable that this fragment is attributable to Plastremys lata as well. However, caution 
is necessary until this fragment has been figured. On the other side, some of the figured fragments described by Vullo et al. (2010) from the Late Cretaceous (Cenomanian) of France clearly exhibit the surface texture of Plastremys lata and are therefore referred to this taxon herein. The remaining fragments from this locality are referred to Helochelys danubina (see above). Finally, although the material from the Cambridge Greensand indeed displays the same shell texture as that from the younger Upper Greensand, it is highly fragmentary and additional material is not expected anytime soon. Its attribution to Plastremys lata is therefore the least testable for the moment.

\section{Solemys}

Lapparent de Broin and Murelaga, 1996

Type species. Apholidemys gaudryi Matheron, 1869.

Diagnosis. Solemys can be diagnosed as a representative of Helochelydridae by the full list of shell characters listed for that clade above. Solemys can be distinguished from all other helochelydrids by the presence of a shell surface sculpture consisting of low vermiculations.

Comments. Many isolated shell fragments with the diagnostic surface sculpturing of Solemys have been reported from Campanian and Maastrichtian deposits throughout southern France and northern Spain (Matheron 1869; Astibia et al. 1987; Le Loeuff 1991; Jiménez Fuentes 1992; Tong et al. 1993; Lapparent de Broin and Murelaga 1996, 1999; Murelaga et al. 1998; PeredaSuberbiola et al. 1999; Canudo, Infante, and Murelaga 2005; Murelaga and Canudo 2005; Murelaga et al. 2005; Marmi et al. 2009; Pérez García 2009; Scheyer et al. 2015). However, given that the two named species can only be distinguished by details and that it is unclear if they overlap spatially or temporally, I agree with Lapparent de Broin and Murelaga (1999) that it is best to classify all such finds as Solemys indet.

\section{Solemys gaudryi (Matheron, 1869)}

Taxonomic history. Aplolidemys gaudryi Matheron, 1869 (new species, incorrect spelling of genus name); [Anosteira gaudryi] Hummel 1929 (new combination, nomen dubium); Solemys gaudryi Lapparent de Broin and Murelaga 1996 (new combination, lectotype designation).

Type material. MHNM 1982-854 (lectotype), partial peripherals VII and VIII and partial plastron (Lapparent de Broin and Murelaga 1996, figs. 3a-c, 4a). The remaining paralectotypes have neither been listed nor figured.

Type locality. Rognac, Bouches-du-Rhône, France (Matheron 1869; Figure 6); argillaceous sandstone at the base of the Rognacien, Maastrichtian, Late Cretaceous (Lapparent de Broin and Murelaga 1996).

Referred material and range. Late Cretaceous (Maastrichtian) of type locality, Bouches-du-Rhône, France (Matheron 1869; Lapparent de Broin and Murelaga 1996).

Diagnosis. Solemys gaudryi can be diagnosed as a helochelydrid and a representative of Solemys by the full list of shell characters listed for this taxon above. Solemys gaudryi can be differentiated relative to Solemys vermiculata by having more elongate gulars that broadly lap onto the entoplastron, a more centrally located entoplastral scute, and a narrower anterior plastral lobe.

Comments. Solemys gaudryi was named by Matheron (1869) on the basis of fragmentary material from the Late Cretaceous (Maastrichtian) of southern France. Matheron (1869) originally referred the species to Apholidemys Pomel, 1847 (misspelled as Aplolidemys), a dubious taxon from the Eocene of southern France (Broin 1977; Joyce 2014) that had been described as being characterized by textured shell elements and the lack of sulci. Over the course of the next century, Solemys gaudryi was mostly ignored, likely because the type material had never been figured, but its purported vicinity of Apholidemys led some to speculate that it is a carettochelyid (Hummel 1929). As part of her review of the fossil record of turtles from France, Broin (1977) restudied the material and noted briefly that the sculpturing observed in this taxon is neither consistent with that of a carettochelyid nor with that of a trionychid.

The identity of Solemys gaudryi was finally revealed when Lapparent de Broin and Murelaga (1996) restudied the type series, designated and figured a lectotype, and provided a reconstruction of the plastron. Although Lapparent de Broin and Murelaga (1999) furnished additional insights into the anatomy of this taxon, a more extensive redescription is still outstanding, but the validity is uncontroversial. The reported differences between the Maastrichtian Solemys gaudryi and the Campanian Solemys vermiculata are rather subtle and it is therefore possible that they represent chronospecies.

\section{Solemys vermiculata}

Lapparent de Broin and Murelaga, 1996

Taxonomic history. Solemys vermiculata Lapparent de Broin and Murelaga, 1996 (new species).

Type material. MCNA 6325 (holotype), an entoplastron (Lapparent de Broin and Murelaga 1996, fig. 3f).

Type locality. Laño locality, Condado de Treviño, Castile and León, Spain (Figure 6); Campanian, Late Cretaceous (Lapparent de Broin and Murelaga 1996).

Referred material and range. Late Cretaceous (Campanian) of type locality, Castile and León, Spain (Astibia et al. 1987; Jiménez Fuentes 1992; Lapparent de Broin and Murelaga 1996, 1999; Pérez García 2009; Scheyer et al. 2015).

Diagnosis. Solemys vermiculata can be diagnosed as a helochelydrid and a representative of Solemys by the full list of shell characters listed for this taxon above. Solemys vermiculata can be differentiated relative to Solemys gaudryi by having shorter gulars with only a minor overlap onto the external surface of the entoplastron, a more anteriorly located entoplastral scute, and a broader anterior plastral lobe.

Comments. The Campanian fossil locality of Laño, Castile and León, Spain, has yielded a rich collection of fossil turtles over the course of the last decades, including many fragments characterized by the surface sculpturing typical of helochelydrid tur- 
tles. Astibia et al. (1987) were the first to report textured turtle fossils from this locality and speculated that they may belong to Adocus, a taxon then classified within the wastebasket taxon Dermatemydidae, but now believed to be a representative of Pan-Trionychia. Jiménez Fuentes (1992) figured more material from Laño, confirmed its identity as a dermatemydid, but noted similarities with the neglected Maastrichtian taxon Apholidemys gaudryi from nearby France. Lapparent de Broin and Murelaga (1996) soon after named a new turtle based on the material from Laño, Solemys vermiculata, and taxonomically confirmed its close relationship with the Maastrichtian material from France by placing Apholidemys gaudryi in Solemys as well. Lapparent de Broin and Murelaga (1999) soon after described and figured select specimens from Laño and extensively discussed the characters that unite helochelydrid turtles. Although the validity of Solemys vermiculata is not controversial to me, I note that the Campanian S. vermiculata and the Maastrichtian S. gaudryi are only differentiated by minor differences in the shell. I therefore find it plausible that these taxa may represent chronospecies.

\section{Meiolaniformes Sterli and de la Fuente, 2013}

Comments. The fossil record of meiolaniform turtles was only recently summarized by Sterli (2015). However, given that some of these stem turtles also occurred during the Mesozoic, I here for completeness only briefly list these species in this section, Appendices 2-4, and Figures 5-7, and otherwise refer the reader to Sterli (2015).

Chubutemys copelloi Gaffney et al., 2007 (see Sterli 2015)

Otwayemys cunicularius Gaffney et al., 1998 (see Sterli 2015)

Patagoniaemys gasparinae

Sterli and de la Fuente, 2011 (see Sterli 2015)

Trapalcochelys sulcata Sterli, de la Fuente, and Cerda 2013 (see Sterli 2015)

\section{Sichuanchelyidae}

Tong, Danilov, Ye, Ouyang, and Peng 2012

Phylogenetic definition. Following Joyce et al. (2016), the name Sichuanchelyidae is herein referred to the clade that includes all turtles more closely related to Sichuanchelys chowi Ye and $\mathrm{Pi}$, 1997 than to Helochelys nopcsai Lapparent de Broin and Murelaga, 1999, Meiolania platyceps Owen, 1886, or any extant turtle.

Diagnosis. Among others, representatives of Sichuanchelyidae are currently differentiated relative to other perichelydians by the presence of enlarged squamosals that partially to fully roof the anterior neck region, close approximation or contact of the jugal and the quadrate, an enlarged antrum postoticum that is not enclosed laterally, entry of the palatine artery through ven- trally open foramina caroticum laterale, paired pits on the ventral side of the basisphenoid, and a nuchal notch delimited by peripherals II.

\section{Mongolochelys efremovi Khosatzky, 1997}

Taxonomic history. Mongolochelys efremovi Khosatzky, 1997 (new species).

Type material. PIN 551/459 (holotype), a partial skeleton consisting of the skull, the complete shell, and much of the limbs and girdles (Khosatzky 1997, figs. 1-3; Sukhanov 2000, fig. $17.28,29)$.

Type locality. Nemegt Basin, Ömnögovi Province, Mongolia (Figure 5); Nemegt Formation, Maastrichtian, Late Cretaceous (Khosatzky 1997).

Referred material and range. Late Cretaceous (Campanian-Maastrichtian) of Nemegt Formation, Ömnögovi Province, Mongolia (Suzuki and Watabe 2000; Suzuki and Chinzorig 2010).

Diagnosis. Mongolochelys efremovi can be diagnosed as a representative of Sichuanchelyidae by the full list of characters listed for that clade above. Mongolochelys efremovi can be differentiated from other sichuanchelyids, among others, by large size, extremely well-developed squamosals that have a midline contact and form an extensive collar that covers the anterior portions of the neck, enlarged quadratojugals that extend above the cavum tympani to contact the squamosal, and by the presence of broadened triturating surfaces with accessory ridges, strongly interfingered plastral elements, and the presence of supernumerary epiplastral bones (exoplastra of Suzuki and Chinzorig 2010)

Comments. Specimens referable to Mongolochelys efremovi were already collected in the 1940s, but were only alluded to in the literature, despite their exquisite preservation and relevance to the evolution of turtles (see Khosatzky 1997 for summary). The two primary exceptions include a large shell piece that was figured by Mlynarski and Narmandach (1972) as an amphichelydian xiphiplastron, actually an epiplastron, and a near-complete skull that was figured by Chkhikvadze (1987) as belonging to Yumenemys inflatus Bohlin, 1953, a somewhat dubious taxon from the Late Cretaceous of Asia. The true nature of this taxon was finally revealed through the type description of Khosatzky (1997), which includes beautifully executed illustrations of the skull and shell of this taxon. Additional, rich material was more recently listed and partially figured by Suzuki and Chinzorig (2010). The plesiomorphic nature of Mongolochelys efremovi was apparent to all previous workers, although little agreement existed to its exact classification (e.g., MYynarski and Narmandach 1972; Chkhikvadze 1987; Khosatzky 1997). The majority of more recent cladistic analyses supported the idea that this species is a derived stem turtle closely related with meiolaniforms from the southern continents (e.g., Hirayama et al. 2000; Joyce 2007; Anquetin 2012; Sterli and de la Fuente 2013). However, following the finding of "Sichuanchelys" palatodentata (Joyce et al. 2016), I here follow the novel hypothesis that Mongolochelys efremovi is the most derived representative of the Asian sichuanchelyid lineage. I here remain neutral in regards to 
a possible relationship of Mongolochelys efremovi with fragmentary shell material from the Late Cretaceous (Maastrichtian) of Volgograd Oblast, Russia (Averianov and Yarkov 2004), which is tantalizing in its morphology, but ultimately too fragmentary to allow drawing rigorous conclusions.

\section{Sichuanchelys Ye and Pi, 1997}

Type species. Sichuanchelys chowi Ye and Pi, 1997.

Comments. In addition to the type species, a second species is here assigned to Sichuanchelys for convenience, because not enough information is yet available to justify placement in its own genus (see "Sichuanchelys" palatodentata below). As a result, I here do not provide a diagnosis for Sichuanchelys.

\section{Sichuanchelys chowi Ye and Pi, 1997}

Taxonomic history. Sichuanchelys chowi Ye and Pi, 1997 (new species).

Type material. ZDM 3014 (holotype), a near-complete shell (Ye and Pi 1997, unnumbered fig.; Tong, Danilov, Ye, Ouyang, and Peng 2012, fig. 8).

Type locality. Dashanpu (= Danshanpu) locality, Zigong, Sichuan, China (Figure 5); Xiashaximiao (= Shaximiao) Formation, Middle Jurassic (Ye and Pi 1997; Tong, Danilov, Ye, Ouyang, and Peng 2012).

Referred material and range. Middle Jurassic of type locality Sichuan, China (Ye and Pi 1997; Danilov and Parham 2008; Tong, Danilov, Ye, Ouyang, and Peng 2012).

Diagnosis. Sichuanchelys chowi can be diagnosed as a representative of Sichuanchelyidae by the presence of a broad nuchal notch that is delimited by peripherals II. This character is not unique globally, but otherwise unique among basal turtles from Asia, which are diagnosed by having broad vertebrals. Sichuanchelys chowi can be differentiated from "Sichuanchelys" palatodentata by lacking plastral fontanelles and a contact of vertebral I with marginal II, and from Mongolochelys efremovi by being much smaller, having much broader vertebrals, and by lacking plastral and carapacial fontanelles.

Comments. Sichuanchelys chowi is known from a small number of shells from the Middle Jurassic Xiashaximiao Formation of Dashanpu, Sichuan, China (Ye and Pi 1997; Danilov and Parham 2008; Tong, Danilov, Ye, Ouyang, and Peng 2012). Although this taxon is of particular relevance to the phylogeny of Middle Jurassic turtles, only the external morphology of the shell has been described (Ye and Pi 1997; Danilov and Parham 2008; Tong, Danilov, Ye, Ouyang, and Peng 2012) and many details are unknown regarding the remaining anatomy of this turtle. The clairvoyant assertion of Danilov and Parham (2008) that Sichuanchelys chowi might represent a stem turtle was recently confirmed by the global phylogenetic analyses of Tong, Danilov, Ye, Ouyang, and Peng (2012) and Joyce et al. (2016). Given that Sichuanchelys chowi can only be scored for few characters, however, its relationships with other sichuanchelyids remain uncertain for the moment. For simplicity, I here refer all less diagnostic material from Zigong to Sichuanchelys chowi as well (Danilov and Parham 2008; Tong, Danilov, Ye, Ouyang, and Peng 2012).

“Sichuanchelys" palatodentata Joyce et al., 2016

Taxonomic history. Sichuanchelys palatodentata Joyce et al., 2016 (new species).

Type material. IVPP V18093 (holotype), a partial skeleton consisting of most of the cranium, the right half of the carapace, and various disarticulated vertebrae, girdle, and limb bones (Joyce et al. 2016, figs. 1, 3, 4, 7a).

Type locality. Wucaiwan locality, Xinjiang Uygur Autonomous Region, China (Figure 5); Shishugou Formation, Oxfordian, Late Jurassic (Joyce et al. 2016).

Referred material and range. Late Jurassic (Oxfordian) of type locality, Xinjiang, China (Brinkman et al. 2013; Joyce et al. 2016).

Diagnosis. "Sichuanchelys" palatodentata can be diagnosed as a representative of Sichuanchelyidae by the full list of characters provided for that clade above. Within that clade, "Sichuanchelys" palatodentata can be differentiated from Sichuanchelys chowi by possessing plastral fontanelles and a contact of vertebral I with marginal II, and from Mongolochelys efremovi by being smaller, exhibiting palatal teeth, having smaller squamosals that do not meet one another along the midline, smaller quadratojugals that lack a dorsal contact with the squamosals, by lacking expanded triturating surfaces with accessory ridges, broad vertebral scutes, and by lacking interfingered plastral elements.

Comments. The presence of a turtle that resembles the Middle Jurassic Sichuanchelys chowi was initially reported by Brinkman et al. (2013) on the basis of poorly preserved shell material from the Late Jurassic locality of Wucaiwan, Xinjiang Province, China. This conclusion was recently confirmed through the description of several partial skeletons, also from Wucaiwan, that include beautifully preserved cranial material (Joyce et al. 2016) and now serve as the basis for a new species, "Sichuanchelys" palatodentata. In general, the shell of "Sichuanchelys" palatodentata greatly resembles that of Sichuanchelys chowi, but phylogenetic analysis highlights a few derived characters that might place this species closer to the Late Cretaceous Mongolochelys efremovi, thereby giving support to the idea that a single sichuanchelyid lineage persisted in Asia throughout most of the late Mesozoic. However, given that the morphology of Sichuanchelys chow is so poorly known, this hypothesis is only poorly supported. I therefore here follow Joyce et al. (2016) by referring the new taxon to Sichuanchelys but highlight phylogenetic ambiguity through the use of quotation marks.

\section{Perichelydia indet.}

Kallokibotion bajazidi Nopcsa, 1923a

(= Kallokibotion magnificum Nopcsa, 1923a

= Thalassodromeus sebesensis Grellet-Tinner and Codrea, 2015) 
Taxonomic history. Kallokibotion bajazidi Nopcsa, 1923a (new species); Kallokibotium bajazidi Nopcsa 1923b (incorrect spelling of genus name); Kallokibotion bajazidi = Kallokibotion magnificum Gaffney and Meylan 1992 (senior synonym, lectotype designation); Kallokibotion bajazidi $=$ Kallokibotion magnificum $=$ Thalassodromeus sebesensis Dyke et al. 2015 (senior synonym).

Type material. BMNH R4916 (lectotype), postcranial skeleton consisting of partial shell, pelvis, and a caudal vertebra (Nopcsa 1923b, fig. 1, pls. 1.18, 23-25, 2.4-6, 4.1; Gaffney and Meylan 1992, figs. 23, 24). See comment below regarding paralectotypes.

Type locality. Sânpetru (= Sinpetru = Szentpéterfalva), Braşov County, Romania (Nopcsa 1923a; Figure 6); Maastrichtian, Late Cretaceous (Gaffney and Meylan 1992).

Referred material and range. Late Cretaceous (Maastrichtian), Haţeg Basin (Nopcsa 1923a, 1923b; Rabi, Vremir, and Tong 2013) and Transylvanian Basin, Romania (Nopcsa 1923a, 1923b; Rabi, Vremir, and Tong 2013; Grellet-Tinner and Codrea 2015).

Diagnosis. Kallokibotion bajazidi can be diagnosed as a mesochelydian and perichelydian by the full list of characters listed for those clades above. Kallokibotion bajazidi can be differentiated from all helochelydrids, meiolaniforms, and sichuanchelyids by lacking the characters listed for those clades above and from Spoochelys ormondea by having a well-developed collar that covers the anterior portions of the neck. Kallokibotion bajazidi is notably characterized by nasals that form a partial internarial process, a narrow median contact of the pterygoids, parasagittal grooves on the palatine, and a superficially enclosed incisura columellae auris and Eustachian tube.

Comments. Kallokibotion bajazidi is based on relatively rich material from the Late Cretaceous (Maastrichtian) of western Romania. Nopcsa (1923a, 1923b) initially recognized two morphotypes among the material available to him from the same locality and named two species: Kallokibotion bajazidi and Kallokibotion magnificum. Gaffney and Meylan (1992) more recently highlighted that the characters that Nopcsa (1923a, 1923b) utilized to diagnose his species are either within the amount of variation apparent among living turtles (i.e., shape and proportions of the vertebrals) or the result of taphonomic alteration (i.e., purported differences to the width of the cervical, purported variability to the midline contact of the mesoplastra) and that the two species named by Nopcsa (1923a, 1923b) are therefore synonymous. This taxonomic assessment is uncontroversial. To aid taxonomic clarity, Gaffney and Meylan (1992) designated lectotype specimens for both taxa. However, given that Nopcsa (1923a, 1923b) did not provide explicit lists of syntypes, it is unclear, and to a certain degree irrelevant, which specimens represent the paralectotypes of each species. The material held at BMNH was described by Nopcsa (1923b) in great detail and thoroughly revised once again by Gaffney and Meylan (1992). Kallokibotion bajazidi is therefore one of the best-described stem turtles and features in the vast majority of global matrices investigating turtle relationships (e.g., Gaffney 1996; Hirayama et al. 2000; Gaffney et al. 2007; Joyce 2007; Tong et al. 2009; Joyce et al. 2016), although the available material certainly is not among the best preserved.
Over the course of the last two decades, fieldwork carried out throughout the Hațeg and Transylvanian basins resulted in the discovery of many new localities that include fragmentary turtle material. Among the turtle faunas of the Late Cretaceous of Romania, Kallokibotion bajazidi is uniquely characterized by a finely crenulated surface texture and it is therefore straightforward to diagnose isolated shell remains. I therefore find these reports to be unproblematic. For simplicity, I here follow the recent summary of all pertinent literature provided by Rabi, Vremir, and Tong (2013).

Grellet-Tinner and Codrea (2015) recently described a new fossil from the Haţeg Basin that they purported to be the headcrest of a new species of pterosaur, Thalassodromeus sebesensis. Dyke et al. (2015) soon after highlighted that the holotype of $T$. sebesensis actually represents the left hypo/xiphiplastron of Kallokibotion bajazidi and that T. sebesensis is therefore its junior synonym, a claim that was most indignantly rebuffed by Codrea and Grellet-Tinner (2015). I agree with Codrea and Grellet-Tinner (2015) that it is difficult to identify fragmentary fossil remains, but this only applies to fragments from taxa with which one is not familiar. The beautifully illustrated holotype of Thalassodromeus sebesensis in actual fact displays a long series of characters that are unique to turtles. In addition to the characters already highlighted by Dyke et al. (2015), for example, overall size, the shape of the xiphiplastron and hypoplastron, the presence of the skin-scute sulcus and pubic attachment site, details in the crenulation near the inguinal buttress, I furthermore note the presence of a thickened ridge that runs between the buttresses. It is therefore obvious to any paleontologists familiar with the anatomy of turtles that the holotype of T. sebesensis is a partial plastron of $K$. bajazidi.

At present, Kallokibotion bajazidi is a "phylogenetic isolate" that does not show close phylogenetic relationships with any other turtle taxon globally (Gaffney 1996; Hirayama et al. 2000; Gaffney et al. 2007; Joyce 2007; Tong et al. 2009; Joyce et al. 2016). This species is therefore expected to have a long ghost lineage that reasonably existed in Europe throughout much of the Cretaceous. A number of finds have been made that are reasonably assignable to this lineage. These include fragments figured and described from the Santonian of Hungary (see Rabi, Vremir, and Tong 2013 for summary) and from the Campanian of Austria (see Emys neumayri below). For simplicity I assign this material to Kallokibotion sp., as there currently is no need to establish yet another higher taxonomic category to hold this material. Broin (1977) and Lapparent de Broin (2001) reported a Kallokibotion-like animal from the Paleocene of Cernay-lesReims, France, but a description is lacking to date and it is therefore not possible to verify this claim. If true, however, this find would extend the presence of the Kallokibotion lineage to western Europe and imply that yet another turtle lineage survived the Cretaceous/Tertiary extinction event.

\section{Spoochelys ormondea Smith and Kear, 2013}

Taxonomic history. Spoochelys ormondea Smith and Kear, 2013 (new species).

Type material. AM F121579-81, anterior peripherals (Smith and Kear 2013, fig. 9.6a, b); AM F121587, a scapula (Smith and Kear 2013, fig. 9.8a); AM F121613, a pedal phalange; AM F121621, an ulna; AM F121641, a caudal vertebra; AM F121643, a quadrate; 
AM F121646, a supraoccipital; AM F121686-7, anterior costal fragments. All specimens were found in association and are hypothesized to originate from a single individual, which is the holotype.

Type locality. T-Bone Extension, about $35 \mathrm{~km}$ west of Lightning Ridge, New South Wales, Australia (Figure 5); Finch clay facies, Wallangulla Sandstone Member, Griman Creek Formation, Albian, Early Cretaceous (Smith and Kear 2013).

Referred material and range. Early Cretaceous (Albian) of type locality, New South Wales, Australia (hypodigm of Smith and Kear 2013).

Diagnosis. Spoochelys ormondea can be diagnosed as a mesochelydian by the presence of a fully formed cavum tympani and antrum postoticum, a pair of basioccipital tubercles, and a processus interfenestralis, and as a perichelydian by the absence of a well-developed interpterygoid vacuity, as inferred by the presence of a fully braced basicranial joint. Spoochelys ormondea can be differentiated from all helochelydrids, meiolaniforms, and sichuanchelyids by lacking the characters listed for those clades above, and from Kallokibotion bajazidi by lacking a well-developed collar that covers the anterior portions of the neck.

Comments. The Early Cretaceous (Albian) locality of Lightning Ridge is best known for yielding gem-quality opals, but the locality has yielded a number of fossils as well. Smith and Kear (2013) recently described a collection of primitive turtle remains from several quarried in the greater vicinity of Lightning Ridge that they ascribed to a single new species, Spoochelys ormondea (Smith and Kear 2013). Assuming that all remains indeed represent the same taxon, the validity of the species is unproblematic, as the partial shell and the two partial skulls included in the sample are easily differentiated from other taxa, in particular the similarly dated Otwayemys cunicularius from Victoria. The most recent phylogenetic analysis places $S$. ormondea within Perichelydia, but outside Meiolaniformes (Joyce et al. 2016).

\section{Invalid and Problematic Taxa}

\section{Chelycarapookus arcuatus Warren, 1969 nomen dubium}

Taxonomic history. Chelycarapookus arcuatus Warren, 1969 (new species).

Type material. NMV P13160 (holotype), the steinkern of a shell with associated plastral elements (Warren 1969, pl. 2; Gaffney 1981, fig. 20).

Type locality. Carapook, near Casterton, Victoria, Australia (Chapman 1919; Warren 1969); Merino Group, Albian, Early Cretaceous (Kear and Hamilton-Bruce 2011).

Comments. Chelycarapookus arcuatus is based on a steinkern with associated plastral fragments from Carapook, Victoria, Australia. The exact locality from which the specimen was collected is not known (Chapman 1919), but the local geological conditions led Warren (1969) to speculate that the specimen originated from the Albian Merino Formation, a conclusion supported by more recent authors (Kear and Hamilton-Bruce 2011). Warren (1969) concluded that the type is neither a meiolaniid, nor a chelid, but admitted that it may represent an early progenitor of either group. Gaffney (1981) concluded with more confidence that the pelvis of the type is not sutured to the shell and that it can safely be concluded to not have been a pleurodire. But even though a lack of character evidence prohibited Gaffney (1981) from assigning the type to any other group, he did not declare Chelycarapookus arcuatus to be a nomen dubium. Although it is possible to distinguish the type from the roughly coeval Otwayemys cunicularius (Gaffney et al. 1998), the lack of positive character evidence leads me to conclude that this taxon should be regarded a nomen dubium.

\section{Chelytherium obscurum Meyer, 1863 nomen dubium}

Taxonomic history. Chelytherium obscurum Meyer, 1863 (new species); Chelyzoum obscurum Jaekel 1914 (incorrect spelling of genus name).

Type material. BMNH 38650-3 (syntype series), a costal, a peripheral, a neural shell fragment (Meyer 1865, pl. 29.2-9), and an unfigured dorsal vertebra, costal bone, and marginal (Lydekker 1889b).

Type locality. Heslach and Kaltental (Fraas 1899), Stuttgart, Baden-Württemberg, Germany (Meyer 1863); Löwenstein Formation (= Stubensandstein of Meyer 1863), Norian, Late Triassic (Villinger 2002).

Comments. Chelytherium obscurum is the first fossil turtle to be reported from the Triassic worldwide (Meyer 1863). The type series consists of three specimens that were collected by Dr. Kapff in the vicinity of Stuttgart (Meyer 1863, 1865) and that were later sold to the BMNH (Lydekker 1889b). Fraas (1899) clarified that the material originated from the quarries of Heslach and Kaltental (= Kaltenthal), which have since been incorporated into the city of Stuttgart. However, this implies that the three syntypes may represent up to three separate individuals from two different, albeit close quarries. The quarries of Heslach and Kaltental are now known to expose sediments of the lower Löwenstein Formation (R. Schoch, pers. comm., 2016), which contrasts the age of all known material of Proganochelys quenstedtii (see above), but it is consistent with the stratigraphic origin of all material assigned to Proterochersis limendorsa and Proterochersis robusta (see above). Meyer $(1863,1865)$ initially reported the three syntypes to be a fragment from the periphery of a carapace, central portions of the shell with underlying vertebrae, and a skull bone. I agree with Lydekker (1889b) and Jaekel (1914), however, that the purported skull bone, as figured, clearly represents a costal.

The holotypes of Proganochelys quenstedtii and Chelytherium obscurum were discovered in the same formation only about $10 \mathrm{~km}$ from one another and it is therefore not surprising that Baur (1887) already noted that the two might be synonymous, a sentiment soon after reiterated by others (e.g., Gaudry 1890; Fraas 1899; Mlynarski 1976). Given that the type of Proterochersis robusta also originates from the same forma- 
tion, however, it is surprising a synonymy was never considered with that taxon. To a certain degree, the types of all taxa are too poorly preserved to allow making a meaningful comparison. However, the rich material that has since been attributed to Proganochelys quenstedtii and Proterochersis robusta (see above) should suffice.

I here consider Chelytherium obscurum to be a nomen dubium, as the type material, at least as presented by Meyer (1865), is too fragmentary to allow rigorous comparison with roughly coeval taxa from central Europe. If the restudy of the type material were to reveal Chelytherium obscurum to be synonymous with Proganochelys quenstedtii or Proterochersis robusta, I would suggest that this name is ignored, as this taxon has not been treated as valid since the 19th century.

Lydekker (1889b) attributed an isolated humerus from the Late Triassic of Scotland to Chelytherium obscurum, but this specimen, the holotype of Saurodesmus robertsoni, is now considered to be non-testudinate (see below).

\section{Emys neumayri Seeley, 1881 nomen dubium/lectotype designation}

Taxonomic history. Emys neumayri Seeley, 1881 (new species); Emys neumayeri Nopcsa 1926 (incorrect spelling of species epithet); Kallokibotion neumayri Kuhn 1964 (new combination).

Type material. IPUW 76/XXI/40 (lectotype), a left costal I (Seeley 1881, pls. 27.27, 31.13; Rabi, Vremir, and Tong 2013, fig. $19.7 \mathrm{a}, \mathrm{b})$. The exact composition of the paralectotype series is unclear.

Type locality. Muthmannsdorf, Lower Austria, Austria (Seeley 1881); Grünbachformation, Gosau Group, early Campanian, Late Cretaceous (Rabi, Vremir, and Tong 2013).

Comments. Emys neumayri is based on a small assortment of shell fragments that were collected in Campanian coalmine deposits in Muthmannsdorf, near Vienna, Austria (Seeley 1881; Rabi, Vremir, and Tong 2013). The collections at IPUW include a few dozen fragments (pers. obs.), of which Seeley (1881) only explicitly discussed two, even though the remaining fragments must have been available to him as well. The exact composition of the syntype series is therefore unclear. To facilitate taxonomic discussion, I here designate IPUW 76/XXI/40 as the lectotype, as this isolated costal is well preserved and was figured by both Seeley (1881) and Rabi, Vremir, and Tong (2013). Seeley (1881) felt certain that he was naming a freshwater turtle, but he ended up assigning it to Emys by default, as he was unable to attribute it to any particular genus. A few decades later, Nopcsa (1926) reviewed the type material of Emys neumayri and noted curtly that this Campanian taxon from Austria is likely a close relative of the Maastrichtian taxon Kallokibotion bajazidi from nearby Romania. More recently, Rabi, Vremir, and Tong (2013) noted that the surface texture of Emys neumayri greatly resembles that of Kallokibotion bajazidi, but that the material is too fragmentary to diagnose a valid taxon. They therefore referred the available material of Emys neumayri to Kallokibotioninae indet. Although I agree that Emys neumayri should be considered a nomen dubium, I here refer this Austrian material to Kallokibotion indet., as there is no need to maintain a taxon more inclusive than Kallokibotion that is redundant in its composition.

\section{Kallokibotion magnificum Nopcsa, 1923b nomen invalidum \\ (junior synonym of Kallokibotion bajazidi Nopcsa, 1923a)}

Taxonomic history. Kallokibotion magnificum Nopcsa, 1923b (new species); Kallokibotion bajazidi = Kallokibotion magnificum Gaffney and Meylan 1992 (junior synonym, lectotype designation).

Type material. BMNH R4930 (lectotype), partial shell (Nopcsa 1923b, figs. 3, 4, pl. 4.2; Gaffney and Meylan 1992, figs. 25-27).

Type locality. Sânpetru (= Szentpéterfalva), Braşov County, Romania (Nopsca 1923b); Maastrichtian, Late Cretaceous (Gaffney and Meylan 1992).

Comments. Nopcsa (1923a, 1923b) felt justified in naming two species of turtles based on material collected at Sânpetru, Romania, but the listed differences have since been shown to fall within the amount of variation seen within extant turtles, or to be taphonomic artifacts (Gaffney and Meylan 1992). Rabi, Vremir, and Tong (2013) recently highlighted that two morphotypes may actually be present among the available Kallokibotion material, but that more extensive analysis is needed to confirm the presence of two species. Given that the type of Kallokibotion magnificum is not referable to the second morphotype, it is apparent that Kallokibotion magnificum is the junior synonym of Kallokibotion bajazidi (see Kallokibotion bajazidi above for more extensive discussion).

\section{Murrhardtia staeschei Karl and Tichy, 2000 nomen invalidum \\ (junior synonym of Proterochersis robusta)}

Taxonomic history. Murrhardtia staeschei Karl and Tichy, 2000 (new species); Proterochersis robusta = Murrhardtia staeschei Gaffney et al. 2006 (junior synonym); Proterochersis robusta $=$ Proterochersis intermedia $=$ Murrhardtia staeschei Szczygielski and Sulej 2016 (junior synonym).

Type material. CSMM uncat. (holotype), a relatively complete shell (Karl and Tichy 2000, fig. 2a, pl. 1.1-3).

Type locality. Murrhardt-Mettelberg, Baden-Württemberg, Germany; lower Löwenstein Formation (Karl and Tichy 2000), Norian, Late Triassic.

Comments. Murrhardtia staeschei is based on a near-complete shell from the Late Triassic (Norian) of Murrhardt-Mettelberg, Germany (Karl and Tichy 2000). Gaffney et al. (2006) already speculated that Karl and Tichy (2000) were led to believe that they were describing a new species by major errors that pervade Fraas's (1913) reconstructions of Proterochersis robusta, which Karl and Tichy (2000) used as their primary source of comparative information. Although a thorough description of the German material of Proterochersis robusta is still outstanding, Szczygielski and Sulej (2016) were able to demonstrate that all characters that purportedly diagnose Murrhardtia staeschei are either not preserved in the type material of Proterochersis 
robusta, on the basis of errors introduced by the reconstruction of Fraas (1913), or on the basis of inconsistencies introduced by Karl and Tichy (2000). I therefore agree that Murrhardtia staeschei is the junior synonym of Proterochersis robusta.

\section{Proterochersis intermedia Fraas, 1913 nomen invalidum \\ (junior synonym of Proterochersis robusta)}

Taxonomic history. Proterochersis intermedia Fraas, 1913 (new species); Proterochersis robusta $=$ Proterochersis intermedia $=$ Murrhardtia staeschei Szczygielski and Sulej 2016 (junior synonym).

Type material. SMNS 11396 (holotype), the partial steinkern of a shell and some associated bony fragments (not figured) (Szczygielski and Sulej 2016).

Type locality. Stuttgart-Rohracker, Baden-Württemberg, Germany (Fraas 1913); lower Löwenstein Formation, Norian, Late Triassic (Szczygielski and Sulej 2016).

Comments. Proterochersis intermedia is mostly based on the partial steinkern of a shell from the Late Triassic (Norian) of Rohracker (Fraas 1913), now a suburb of Stuttgart, Germany. In the type description, Fraas (1913) did not provide a photograph or illustration of the specimen, but rather just a hypothetical drawing of the outline of the shell in anterior view that demonstrated that this taxon was purportedly less domed than its sister from the same region, Proterochersis robusta. Mlynarski $(1969,1976)$ already speculated that the two taxa may be synonymous, but did not provide a formal synonymization. This taxon was otherwise mostly ignored. Szczygielski and Sulej (2016) most recently demonstrate that all characters that purportedly diagnose this taxon are based on taphonomic biases, misinterpretations of the holotype, or referable to intraspecific variation. I therefore agree that Proterochersis intermedia is the junior synonym of Proterochersis robusta.

\section{Psammochelys keuperina Quenstedt, 1889 nomen invalidum \\ (objective junior synonym of Proganochelys quenstedtii Baur, 1887)}

Taxonomic history. Proganochelys quenstedtii = Psammochelys keuperina Quenstedt, 1889 (new species and junior synonym); Proganochelys quenstedt $i=$ Psammochelys keuperina $=$ Stegochelys dux Gaffney 1985 (senior synonym and incorrect spelling of species epithet).

Type material. Same as for Proganochelys quenstedtii.

Type locality. Same as for Proganochelys quenstedtii.

Comments. The holotype of Psammochelys keuperina Quenstedt, 1889 is the same as that for Proganochelys quenstedtii Baur, 1887. These two names are therefore objective synonyms and the latter must be given priority. This is certainly unfortunate, as Quenstedt (1889) provided a full description of the type material whereas Baur (1887) only named Proganochelys quenstedtii in passing and, apparently, without permission from Quenstedt, who served as curator at GPIT. The rules of the ICZN (1999), however, are clear on this issue.

\section{Stegochelys dux Jaekel, 1914} nomen invalidum

(objective junior synonym of Proganochelys quenstedtii Baur, 1887)

Taxonomic history. Stegochelys dux Jaekel, 1914 (new species); Triassochelys dux Jaekel 1918 (new combination); Proganochelys quenstedt $i=$ Psammochelys keuperina $=$ Stegochelys dux Gaffney 1985 (junior synonym).

Type material. MB 1910.45.2 (holotype), a partial skeleton consisting of the cranium, carapace, partial plastron, cervicals, left scapula and coracoid, and osteoderms (Jaekel 1914, figs. 23-25; Gaffney 1990, figs. 21, 24, 28, 31, 34, 37, 53, 55, 58c, 60c, d, 73 , $74,79-82,90,91,113-120,122,136)$.

Type locality. Halberstadt, Saxony-Anhalt, Germany (Jaekel 1914); Trossingen Formation, Norian, Late Triassic (Gaffney 1990).

Comments. Stegochelys dux is based on material from the Late Triassic (Norian) quarries of Halberstadt (Jaekel 1914), in what is now the state of Saxony-Anhalt, northern Germany. The locality correlates broadly with those of Trossingen and Aixheim in southern Germany, but given the large uncertainties that prevail in the dating of continental sediments, it is unclear if these localities are fully synchronous. As originally described, the material from southern Germany (Fraas 1899) is quite different from the material from northern Germany (Jaekel 1914, 1915-1916). The greatest purported differences between the northern and southern material supposedly pertains to the morphology of the plastron (Jaekel 1914, 1915-1916), but Ballerstedt (1921) already noted that these differences are a taphonomic artifact and that little evidence was available to support the validity of two species. This comment, however, was mostly ignored and both taxa were presumed to be valid until quite recently (e.g., Myynarski 1976). Jaekel (1914) originally proposed the name Stegochelys dux for the north German material, but later transferred the species to Triassochelys, because Stegochelys is preoccupied by a plesiochelyid turtle from the Late Jurassic of England (Lydekker 1889b).

Although the preservation of the north and south German material is excellent considering its age, all specimens are heavily cracked and therefore difficult to interpret (Gaffney 1990). The north German material was furthermore strongly distorted by tectonic processes. The detailed morphological study of Gaffney (1990), however, took these factors into account and only found minor differences between the north and south German material that he interpreted as intraspecific variation. I agree with this assessment.

\author{
Thalassodromeus sebesensis \\ Grellet-Tinner and Codrea, 2015 \\ nomen invalidum \\ (junior synonym of \\ Kallokibotion bajazidi Nopcsa, 1923a)
}


Taxonomic history. Thalassodromeus sebesensis Grellet-Tinner and Codrea, 2015 (new species); Kallokibotion bajazidi $=$ Kallok ibotion magnificum $=$ Thalassodromeus sebesensis Dyke et al. 2015 (junior synonym).

Type material. UBB ODA28 (holotype), a partial left hypoplastron and xiphiplastron (Grellet-Tinner and Codrea 2015, figs. $3,4)$.

Type locality. Oarda de Jos, Alba County, Romania; Şard Formation, Maastrichtian, Late Cretaceous (Grellet-Tinner and Codrea 2015).

Comments. Thalassodromeus sebesensis was originally described as the partial head crest of a new pterosaur (Grellet-Tinner and Codrea 2015), but was soon after conclusively shown to be a partial plastron referable to Kallokibotion bajazidi (Dyke et al. 2015). For more details, see Kallokibotion bajazidi above.

\section{Trachyaspis turbulensis Bergounioux, 1957 nomen invalidum (junior synonym of \\ Plastremys lata Owen in Parkinson, 1881)}

Taxonomic history. Trachyaspis turbulensis Bergounioux, 1957 (new species); [Trachyaspis turbulensis] Broin 1977 (nomen nudum); Plastremys lata $=$ Trachydermochelys rutteri $=$ Trachyaspis turbulensis Joyce et al. 2011 (senior synonym).

Type material. STUS 8371 (holotype), a flattened, partial shell (Bergounioux 1957, pls. 41, 42; Jiménez et al. 1990, fig. 1c, d).

Type locality. Mina Pintada, Gargallo, Aragon, Spain; Aptian?, Early Cretaceous (Bergounioux 1957; Jiménez-Fuentes et al. 1988).

Comments. Trachyaspis turbulensis is based on a poorly preserved partial shell from the early Cretaceous of Aragon, Spain. Bergounioux (1957) provided a photograph and a reconstruction of the type specimen, but only few details can be gleaned from the photograph and the reconstruction is therefore not reproducible. Jiménez et al. (1990) more recently published line drawings of the specimen, but these are neither labeled nor accompanied by a description, making it difficult again to interpret them. Bergounioux (1957) originally speculated that Trachyaspis turbulensis might be a carettochelyid turtle, but Broin (1977) clarified that there was no relationship with that group. Lapparent de Broin and Murelaga (1999) finally highlighted that Trachyaspis turbulensis is a representative of Helochelydridae (= Solemydidae), a conclusion that has been universally accepted ever since. The synonymy of Trachyaspis turbulensis with Plastremys lata, as first proposed by Joyce et al. (2011) using temporal considerations and similarity in shell sculpturing, is discussed above.

\section{Trachydermochelys phlyctaenus Seeley 1869 nomen nudum}

Material. CAMSM 56340-6, seven peripheral plates (not figured).

Locality. Cambridge, United Kingdom; Cambridge Greensand (Seeley 1869), Albian, Early Cretaceous (Joyce et al. 2011).
Comments. The name Trachydermochelys phlyctaenus was first used by Seeley (1869) in reference to rich fossil remains from the Early Cretaceous Cambridge Greensands, but he explicitly noted in the introduction to his book (Seeley 1869, p. xv) that he did not intend the names he used to be valid, even though he designated seven "type specimens." Trachydermochelys phlyctaenus must therefore be considered unavailable for nomenclatural considerations (Joyce et al. 2011). Lydekker (1889b) later referred additional turtle material from the Cambridge Greensands to Trachydermochelys phlyctaenus, but he placed the name in quotation marks, thereby indicating that he did not think it to be valid as well. Interestingly, among the hundreds of specimens that Seeley (1869) referred to Trachydermochelys phlyctaenus many partial skulls and long bones are listed, which may indicate that this is one of the best-documented helochelydrid turtles. However, given that marine turtles referable to Rhinochelys are common occurrences in the Cambridge Greensands, it is more likely that this material is referable to this marine taxon. Indeed, Lydekker (1889b) suggested that Trachydermochelys phlyctaenus may represent the shell of Rhinochelys. Although the vast majority of remains housed at CAMSM are fragmentary, or not referable to Plastremys lata, the only available helochelydrid taxon from the Cambridge Greensands, a review of this material might provide some novel insights into the anatomy of this helochelydrid turtle.

\section{Trachydermochelys rutteri Andrews, 1920 nomen invalidum (junior synonym of Plastremys lata Owen in Parkinson, 1881)}

Taxonomic history. Trachydermochelys rutteri Andrews, 1920 (new species); Plastremys lata $=$ Trachydermochelys rutter $i=$ Trachyaspis turbulensis Joyce et al. 2011 (senior synonym).

Type material. BMNH R4214 (holotype), a steinkern with most of the plastron, but only portions of the carapace (Andrews 1920, fig. 1).

Type locality. Melbury Down, Shaftesbury, Dorset, United Kingdom; Upper Greensand (Andrews 1920), Albian-?earliest Cenomanian, "mid" Cretaceous (Joyce et al. 2011).

Comments. The name Trachydermochelys was originally coined by Seeley (1869), but he explicitly noted in the introduction to his book that he did not intend the names he proposed to be formal. Given that the ICZN (1999) requires that all names need to be intended as valid to be considered available for nomenclatural considerations, Seeley's (1869) name must be disregarded. Lydekker (1889b) used the name Trachydermochelys as well and with clear reference to the work of Seeley (1869), but he placed the name in quotation marks to indicate that it is invalid. Andrews (1920) finally described a new helochelydrid turtle from the mid-Cretaceous of Dorset under the name Trachydermochelys rutteri. Given that Andrews is the first to treat Trachdermochelys as valid, he is the author of this taxon and T. rutteri serves as its type (ICZN 1999). For the synonymy of T. rutteri with Plastremys lata, please see Plastremys lata above. 


\section{Tretosternon punctatum Owen, 1842 nomen dubium}

Taxonomic history. Tretosternon punctatum Owen, 1842 (new species); Tretosternum bakewelli $=$ Tretosternum punctatum $=$ Peltochelys duchastelli Lydekker and Boulenger 1887 (senior synonym, new combination, incorrect spelling of genus name); [Tretosternon punctatum] Milner 2004 (lectotype designation, nomen dubium)

Type material. The posterior portions of a carapace (lectotype), never figured and now lost (Lydekker 1889b; Milner 2004); BMNH 39457 (paralectotype), the left half of a plastron, referable to Hylaeochelys latiscutata Owen, 1853 (Milner 2004, fig. 1); BMNH 2265 (paralectotype), an isolated costal (Mantell 1827, pl. 4.1; Mantell 1833, p. 255; Joyce et al. 2011, fig. 3a), also the lectotype of "Helochelydra" bakewelli Mantell, 1833 (see below).

Type locality. The lectotype and the first paralectotype are from the Late Cretaceous (Berriasian) Purbeck Limestone Group of the United Kingdom (Joyce et al. 2011), the second paralectotype from the Late Cretaceous (Valanginian) Cuckfield Stone of West Sussex, United Kingdom (Joyce et al. 2011).

Comments. Tretosternon punctatum is a name that was seemingly omnipresent in the fossil turtle literature for more than 100 years, but apparently not understood at a deeper level. Milner (2004) recently revised this species, highlighted that it is a chimera, and rendered it a nomen dubium by designating a lost and unfigured specimen as its lectotype. After having read the type description, I arrive at slightly different interpretation, but the conclusions remain the same.

Milner (2004) correctly highlighted that Owen (1842) based Tretosternon punctatum on two partial turtles, a carapace and a plastron, from the Early Cretaceous Purbeck Limestone of southern England. These two specimens were originally in private hands, were not figured by Owen (1842), and were later declared lost (Lydekker 1889b). After having extensively searched collections in the United Kingdom, Milner (2004) concluded that the first Purbeck specimen indeed appears to be lost, but that the description does not seem to refer to a helochelydrid turtle, but perhaps rather to Pleurosternon bullockii Owen, 1842. The second Purbeck specimen, on the other hand, is housed at the BMNH and can be diagnosed as Hylaeochelys latiscutata Owen, 1853, currently interpreted as a basal pan-cryptodire (Pérez García 2009). As a consequence, if the first type is a helochelydrid, Owen's (1842) taxon is a chimera. If the first type is not a helochelydrid, Owen's taxon (1842) is simply not a helochelydrid. However, this would contradict 150 years of nomenclatural practice, as turtles with tubercles from the Cretaceous of Europe were generally referred, or at least compared with Tretosternon punctatum. Milner (2004) created clarity by designating the lost specimen as the lectotype, thereby rendering Tretosternon punctatum a nomen dubium.

I mostly agree with the assessment of Milner (2004), but my reading of Owen (1842) adds a third specimen to the list of syntypes, the holotype of Trionyx bakewelli Mantell, 1833, which Owen (1842) explicitly lists as belonging to Tretosternon punctatum as well. This is the only figured specimen among the three syntypes and it is therefore perhaps not surprising that the sculp- turing consisting of tubercles apparent in this specimen became the defining characteristic of Tretosternon punctatum for the following 150 years. If my understanding of the situation is correct, Milner (2004) could have designated the holotype of Trionyx bakewelli the lectotype of Tretosternon punctatum, thereby rendering both taxa objective synonyms. However, the designation of the lost specimen, as done by Milner (2004) is an equally good solution to this taxonomic conundrum. Given that the designation of a lectotype is taxonomically binding, Tretosternon punctatum now clearly represents a nomen dubium, as the morphology of this taxon is not apparent from the description of Owen.

Despite the taxonomic difficulties listed above, Lydekker (1889b) recognized Tretosternon punctatum as valid and referred a relatively complete shell from the Early Cretaceous (Barremian) of the Isle of Wight, United Kingdom, to this taxon, BMNH R171, which had previously been referred to Tretosternon bakewelli (Lydekker and Boulenger 1887). This specimen now serves as the holotype of Helochelydra nopcsai (Lapparent de Broin and Murelaga 1999).

Borsuk-Bialynicka and Mlynarski (1968) reported a fragmentary carapace from the Late Jurassic of Poland that they felt to have a surface pattern consisting of tubercles that greatly resembles that of Tretosternon punctatum. The accompanying illustration does not depict a pattern of small, raised pedicles, but rather of large pits and Joyce et al. (2011) therefore speculated that this taxon does not actually represent a helochelydrid. I have since been able to obtain pictures of the material described by Borsuk-Bialynicka and Mlynarski (1968) and must conclude that it does not even remotely resemble what is being depicted in the figure of Borsuk-Bialynicka and Mlynarski (1968). Although more detailed reanalysis of this important specimen is needed, it appears more likely that this fossil represents a plesiochelyid turtle (J. Anquetin, pers. comm., 2016).

\section{Non-Testudinate Taxa}

\section{Archaeochelys pougeti Bergounioux 1938}

Comments. Bergounioux (1938) figured and described a fossil turtle under the name Archaeochelys pougeti based on a large specimen from the Permian of France. If correct, this specimen would extend the fossil record of testudinates from the Late Triassic to the Permian. However, all subsequent workers have since concluded that the type specimen is a large concretion and that the fanciful shell reconstruction accompanying the type description has no factual basis (e.g., Woodward 1939; Huene 1956; Lapparent de Broin 2001). I fully agree with this assessment. Given that names have to be based on actual animal remains to be considered available for nomenclatural purposes (ICZN 1999), it is clear that the name Archaeochelys pouget is not available for nomenclatural purposes. As the name Archaeochelys is already preoccupied by Lydekker (1889b), Kuhn (1958) suggested replacement name Archaeochelydium for this taxon, but this name, too, is not available as it is not typified by an available species name.

\section{Arctosaurus osborni Adams, 1875}

Comments. This species is based on an isolated cervical vertebra (Adams 1875) that originated from Late Triassic sediments exposed on Cameron Island, Nunavut, Canada (Nesbitt et al. 
2007). Given that the taxonomic affinities of this vertebra remain uncertain, it is not surprising that various workers discussed possible affinities with turtles (e.g., Huene 1902; Kuhn 1964 White 1973). A more recent review, however, concludes that Arctosaurus osborni is referable to Archosauriformes (Nesbitt et al. 2007).

\section{Chelyzoon latum Huene, 1902}

Comments. This species is based on a purported marine turtle cervical from the Middle Triassic of Laineck, now a quarter of Bayreuth, Bavaria, Germany. However, this specimen was more recently identified as the cervical vertebra of the long-necked protorosaur Tanystropheus (Wild 1974).

\section{Chelyzoon blezingeri Huene, 1902}

Comments. This specimen shows many parallels with the previous one in that it is based on a purported marine turtle cervical, this time from the Middle Triassic of Crailsheim, Baden-Württemberg, Germany. This cervical has since been identified as belonging to the protorosaur Tanystropheus (Wild 1974).

\section{Entoplastrites nuertingensis Huene, 1956}

Comments. Huene (1926) reported a purported turtle entoplastron from the Late Triassic of Nürtingen, Baden-Württemberg, Germany, that he later used as the basis of a new species, Entoplastrites nuertingensis (Huene 1956). The type description is extremely brief, but, unfortunately, satisfies the conditions of the ICZN (1999) to be considered an available name. Within the two-sentence description, Huene (1956) contradicts himself by listing two different localities, Nürtingen and Hägnach, even though he initially reported the type as being from Nürtingen (Huene 1926). Karl (2002) more recently was able to identify the holotype in the collections of SMNS and to clarify that it originated from Nürtingen. Karl (2002) furthermore concluded that the holotype does not represent the entoplastron of a turtle. I agree with this assessment.

\section{Pleuropeltus suessi Seeley, 1881}

Comments. This species is based on four fragments from the Late Cretaceous (Campanian) of Austria that were originally interpreted by Seeley (1881) as a skull element, two costals, and the scapula of a large turtle. The purported skull element and costals have since been shown to be referable to a nodosaurid dinosaur (Pereda-Suberbiola and Galton 2001), whereas the large scapula remains unidentifiable at the moment (Rabi, Vremir, and Tong 2013). I therefore disregard this taxon herein.

\section{Priscochelys hegnabrunnensis Karl, 2005}

Comments. Wild (1972) briefly reported the presence of a purported turtle fragment from the Middle Triassic of Hegnabrunn, which is now a quarter of Neuenmarkt, Bavaria, Germany. After many decades of languishing in the collections of the SMNS, Karl (2005) briefly described this fragment under the name
Priscochelys hegnabrunnensis, but did not discuss why it was diagnosable as a turtle. Joyce and Karl (2006) provided more detailed account of the holotype of Priscochelys hegnabrunnensis, highlighted numerous placodont and turtle characteristics, but ultimately concluded that it indeed may represent a turtle. Scheyer (2008) finally studied the bone microstructure of this specimen and concluded that it had clear placodont affinities. I here follow this final assessment.

\section{Saurodesmus robertsoni Seeley, 1891}

Comments. Owen (1842) and Duff (1842) reported and figured a long bone from the Late Triassic of Linksfield near Elgin, United Kingdom, that they both interpreted as the remains of a turtle. Lydekker (1889b) referred this fossil to Chelytherium obscurum Meyer, 1863, which is typified based on material from the Late Triassic of Germany, but noted that it did not resemble the long bones of any known turtle. Seeley (1891) soon after named this fossil Saurodesmus robertsoni and interpreted it as a crocodilian. It appears that Saurodesmus robertsoni has since been mostly ignored in the literature. I can only find reference to this taxon in Kuhn (1964), who lists this species as a potential fossil turtle, though without any justification. However, although the figure provided by Duff (1842, pl. 10.5) is highly schematic, I agree with Lydekker (1889b) that it does not resemble a fossil turtle and therefore disregard this taxon herein.

\section{Saurischiocomes keuperinus Kuhn, 1939}

Comments. This species is based on a small collection of purported plastron and coracoid remains from the Late Triassic of Halberstadt, Saxony-Anhalt, Germany, the locality that also yielded rich material of Proganochelys quenstedtii (see above). Kuhn (1939) believed the plastral remains to show evidence of large plastral fontanelles and therefore postulated that this is a marine taxon. Karl (2002) more recently noted that the purported plastral remains generally resemble the interclavicle of temnospondyls. I agree with that assessment. The coracoid, as figured, does not particularly resemble that of temnospondyls, nor that of a turtle. I therefore disregard this taxon from consideration.

\section{Acknowledgments}

I would like to thank in alphabetical order Matt Riley (CAMSM), Rainer Schoch (SMNS), Thomas Schossleitner (MB), Ingmar Werneburg (GPIT), and Hansjörg Wunderer (Naturkundemuseum Ostbayern) for providing me with information regarding specimens in their care. I furthermore would like to thank Jacques Gauthier, Tyler Lyson, Márton Rabi, Juliana Sterli, and Ingmar Werneburg for providing me with much valuable discussion over the years that helped shape my ideas about stem turtles. Giorgos Giorgalis, Márton Rabi, and Juliana Sterli are thanked for thoughtful comments or reviews that helped improve the quality of this paper, while Virginie 
Volpato is thanked for proofreading French-language citations.

Received 29 September 2016; revised and accepted 1 December 2016.

\section{Appendix 1 Institutional Abbreviations}

AM Australian Museum, Sydney, Australia

AMNH American Museum of Natural History,

BMNH Natural History Museum, London,

BP Bernard Price Institute, Johannesburg,

CAMSM University of Cambridge Sedgwick

CSMM Carl-Schweizer-Museum, Murrhardt,

DMR Department of Mineral Resources,

GPIT Paläontologische Sammlung der Uni-

GSI

IPUW

IVPP

MB

MCNA

MCZ

MHNM

MNA

MPEF

NMMNH

NMS

NMV

PIN

PULR

Museum of Northern Arizona, Flagstaff, New York, New York, USA United Kingdom South Africa Museum of Earth Sciences, Cambridge, United Kingdom Germany Bangkok, Thailand versität Tübingen, Tübingen, Germany

SMNS

STUS

UBB

ZDM

ZPAL

Geological Survey of India, Kolkata, India

Institut für Paläontologie der Universität Wien, Vienna, Austria

Institute for Vertebrate Paleontology and Paleoanthropology, Beijing, China

Museum für Naturkunde, Berlin, Germany

Museo de Ciencias Naturales de Álava, Vitoria, Spain

Museum of Comparative Zoology, Harvard University, Cambridge, Massachusetts, USA

Museum d'histoire naturelle de Marseille, Marseille, France Arizona, USA

Museo Paleontológico Egidio Feruglio, Trelew, Argentina

New Mexico Museum of Natural History and Science, Albuquerque, New Mexico, USA

National Museum of Scotland, Edinburgh, United Kingdom

Museum Victoria, Melbourne, Australia

Paleontological Institute, Russian Academy of Science, Moscow, Russia

Universidad Nacional de La Rioja, Paleontología, La Rioja, Argentina
Staatliches Museum für Naturkunde, Stuttgart, Germany

Sala de las Tortugas, Universidad de Salamanca, Salamanca, Spain

Vertebrate Paleontology Laboratory, University Babeş-Bolyai, ClujNapoca, Romania

Zigong Dinosaur Museum, Zigong, China

Institute of Palaeobiology, Polish Academy of Sciences, Warsaw, Poland

\section{Appendix 2 \\ Named Mesozoic \\ Basal Turtle Genera}

Australochelys Gaffney and Kitching, 1994 (type species: Australochelys africanus Gaffney and Kitching, 1994)

Chelycarapookus arcuatus Warren, 1969 (type species: Chelycarapookus arcuatus Warren, 1969)

Chelytherium Meyer, 1863 (type species: Chelytherium obscurum Meyer, 1863)

Chinlechelys Joyce et al., 2009 (type species: Chinlechelys tenertesta Joyce et al., 2009)

Chubutemys Gaffney et al., 2007 (type species: Chubutemys copelloi Gaffney et al., 2007)

Condorchelys Sterli, 2008 (type species: Condorchelys antiqua Sterli, 2008)

Eileanchelys Anquetin et al., 2009 (type species: Eileanchelys waldmani Anquetin et al., 2009)

Heckerochelys Sukhanov, 2006 (type species: Heckerochelys romani Sukhanov, 2006)

Helochelydra Nopcsa, 1928a (type species: Helochelydra nopcsai Lapparent de Broin and Murelaga, 1999)

Helochelys Meyer, 1854 (type species: Helochelys danubina Meyer, 1854)

Indochelys Datta et al., 2000 (type species: Indochelys spatulata Datta et al., 2000)

Kayentachelys Gaffney et al., 1987 (type species: Kayentachelys aprix Gaffney et al., 1987)

Kallokibotion Nopcsa 1923a (type species: Kallokibotion bajazidi Nopcsa 1923a)

Keuperotesta Szczygielski and Sulej, 2016 (type species: Keuperotesta limendorsa Szczygielski and Sulej, 2016

Mongolochelys Khosatzky, 1997 (type species: Mongolochelys efremovi Khosatzky, 1997)

Murrhardtia Karl and Tichy, 2000 (Murrhardtia staeschei Karl and Tichy, 2000)

Naomichelys Hay, 1908 (type species: Naomichelys speciosa Hay, 1908)

Otwayemys Gaffney et al., 1998 (type species: Otwayemys cunicularius Gaffney et al., 1998)

Patagoniaemys Sterli and de la Fuente, 2011 (type species: Patagoniaemys gasparinae Sterli and de la Fuente, 2011) 
Palaeochersis Rougier et al. 1995 (type species: Palaeochersis talampayensis Rougier et al., 1995)

Plastremys Owen in Parkinson, 1881 (type species: Plastremys lata Owen in Parkinson, 1881)

Proganochelys Baur, 1887 (type species: Proganochelys quenstedtii Baur, 1887)

Proterochersis Fraas, 1913 (type species Proterochersis robusta Fraas, 1913)

Psammochelys Quenstedt, 1889 (type species: Psammochelys keuperina Quenstedt 1889 = Proganochelys quenstedtii Baur, 1887)

Sichuanchelys Ye and Pi, 1997 (type species: Sichuanchelys chowi Ye and $\mathrm{Pi}, 1997)$

Solemys Lapparent de Broin and Murelaga, 1996 (type species: Apholidemys gaudryi Matheron, 1869)

Spoochelys Smith and Kear, 2013 (type species: Spoochelys ormondea Smith and Kear, 2013)

Thalassodromeus Grellet-Tinner and Codrea, 2015 (type species: Thalassodromeus sebesensis Grellet-Tinner and Codrea, 2015)

Trachydermochelys Andrews, 1920 [non Seeley 1869] (Trachydermochelys rutteri Andrews, 1920; non Trachydermochelys phlyctaenus Seeley 1869])

Trapalcochelys Sterli et al., 2013a (type species: Trapalcochelys sulcata Sterli et al., 2013a)

Tretosternon Owen, 1842 (type species: Tretosternon punctatum Owen, 1842)

Triassochelys Jaekel, 1918 (type species: Stegochelys dux Jaekel, 1914)

\section{Appendix 3 \\ Biogeographical Summary of Mesozoic Stem Turtles}

Numbers in brackets reference Figures 5, 6 and 7. Four records $[3,4,5,7]$ overlap with those reported by Sterli (2015) for Cretaceous meiolaniform turtles. Abbreviation: TL, type locality.

\section{Argentina}

[1] Late Triassic, Norian/Rhaetian; La Rioja Province; Palaeochersis talampayensis (TL) (Rougier et al. 1995; Sterli et al. 2007), Testudinata indet. (Martínez et al. 2015)

[2] Early-Middle Jurassic, Toarcian-Bajocian; Chubut; Condorchelys antiqua (Sterli 2008; Sterli and de la Fuente 2010; Cerda et al. 2016)

[3] Early Cretaceous, Aptian/Albian; Chubut Province; Chubutemys copelloi (TL) (Gaffney et al. 2007; Sterli et al. 2015) (for more information see Sterli 2015)

[4] Late Cretaceous, Campanian/Maastrichtian; Chubut Province; Patagoniaemys gasparinae (TL) (Sterli and de la Fuente 2011) (for more information see Sterli 2015)

[5] Late Cretaceous, Campanian/Maastrichtian; Río Negro Province; Trapalcochelys sulcata (TL) (Sterli, de la Fuente, and Cerda, 2013) (for more information see Sterli 2015)

\section{Australia}

[6] Early Cretaceous; Shire of Glenelg, Victoria; Testudinata indet. (Chelycarapookus arcuatus of Warren 1969)

[7] Early Cretaceous; Shire of Colac Otway, Victoria; Otwayemys cunicularius (TL) (Gaffney et al. 1998) (for more information see Sterli 2015)

[8] Early Cretaceous, Albian; Shire of Walgett, New South Wales; Spoochelys ormondea (TL) (Smith and Kear 2013)

\section{Austria}

[9] Late Cretaceous, Campanian; Lower Austria; Kallokibotion indet. (Emys neumayri of Seeley 1881; Kallokibotioninae indet. of Rabi, Zhou, et al. 2013)

[10] Late Cretaceous, Campanian; Upper Austria; Kallokibotion indet. (Kallokibotioninae indet. of Rabi, Zhou, et al. 2013)

\section{Canada}

[11] Late Cretaceous, Turonian; British Columbia; Naomichelys indet. (Rylaarsdam et al. 2006)

[12] Late Cretaceous, Santonian-Campanian; Alberta; Naomichelys indet. (Naomichelys speciosa of Joyce et al. 2011; Helochelydridae indet. of Brinkman 2003)

[13] Late Cretaceous, Campanian; Alberta; Naomichelys indet. (Peng et al. 2001; Scheyer and Anquetin 2008; Scheyer et al. 2015; Naomichelys speciosa of Joyce et al. 2011)

\section{China}

[14] Middle Jurassic; Sichuan; Sichuanchelys chowi (TL) (Ye and Pi 1997; Danilov and Parham 2008; Tong et al. 2012a)

[15] Late Jurassic, Oxfordian; Xinjiang; "Sichuanchelys" palatodentata (TL) (Joyce et al. 2016; Sichuanchelys sp. of Brinkman et al. 2013)

\section{France}

[16] Early Cretaceous, Hauterivian-Barremian; Nouvelle-Aquitaine; Helochelydra nopcsai (Helochelydridae indet. of Néraudeau et al. 2012)

[17] Late Cretaceous, Cenomanian; Nouvelle-Aquitaine; Helochelydra danubina, Plastremys lata (Helochelydridae indet. of Vullo et al. 2010)

[18] Late Cretaceous, Campanian/Maastrichtian; Occitanie; Solemys indet. (Le Loeuff 1991; Tong et al. 1993; Lapparent de Broin and Murelaga 1999)

[19] Late Cretaceous, Maastrichtian; Provence-AlpesCôte d'Azur; Solemys gaudryi (TL) (Matheron 1869; Lapparent de Broin and Murelaga 1996) 


\section{Germany}

[20] Late Triassic, Norian; central Baden-Württemberg; Proganochelys quenstedtii (TL) (Baur 1887; Quenstedt 1889), Proterochersis limendorsa (Joyce, Schoch, and Lyson 2013; Szczygielski and Sulej 2016), Proterochersis robusta (TL) (Fraas 1913; Broin 1984; Gaffney 1986, 1990; Karl and Tichy 2000; Szczygielski and Sulej 2016), Testudinata indet. (Chelytherium obscurum of Meyer 1863)

[21] Late Triassic, Norian; southern Baden-Württemberg; Proganochelys quenstedtii (Fraas 1899; Huene 1926; Parsons and Williams 1961; Gaffney and Meeker 1983; Gaffney 1985, 1990)

[22] Late Triassic, Norian; Saxony-Anhalt; Proganochelys quenstedtii (Triassochelys dux of Jaekel 1914, 19151916)

[23] Early Jurassic, Sinemurian; Bavaria; Testudinata indet. (Thalassemydidae indet. of Schleich 1984)

[24] Early Cretaceous, Barremian; Bavaria; Helochelys danubina (TL) (Meyer 1854, 1855)

\section{Greenland}

[25] Late Triassic, Norian; Sermersooq; Proganochelys indet. (Jenkins et al. 1994)

\section{Hungary}

[26] Late Cretaceous, Santonian; Kallokibotion indet. (Kallokibotioninae indet. of Rabi, Vremir, and Tong 2013)

\section{India}

[27] Early Jurassic; Maharashtra State; Indochelys spatulata (TL) (Datta et al. 2000)

\section{Mongolia}

[28] Late Cretaceous, Campanian-Maastrichtian; Ömnögovi Province; Mongolochelys efremovi (TL) (Khosatzky 1997; Suzuki and Chinzorig 2010)

\section{Morocco}

[29] Middle Jurassic, Bathonian; Oriental Department; Testudinata indet. (TL) (Haddoumi et al. 2016)

\section{Poland}

[30] Late Triassic, Norian; Silesian Voivodeship; Proterochersis porebensis (TL) (Szczygielski and Sulej 2016)

\section{Romania}

[31] Late Cretaceous, Maastrichtian; Haţeg Basin; Kallokibotion bajazidi (TL) (Nopcsa 1923a, 1923b; Rabi, Vremir, and Tong 2013; Grellet-Tinner and Codrea 2015)

[32] Late Cretaceous, Maastrichtian; Transylvanian Basin; Kallokibotion bajazidi (Nopcsa 1923a, 1923b)

\section{Russia}

[33] Middle Jurassic, Bathonian; Moscow Oblast; Heckerochelys romani (TL) (Sukhanov 2006)

\section{South Africa}

[34] Early Jurassic, Hettangian/Sinemurian; Orange Free State; Australochelys africanus (TL) (Gaffney and Kitching 1994)

\section{Spain}

[35] Early Cretaceous, Valanginian/Hauterivian, Barremian; Aragon; Helochelydridae indet. (Helochelydra sp. of Pérez-García et al. 2013)

[36] Early Cretaceous, Barremian; Castile and León; Helochelydra nopcsai (Helochelydra sp. of Pérez-García et al. 2012)

[37] Early Cretaceous, Barremian; La Rioja; Helochelydra nopcsai (Solemydidae indet. of Pérez García 2009; Pérez-García et al. 2012)

[38] Early Cretaceous, Barremian; Valencia; Helochelydra nopcsai (Helochelydra sp. of Scheyer et al. 2015)

[39] Early Cretaceous, Barremian-Albian; Aragon; Helochelydra nopcsai (Helochelydra sp. of Pérez-García et al. 2013), Plastremys lata (= Trachyaspis turbulensis of Bergounioux 1957; Trachydermochelys sp. of Canudo, Cobos, et al. 2005)

[40] Late Cretaceous, Cenomanian; Castilla-La Mancha; Helochelys danubina (Solemydidae indet. of Torices et al. 2012)

[41] Late Cretaceous, Campanian; Castile and León Solemys vermiculata $(\mathrm{TL})$ (Lapparent de Broin and Murelaga 1996, 1999; Pérez García 2009; Scheyer et al. 2015; Dermatemydidae indet. of Astibia et al. 1987 and Jiménez Fuentes 1992)

[42] Late Cretaceous, Campanian/Maastrichtian; Castile and León; Solemys indet. (Lapparent de Broin and Murelaga 1999; Dermatemydidae indet. of Jiménez Fuentes 1992)

[43] Late Cretaceous, Campanian/Maastrichtian Basque Country; Solemys indet. (Solemydidae indet. of Pereda-Suberbiola et al. 1999)

[44] Late Cretaceous, Maastrichtian; Castile and León; Solemys indet. (Solemydidae indet. of Murelaga et al. 2005)

[45] Late Cretaceous, Maastrichtian; Aragon; Solemys indet. (Canudo, Infante, and Murelaga 2005; Solemydidae indet. of Murelaga and Canudo 2005)

[46] Late Cretaceous, Maastrichtian; Catalonia; Solemys indet. (Murelaga et al. 1998)

[47] Late Cretaceous, Maastrichtian; Catalonia; Solemys indet. (Marmi et al. 2009)

\section{Thailand}

[48] Late Triassic, Norian; Phetchabun Province; Proganochelys ruchae (TL) (Broin et al. 1982; Broin 1984) 


\section{United Kingdom}

[49] Middle Jurassic, Bathonian; Highland; Eileanchelys waldmani (TL) (Anquetin et al. 2009; Anquetin 2010)

[50] Late Jurassic, Tithonian; Wiltshire; Helochelydridae indet. (Joyce et al. 2011)

[51] Early Cretaceous, Berriasian; Dorset; "Helochelydra" anglica (TL) (Lydekker 1889b), Helochelydridae indet. (Joyce et al. 2011; including Tretosternon punctatum of Owen 1842, 1878, in part, and granicones of Owen 1878, Barrett et al. 2002)

[52] Early Cretaceous, Berriasian-Valanginian; Sussex; "Helochelydra" bakewelli (TL) (Mantell 1827, 1833; Lydekker 1889b; Joyce et al. 2011); Helochelydridae indet. (Joyce et al. 2011)

[53] Early Cretaceous, Barremian; Isle of Wight; Helochelydra nopcsai (TL) (Lapparent de Broin and Murelaga 1999; Sweetman and Insole 2010; Joyce et al. 2011; including Tretosternon bakewelli of Lydekker and Boulenger 1887, Tretosternum [sic] punctatum of Lydekker 1889b, and Helochelydra of Nopcsa 1923b)

[54] Early Cretaceous, Albian; Cambridge; Helochelys danubina (Joyce et al. 2011), Plastremys lata (Seeley 1869; Lydekker 1889b)

[55] "Mid" Cretaceous, Albian-Cenomanian; Isle of Wight and Dorset; Plastremys lata (TL) (Parkinson 1881; including Trachydermochelys phlyctaenus of Seeley 1869 and Trachydermochelys rutteri of Andrews 1920)

\section{United States of America}

[56] Late Triassic, Norian; New Mexico; Proganochelys tenertesta (Lucas et al. 2000; Joyce et al. 2009)

[57] Early Jurassic; Arizona; Kayentachelys aprix (TL) (Gaffney et al. 1987; Sterli and Joyce 2007; Gaffney and Jenkins 2010)

[58] Early Cretaceous, Aptian; Montana; Naomichelys speciosa (TL) (Hay 1908; Ostrom 1970; Joyce et al. 2011; Oreska et al. 2013)

[59] Early Cretaceous, Aptian; Wyoming; Naomichelys speciosa (Oreska et al. 2013)

[60] Early Cretaceous, Aptian; Maryland; Naomichelys speciosa (Kranz 1998)

[61] Early Cretaceous, Aptian-Albian; Texas; Naomichelys speciosa (Jacobs et al. 1991; Scheyer and Anquetin 2008; Joyce et al. 2014; Scheyer et al. 2015)

[62] Early Cretaceous, Albian; Nevada; Naomichelys speciosa (Bonde et al. 2008)

[63] "Mid" Cretaceous, Albian-Cenomanian; Utah; Naomichelys speciosa (Joyce et al. 2011)

[64] Late Cretaceous, Turonian-Santonian; Utah; Naomichelys indet. (Albright et al. 2013; Naomichelys speciosa of Joyce et al. 2011)

[65] Late Cretaceous, Campanian; Montana; Naomichelys indet. (Naomichelys speciosa of Joyce et al. 2011)

[66] Late Cretaceous, Campanian; Wyoming; Naomichelys indet. (Solemydidae indet. of Demar and Breithaupt 2006)
[67] Late Cretaceous, Campanian; Utah; Naomichelys indet. (Naomichelys speciosa of Joyce et al. 2011)

[68] Late Cretaceous, Campanian; New Mexico; Naomichelys indet. (Lichtig and Lucas 2015; Naomichelys speciosa of Joyce et al. 2011)

\section{Appendix 4 \\ Hierarchical Taxonomy of Mesozoic Stem Turtles}

Testudinata Joyce et al., 2004

Australochelys africanus Gaffney and Kitching, 1994

Palaeochersis talampayensis Rougier et al., 1995

Proganochelys Baur, 1887

Proganochelys quenstedtii Baur, 1887

Proganochelys ruchae Broin, 1984

Proganochelys tenertesta (Joyce et al., 2009)

Proterochersis Fraas, 1913

Proterochersis limendorsa (Szczygielski and Sulej, 2016)

Proterochersis porebensis Szczygielski and Sulej, 2016

Proterochersis robusta Fraas, 1913

Mesochelydia New Clade Name

Condorchelys antiqua Sterli, 2008

Eileanchelys waldmani Anquetin et al., 2009

Heckerochelys romani Sukhanov, 2006

Indochelys spatulata Datta et al., 2000

Kayentachelys aprix Gaffney et al., 1987

Perichelydia New Clade Name

Helochelydridae Nopcsa, 1928a

Helochelydra Nopcsa, 1928a

"Helochelydra" anglica (Lydekker, 1889b)

"Helochelydra" bakewelli Mantell, 1833

Helochelydra nopcsai Lapparent de Broin and Murelaga, 1999

Helochelys danubina Meyer, 1854

Naomichelys speciosa Hay, 1908

Plastremys lata Owen in Parkinson, 1881

Solemys Lapparent de Broin and Murelaga, 1996

Solemys gaudryi (Matheron, 1869)

Solemys vermiculata Lapparent de Broin and Murelaga, 1996

Kallokibotion bajazidi Nopcsa, 1923a

Meiolaniformes Sterli and de la Fuente, 2013

Chubutemys copelloi Gaffney et al., 2007

Otwayemys cunicularius Gaffney et al., 1998

Patagoniaemys gasparinae Sterli and de la Fuente, 2011

Trapalcochelys sulcata Sterli, de la Fuente, and Cerda 2013 
Sichuanchelyidae Tong, Danilov, Ye, Ouyang, and Peng 2012

Mongolochelys efremovi Khosatzky, 1997

Sichuanchelys Ye and Pi, 1997

Sichuanchelys chowi Ye and Pi, 1997

"Sichuanchelys" palatodentata Joyce et al., 2016

Spoochelys ormondea Smith and Kear, 2013

\section{Literature Cited}

ADAms, A.L. 1875. On a fossil saurian vertebra, Arctosaurus osborni, from the arctic regions. Proceedings of the Royal Irish Academy 2:177-179.

Albright, L.B., D.D. Gillette and A.L. Titus. 2013. Fossil vertebrates from the Tropic Shale (Upper Cretaceous), Southern Utah. In: A.L. Titus and M.A. Loewen, eds. At the Top of the Grand Staircase. Bloomington: Indiana University Press. pp. 536-562.

ANDREws, C.W. 1920. Note on two new species of fossil tortoises. Annals and Magazine of Natural History 9:145-150.

ANQUETIN, J. 2010. The anatomy of the basal turtle Eileanchelys waldmani from the Middle Jurassic of the Isle of Skye, Scotland. Earth and Environmental Science Transactions of the Royal Society of Edinburgh 101:67-96.

-2012. Reassessment of the phylogenetic interrelationships of basal turtles (Testudinata). Journal of Systematic Palaeontology 10:3-45.

Anquetin, J., P.M. Barrett, M.E.H. Jones, S. MoOre-Fay AND S.E. Evans. 2009. A new stem turtle from the Middle Jurassic of Scotland: new insights into the evolution and palaeoecology of basal turtles. Proceedings of the Royal Society B 276:879-886.

Astibia, H., F. Garcia-Garmilla, X. Orue-Etxebarria, J. Rodriguez-Lazaro, A.D. Buscalioni, J.L. Sanz and E. JiMENEZ-FuENTES. 1987. The Cretaceous-Tertiary boundary in a sector of the south limb of the Miranda-Treviño synclinal: the first appearance of Chelonia and Archosauria in the Basque Country. Cretaceous Research 8:15-27.

Averianov, A.O. AND A.A. Yarkov. 2004. New turtle remains from the Late Cretaceous and Paleogene of Volgograd Region, Russia. Russian Journal of Herpetology 11:41-50.

BALlerstedt, M. 1921. Über das Plastron der Schildkröten des Keupers und die Gestalt der Panzerschale von Proganochelys quenstedtii Baur nach dem Tübingen Fossil. Paleontologische Zeitschrift 4:64-74.

Barrett, P.M., J.B. Clarke, D.B. Brinkman, S.D. Chapman AND P.C. ENSOM. 2002. Morphology, histology and identification of the 'granicones' from the Purbeck Limestone Formation (Lower Cretaceous: Berriasian) of Dorset, southern England. Cretaceous Research 23:279-295.

BAUR, G. 1887. Ueber den Ursprung der Extremitäten der Ichthyopterygia. Bericht des Oberrheinischen Geologischen Vereins 20:17-20.

-1888. Osteologische Notizen über Reptilien (Fortsetzung III). Zoologischer Anzeiger 285:417-424.

Bergounioux, F.-M. 1938. Archaeochelys Pougeti nov. gen., nov. sp. Tortue fossile du Permien de l'Aveyron. Bulletin de la Société Géologique de France 8:67-75.
-1957. Trachyaspis turbulensis nov. sp. Tortue paludine nouvelle de la province de Teruel. Estudios Geológicos 13:279-286.

BoHlin, B. 1953. Fossil reptiles from Mongolia and Kansu. Sino-Swedish Expedition Publication 37:1-105.

Bonde, J.W., D.J. VARRICCHIO, F.D. JACKSON, D.B. LOOPE AND A.M. SHIRK. 2008. Dinosaurs and dunes! Sedimentology and paleontology of the Mesozoic in the Valley of Fire State Park. Geological Society of America Field Guide 11: 249-262.

Borsuk-Bialynicka, M. And M. Mlynarski. 1968. The first finding of the Mesozoic marine turtle Tretosternon aff. punctatum Owen, 1848 in Poland. Prace Muzeum Ziemi 12:217-222.

Boulenger, G.A. 1889. Catalogue of the Chelonians, Rhynchocephalians, and Crocodiles in the British Museum (Natural History). London: Taylor and Francis. $311 \mathrm{pp}$.

BRINKMAN, D.B. 2003. A review of non-marine turtles from the Late Cretaceous of Alberta. Canadian Journal of Earth Sciences 40:557-571.

Brinkman, D.B., D. Eberth, J. Clark, X. Xing and X.-C. Wu. 2013. Turtles from the Jurassic Shishugou formation of the Junggar Basin, People's Republic of China, and the basicranial region of basal eucryptodires. In: D.B. Brinkman, P.A. Holroyd and J.D. Gardner, eds. Morphology and Evolution of Turtles. Dordrecht, Netherlands: Springer. pp. $147-172$.

Broln, F. DE. 1977. Contribution à l'étude des Chéloniens. Chéloniens continentaux du Crétacé et du Tertiaire de France. Mémoires du Muséum National d'Histoire Naturelle, Série C 38:1-366.

-1984. Proganochelys ruchae n. sp., chélonien du Trias supérieur de Thailande. Studia Palaeocheloniologica 1:87-97.

Broin, F. DE, R. IngaVAT, P. JANVIER AND N. Sattayarak. 1982. Triassic turtle remains from northeastern Thailand. Journal of Vertebrate Paleontology 2:41-46.

BURKE, A.C. 1989. Development of the turtle carapace: implications for the evolution of a novel bauplan. Journal of Morphology 199:363-378.

Canudo, J.I., A. Cobos, C. Martín-Closas, X. Murelaga, X. Pereda-Suberbiola, R. Royo-Torres, J.I. Ruiz-OmeñaCA AND L.M. SENDER. 2005. Sobre la presencia de dinosaurios ornitópodos en la Formación Escucha (Cretácico Inferior, Albiense): redescubierto "Iguanodon" de Utrillas (Teruel). Fundamental 6:51-56.

CANUdo, J.I., P. INFANTE AND X. MuRELAGa. 2005. Primer registro de vertebrados continentales (Dinosauria y Quelonii) en el Maastrichtiense de Teruel (Cirugeda, Aliaga). Fundamental 6:57-62.

Cerda, I.A., J. Sterli And T.M. ScheYer. 2016. Bone shell microstructure of Condorchelys antiqua Sterli, 2008, a stem turtle from the Jurassic of Patagonia. Comptes Rendus Palevol 15:128-141.

CHAPMAN, F. 1919. New or little-known Victorian fossils in the National Museum. Part XXIV, On a fossil tortoise in iron stone from Carapook, near Casterton. Proceedings of the Royal Society of Victoria 32:31-32.

CHKHIKVADZE, V.M. 1987. Sur la classification et les caractères de certaines tortues fossiles d'Asie rares et peu etudiees [sic]. Studia Palaeocheloniologica 2:55-86. 
Cifelli, R.L., J.D. GARDNER, R.L. NydAM AND D.L. BRINKMAN. 1997. Additions to the vertebrate fauna of the Antlers Formation (Lower Cretaceous), southeastern Oklahoma. Oklahoma Geology Notes 57:124-131.

CodreA, V.A. And G. Grellet-Tinner. 2015. Reply to comment by Dyke et al. on "Thalassodromeus sebesensis, an out of place and out of time Gondwanan tapejarid pterosaur" by Grellet-Tinner and Codrea (July 2014). Gondwana Research 27:1683-1685.

COPE, E.D. 1875. Check-list of North American Batrachia and Reptilia with a systematic list of the higher groups, and an essay on geographic distribution. Washington, DC: Government Printing Office. 104 pp.

Cúneo, R., J. Ramezani, R. Scasso, D. Pol, I. Escapa, A.M. ZaVATTIERI AND S.A. Bowring. 2013. High-precision U-Pb geochronology and a new chronostratigraphy for the Cañadón Asfalto Basin, Chubut, central Patagonia: implications for terrestrial faunal and floral evolution in Jurassic. Gondwana Research 24:1267-1275.

DANILOV, I.G. AND J.F. PARHAM. 2008. A reassessment of some poorly known turtles from the Middle Jurassic of China, with comments on the antiquity of extant turtles. Journal of Vertebrate Paleontology 28:306-318.

DatTa, P.M., P. Manna, S.C. GHosh And D.P. Das. 2000. The first Jurassic turtle from India. Palaeontology 43:99109.

DEMAR, D.G. AND B.H. BREITHAUPT. 2006. The nonmammalian vertebrate microfossil assemblages of the Mesaverde Formation (Upper Cretaceous, Campanian) of the Wind River and Bighorn basins, Wyoming. New Mexico Museum of Natural History and Science Bulletin 35:33-53.

Dollo, M.L. 1884. Première note sur les chéloniens de Bernissart. Bulletin du Musée Royal d'Histoire Naturelle de Belgique 3:63-84.

-1886. Première note sur les chéloniens du Bruxelliens (Éocène moyen) de la Belgique. Bulletin du Musée Royal d'Histoire Naturelle de Belgique 4:75-96.

DuFF, P. 1842. Sketch of the Geology of Moray. Elgin, United Kingdom: Forsyth \& Young. 72 pp.

Dyke, G., M. Vremir, S.L. Brusatte, G.S. Bever, E. Buffetaut, S. Chapman, Z. Csiki-Sava, A. Kellner, E. Martin, D. Naish, M. Norell, A. Ösi, F.L. Pinheiro, E. Prondvai, M. Rabi, T. Rodrigues, L. Steel, H. Tong, B.C. Vila Nova AND M. WitTon. 2015. Thalassodromeus sebesensis - a new name for an old turtle. Comment on "Thalassodromeus sebesensis, an out of place and out of time Gondwanan tapejarid pterosaur", Grellet-Tinner and Codrea. Gondwana Research 27:1680-1682.

Eaton, J.G., J. LaUrin, J.I. KiRKLAND, N.E. TiberT, R.M. LeCKIE, B.B. Sageman, P.M. Goldstrand, D.W. Morre, A.W. Straub, W.A. Cobban and J.D. Dalebout. 2001. Cretaceous and early Tertiary geology of Cedar and Parawan Canyons, western Markagunt Plateau, Utah. Utah Geological Association Publication 30:337-363.

FIX, M.F. AND G.E. Darrough. 2004. Dinosauria and associated vertebrate fauna of the Late Cretaceous Chronister site of southeast Missouri. Abstracts with Programs, Geological Society of America 36:14.

Foth, C., M. RABI AND W.G. JoyCE. Skull shape variation in extant and extinct Testudinata and its relation to habitat and feeding ecology. Acta Zoologica. In press.
FraAs, E. 1899. Proganochelys Quenstedtii Baur (Psammochelys Keuperina Qu.). Ein neuer Fund der Keuperschildkröte aus dem Stubensandstein. Jahreshefte des Vereins für vaterländische Naturkunde in Württemberg 55:401-424.

-1913. Proterochersis, eine pleurodire Schildkröte aus dem Keuper. Jahreshefte des Vereins für vaterländische Naturkunde in Württemberg 64:13-30.

GAFFNEY, E.S. 1975. A phylogeny and classification of the higher categories of turtles. Bulletin of the American Museum of Natural History 155:389-436.

-1981. A review of the fossil turtles of Australia. American Museum Novitates 2720:1-20.

-1983. The cranial morphology of the extinct horned turtles, Meiolania platyceps, from the Pleistocene of Lord Howe Island, Australia. Bulletin of the American Museum of Natural History 175:361-480.

-1984. Historical analysis of theories of chelonian relationship. Systematic Zoology 33:283-301.

-1985. The shell morphology of the Triassic turtle Proganochelys. Neues Jahrbuch für Geologie und Paläontologie, Abhandlungen 170:1-26.

-1986. Triassic and Early Jurassic turtles. In: K. Padian, ed. The Beginning of the Age of Dinosaurs. Cambridge: Cambridge University Press. pp. 183-187.

-1990. The comparative osteology of the Triassic turtle Proganochelys. Bulletin of the American Museum of Natural History 194:1-263.

-1996. The postcranial morphology of Meiolania platyceps and a review of the Meiolaniidae. Bulletin of the American Museum of Natural History 229:1-166.

Gaffney, E.S., J.H. Hutchison, F.A. Jenkins And L.J. MeEKer. 1987. Modern turtle origins: the oldest known cryptodire. Science 237:289-291.

GAFFNEY, E.S. AND F.A. JENKINs. 2010. The cranial morphology of Kayentachelys, an Early Jurassic cryptodire, and the early history of turtles. Acta Zoologica 91:335-368.

GafFney, E.S. AND J.W. Kitching. 1994. The most ancient African turtle. Nature 369:55-58.

-1995. The morphology and relationships of Australochelys, an early Jurassic turtle from South Africa. American Museum Novitates 3130:1-29.

Gaffney, E.S., L. Kool, D.B. Brinkman, T.H. Rich and P. VICKERS-RICH. 1998. Otwayemys, a new cryptodiran turtle from the Early Cretaceous of Australia. American Museum Novitates 3233:1-28.

GAFFNEY, E.S. AND L.J. MEEKER. 1983. Skull morphology of the oldest turtles: a preliminary description of Proganochelys quenstedti. Journal of Vertebrate Paleontology 3:25-28.

GaFfney, E.S. AND P.A. MeYLAN. 1988. A phylogeny of turtles. In: M.J. Benton, ed. The Phylogeny and Classification of the Tetrapods, Volume 1: Amphibians, Reptiles, Birds. Oxford: Clarendon Press. pp. 157-219.

-1992. The Transylvanian turtle, Kallokibotion, a primitive cryptodire of Cretaceous age. American Museum Novitates 3040:1-37.

GafFneY, E.S., P.A. MEYLAN AND A.R. WYss. 1991. A computer assisted analysis of the relationships of the higher categories of turtles. Cladistics 7:313-335.

GAFFney, E.S., T.H. Rich, P. Vickers-Rich, A. CONSTANTINE, R. VACCA AND L. KoOL. 2007. Chubutemys, a new eucryptodi- 
ran turtle from the Early Cretaceous of Argentina, and the relationships of the Meiolaniidae. American Museum Novitates 3599:1-35.

Gaffney, E.S., H. Tong and P.A. Meylan. 2006. Evolution of the side-necked turtles: the families Bothremydidae, Euraxemydidae, and Araripemydidae. Bulletin of the American Museum of Natural History 300:1-318.

GAUDRY, A. 1890. Les enchainement du monde animal dans les temps géologiques fossiles secondaires. Paris: F. Savy. 522 pp.

Geyer, M., E. Nitsch and T. Simon. 2011. Geologie von Baden-Württemberg. Stuttgart: Schweizerbart. 627 pp.

GoRdEnKo, N.V. 2008. Middle Jurassic flora of the Peski locality (Moscow Region): systematics, paleoecology, and phytogeography. Paleontological Journal 42:1285-1382.

Grellet-Tinner, G. AND V.A. CodreA. 2015. Thalassodromeus sebesensis, an out of place and out of time Gondwanan tapejarid pterosaur. Gondwana Research 27:1673-1679.

Haddoumi, H., R. Allain, S. Meslouh, G. Metais, M. Monbaron, D. Pons, J.-C. Rage, R. Vullo, S. Zouhri and E. GheERBRAnt. 2016. Guelb el Ahmar (Bathonian, Anoual Syncline, eastern Morocco): first continental flora and fauna including mammals from the Middle Jurassic of Africa. Gondwana Research 29:290-319.

HAY, O.P. 1905. On the group of fossil turtles known as the Amphichelydia; with remarks on the origin and relationships of the suborders, superfamilies, and families of Testudines. Bulletin of the American Museum of Natural History 21:137-175.

-1908. The fossil turtles of North America. Publications of the Carnegie Institution of Washington 75:1-568.

-1922 . On the phylogeny of the shell of the Testudinata and the relationships of Dermochelys. Journal of Morphology 36:421-445.

Hirayama, R., D.B. Brinkman ANd I.G. Danilov. 2000. Distribution and biogeography of non-marine Cretaceous turtles. Russian Journal of Herpetology 7:181-198.

HuENE, F. vON. 1902. Übersicht über die Reptilien der Trias. Geologische und Paläontologische Abhandlungen 6:1-84.

-1926. Einige Schildkrötenreste aus der obersten Trias Württembergs. Centralblatt für Mineralogie, Geologie und Paläontologie 1925/26:509-514.

-1956. Paläontologie und Phylogenie der niederen Tetrapoden. Jena, Germany: Fischer Verlag. 718 pp.

Hummel, K. 1929. Die fossilen Weichschildkröten (Trionychia). Geologische und Palaeontologische Abhandlungen 20:359-487.

[ICZN] INTERNATIONAL COMMISSION ON ZOOLOGICAL NOMENCLATURE. 1999. International Code of Zoological Nomenclature. 4th ed. London: International Trust for Zoological Nomenclature. 306 pp.

JACOBS, L.L., D.A. WinKLER AND P.A. MurRy. 1991. On the age and correlation of the Trinity mammals, Early Cretaceous of Texas, USA. Newsletter on Stratigraphy 24:35-43.

JAEKEL, O. 1914. Über die Wirbeltierfunde in der oberen Trias von Halberstadt. Paläontologische Zeitschrift 1:155-215.

-1915-1916. Die Wirbeltierfunde aus dem Keuper von Halberstadt. Testudinata. Paläontologische Zeitschrift 2:88-112, 113-214.

-1918. Mitteilungen des Herausgebers. Paläontologische Zeitschrift 2:251.
Jenkins, F.A., N.H. Shubin, W.W. Amaral, S.M. Gatesy, C.R. Schaff, L.B. Clemmensen, W.R. Downs, A.R. Davidson, N. Bonde AND F. OsBæcK. 1994. Late Triassic continental vertebrates and depositional environments of the Fleming Fjord Formation, Jameson Land, East Greenland. Meddelelser om $\mathrm{Gr}^{-}$nland, Geoscience 32:1-25.

Jiménez, E., S. Martín, E. Mulas and E. Pérez. 1990. Yacimientos con quelonios del Cretácico español. Actas de Paleontología 113:173-176.

JimÉNEZ Fuentes, E. 1992. Quelonios fósiles de Castilla y León. In: E. Jiménez Fuentes, ed. Vertebrados Fósiles de Castilla y León. Salamanca, Spain: Museo de Salamanca. pp. 71-100.

Jiménez-Fuentes, E., E. Mulas Alonso, S. Martín de Jesús AND E. PÉrez Ramos. 1988. Tipos depositados en la Sala de las Tortugas de la Universidad de Salamanca. Studia Geologica Salmanticensia 25:205-210.

JoYCE, W.G. 2007. Phylogenetic relationships of Mesozoic turtles. Bulletin of the Peabody Museum of Natural History 48:3-102.

-2014. A review of the fossil record of turtles of the clade PanCarettochelys. Bulletin of the Peabody Museum of Natural History 55:3-33.

-2015. The origin of turtles: a paleontological perspective. Journal of Experimental Zoology Part B: Molecular and Developmental Evolution 324:181-193.

JOYCE, W.G., S.D. CHAPMAN, R.T.J. MOODY AND C.A. WALKER. 2011. The skull of the solemydid turtle Helochelydra nopcsai from the Early Cretaceous (Barremian) of the Isle of Wight (UK) and a review of Solemydidae. Special Papers in Paleontology 86:75-97.

Joyce, W.G. AND J.A. GaUTHIER. 2004. Palaeoecology of Triassic stem turtles sheds new light on turtle origins. Proceedings of the Royal Society B 271:1-5.

Joyce, W.G., F.A. JENKINS AND T. RowE. 2006. The presence of cleithra in the basal turtle Kayentchelys aprix. Fossil Turtle Research 1:93-103.

Joyce, W.G. AND H.-V. KarL. 2006. The world's oldest fossil turtle: fact versus fiction. Fossil Turtle Research 1:104-111.

Joyce, W.G., S.G. Lucas, T.M. SCHEyer, A.B. HeCKERT AND A.P. HunT. 2009. A thin-shelled reptile from the Late Triassic of North America and the origin of the turtle shell. Proceedings of the Royal Society B 276:507-513.

JoyCE, W.G. AND T.R. LYsON. 2015. A review of the fossil record of turtles of the clade Baenidae. Bulletin of the Peabody Museum of Natural History 56:147-183.

JOYCE, W.G., J.F. PARHAM AND J.A. GAUTHIER. 2004. Developing a protocol for the conversion of rank-based taxon names to phylogenetically defined clade names, as exemplified by turtles. Journal of Paleontology 78:989-1013.

Joyce, W.G., J.F. PARHAM, T.R. LYSON, R.C.M. WARNOCK AND P.C.J. DonOGHUE. 2013. A divergence dating analysis of turtles using fossil calibrations: an example of best practices. Journal of Paleontology 87:612-634.

Joyce, W.G., M.R. Rabi, J.M. Clark and X. Xu. 2016. A toothed turtle from the Late Jurassic of China and the global biogeographic history of turtles. BMC Evolutionary Biology $16: 236$

Joyce, W.G., R.R. SCHOCH AND T.R. LySON. 2013. The girdles of the oldest fossil turtle, Proterochersis robusta, and the age of the turtle crown. BMC Evolutionary Biology 13:266. 
JOYCE, W.G. AND J. STERLI. 2012. Congruence, non-homology, and the phylogeny of basal turtles. Acta Zoologica 93: 149-159.

Joyce, W.G., J. Sterli AND S.D. Chapman. 2014. The skeletal morphology of the solemydid turtle Naomichelys speciosa from the Early Cretaceous of Texas. Journal of Paleontology 88:1257-1287.

JOYCE, W.G., I. WERnEBURG AND T.R. LYSON. 2013. The hooked element in the pes of turtles (Testudines): a global approach to exploring primary and secondary homology. Journal of Anatomy 223:421-441.

KARL, H.-V. 2002. Übersicht über die fossilen marinen Schildkrötenfamilien Zentraleuropas. Mauritiana 18:171202.

-2005. The homology of supramarginals in turtles (Reptilia: Chelonii). Studia Geologica Salmanticensia 41:63-75.

KARL, H.-V. AND G. TiCHY. 2000. Murrhardtia staeschei n. gen. n. sp. - eine neue Schildkröte aus der oberen Trias von Süddeutschland. Joannea - Geologie und Paläontologie 2:57-72.

Kear, B.P and R.J. Hamilton-Bruce. 2011. Dinosaurs in Australia. Collingwood, Australia: CSIRO Publishing. 190 pp.

KHOSATZKY, L.I. 1997. Big turtle of the Late Cretaceous of Mongolia. Russian Journal of Herpetology 4:148-154.

KordiKovA, E.G. 2002. Comparative morphology of the palate dentition in Proganochelys quenstedti Baur 1887 from the Upper Triassic of Germany and chelonian ancestry. Neues Jahrbuch für Geologie und Paläontologie, Abhandlungen 225:195-249.

KRANZ, P.M. 1998. New fossil turtles from the Potomac Group (Arundel Formation) (Aptian age), Maryland, USA. New Mexico Museum of Natural History and Science Bulletin 14:193-194.

KuHN, O. 1939. Beiträge zur Keuperfauna von Halberstadt. Paläontologische Zeitschrift 21:258-286.

-1941. Testudinata triadica. Fossilium Catalogus 94:1-12.

-1958. Ein neuer Lacertilier aus dem fränkischen Lithographieschiefer. Neues Jahrbuch für Geologie und Paläontologie 1958:380-382.

-1964. Testudines. Fossilium Catalogus 107:1-299.

LAPPARENT DE BRoIn, F. DE. 2001. The European turtle fauna from the Triassic to the Present. Dumerilia 4:155-217.

Lapparent de Broin, F. DE AND X. Murelaga. 1996. Une nouvelle faune de chéloniens dans le Crétacé supérieur européen. Comptes Rendus de l'Académie des Sciences, Sciences de la Terre et des Planètes, Série IIa 323: 729-735.

-1999. Turtles from the Upper Cretaceous of Laño (Iberian peninsula). Estudios del Museo de Ciencias Naturales de Alava 14:135-211.

Larson, D., D. BrinKman AND J. Morin. 2010. Late Cretaceous Canadian specimens of family Solemydidae (Testudines) with special mention of a new genus and species. Journal of Vertebrate Paleontology, Program and Abstracts 2010, 120A.

LEIDY, J. 1856. Notices of extinct Vertebrata discovered by Dr. F. V. Hayden, during the expedition to the Sioux country under command of Lieut. G. K. Warren. Academy of Natural Sciences of Philadelphia Proceedings 8:311-312.

Le LoeufF, J. 1991. Les vertébrés maastrichtiens du Mas-d’Azil (Ariège, France): étude préliminaire de la collection Pouech. Revue de Paléobiologie 10:61-67.
Li, C., X.-C. Wu, O. Rieppel, L.-T. WANG AND L.-J. ZhaO. 2008. An ancestral turtle from the Late Triassic of southwestern China. Nature 456:497-501.

LiCHTIG, A.J. AND S.G. LUCAS. 2015. Cretaceous turtles of New Mexico. New Mexico Museum of Natural History and Science Bulletin 67:129-137.

LiNNAEUs, C. 1758. Systema Naturae, Volume 1. 10th ed. Stockholm: Laurentius Salvius. 824 pp.

LuCAS, S.G., A.B. HeckerT AND A.P. Hunt. 2000. Probable turtle from the Upper Triassic of east-central New Mexico. Neues Jahrbuch für Geologie und Paläontologie, Monatshefte 2000:287-300.

LYDEKKER, R. 1889a. On certain Chelonian Remains from the Wealden and Purbeck. Quarterly Journal of the Geological Society 45:511-518.

-1889b. Catalogue of the Fossil Reptilia and Amphibia in the British Museum (Natural History), Part III. The Order Chelonia. London: Longmans. 239 pp.

LYDEKKER, R. AND G.A. BOULENGER. 1887. Notes on Chelonia. Geological Magazine 1887:270-275.

Lyson, T.R., G.S. Bever, B.-A.S. BHULLAR, W.G. JOYCE AND J.A. GAUTHIER. 2010. Transitional fossils and the origin of turtles. Biology Letters 6:830-833.

Lyson, T.R., G.S. Bever, T.M. Scheyer, A.Y. Hsiang AND J.A. GAUTHIER. 2013. Evolutionary origin of the turtle shell. Current Biology 23:1113-1119.

Lyson, T.R., B.-A.S. Bhullar, G.S. Bever, W.G. JoYCE, K. DE Queiroz, A. Abzhanov and J.A. Gauthier. 2013. Homology of the enigmatic nuchal bone reveals novel reorganization of the shoulder girdle in the evolution of the turtle shell. Evolution and Development 15:317-325.

Mantell, G. 1827. Illustrations of the Geology of Sussex: Containing a General View of the Geological Relations of the South-Eastern Part of England; with Figures and Descriptions of the Fossils of Tilgate Forest. London: Lupton Relfe. $92 \mathrm{pp}$.

-1833. The Geology of the South East of England. London: Longman. $415 \mathrm{pp}$.

Marmi, J., B. Vila and A. Galobart. 2009. Solemys (Chelonii, Solemydidae) remains from the Maastrichtian of Pyrenees: evidence for a semi-aquatic lifestyle. Cretaceous Research 30:1307-1312.

Martínez, R.N., C. Apaldetti, G. Correa, C.E. Colombi, E. Fernández, P. Santi Malnis, A. Praderio, D. Abelín, L.G. Benegas, A. Aguilar-Cameo and O.A. Alcober. 2015. A new Late Triassic vertebrate assemblage from Northwestern Argentina. Ameghinia 52:379-390.

MAtHeron, P. 1869. Notice sur les reptiles fossiles des dépots fluvio-lacustres crétacés du bassin a lignite de Fuveau. Mémoires de l'Académie des sciences, lettres et arts de Marseille 69:345-379.

Meyer, H. von. 1854. Mittheilung, an Professor Bronn gerichtet. Neues Jahrbuch für Mineralogie, Geognosie, Geologie und Petrefakten-Kunde 1854:575-581.

-1855. Helochelys Danubina aus dem Grünsande von Kelheim in Bayern. Palaeontographica 4:96-105.

-1863. Mittheilung an Professor H.B. Geinitz. Neues Jahrbuch für Mineralogie, Geologie und Palaeontologie 1863: 444-450.

-1865. Reptilien aus dem Stubensandstein des oberen Keupers. Palaeontographica 14:99-124. 
Meylan, P.A. 1988. Peltochelys Dollo and the relationships among the genera of the Carettochelyidae (Testudines: Reptilia). Herpetologica 44:440-450.

-1996. Skeletal morphology and relationships of the Early Cretaceous side-necked turtle, Araripemys barretoi (Testudines: Pelomedusoides: Araripemydidae), from the Santana Formation of Brazil. Journal of Vertebrate Paleontology 16:20-33.

Milner, A.R. 2004. The turtles of the Purbeck Limestone Group of Dorset, southern England. Palaeontology 47:1441-1467.

MlynarsKi, M. 1969. Fossile Schildkröten. Wittenberg: Ziemsen Verlag. $128 \mathrm{pp}$

-1976. Handbuch der Paläoherpetologie, Part 7: Testudines. Stuttgart: Gustav Fischer Verlag. 130 pp.

MuYNARSKI, M. AND P. NARMANDACH. 1972. New turtle remains from the Upper Cretaceous of the Gobi Desert, Mongolia. Palaeontologica Polonica 27:55-102.

Münster, G.G. ZU. 1834. Mittheilung, an Professor Bronn gerichtet. Neues Jahrbuch für Mineralogie, Geognosie, Geologie und Petrefaktenkunde 1834:42-43.

Murelaga, X. And J.I. Canudo. 2005. Descripción de los restos de quelonios del Maastrichtiense superior de Aren y Serraduy (Huesca). Geogaceta 38:51-54.

Murelaga, X., F. García Garmilla and X. Pereda-SuberBIOLA. 2005. Primeros restos de vertebrados del Cretácico superior de Quecedo de Valdivielso (Burgos). Geogaceta 37:195-198.

Murelaga, X., X. Pereda Suberbiola, H. Astibia and F. DE LAPPARENT DE BROIN. 1998. Primeros datos sobre los quelonios del Cretácico superior de Lleida. Geogaceta 24:239242.

NATH, T.T., P. YADAGIRI AND A.K. MoITRA. 2002. First record of armoured dinosaur from the Lower Jurassic Kota Formation, Pranhita-Godavari Valley, Andhra Pradesh. Journal of the Geological Society of India 59:575-577.

Néraudeau, D., R. Allain, M. Ballèvre, D.J. Batten, E. BufFETAut, J.P. Colin, M.P. Dabard, V. DaVIERO-Gomez, A. El Albani, B. Gomez, D. Grosheny, J. Le Leeuff, A. Leprince, C. Martín-Closas, E. Masure, J.-M. Mazin, M. Philippe, J. Pouech, H. Tong, J.F. Tournepiche And R. Vullo. 2012 The Hauteriviane-Barremian lignitic bone bed of Angeac (Charente, south-west France): stratigraphical, palaeobiological and palaeogeographical implications. Cretaceous Research 37:1-14.

NesbitT, S. J., R.B. IRMIS AND W.G. PARKER. 2007. A critical reevaluation of the Late Triassic dinosaur taxa of North America. Journal of Systematic Palaeontology 5:209-243.

NopCSA, F. 1923a. On the geological importance of the primitive reptilian fauna in the uppermost Cretaceous of Hungary; with a description of a new tortoise (Kallokibotion). Quarterly Journal of the Geological Society 79:100-116.

-1923b. Kallokibotium a primitive amphichelydean tortoise from the uppermost Cretaceous of Hungary. Palaeontologia Hungarica 1:1-34.

-1926. Die Reptilien der Gosau in neuer Beleuchtung. Centralblatt für Mineralogie, Geologie und Paläontologie B 1926:520-523.

-1928a. Palaeontological notes on reptiles. Geologica Hungarica, Palaeontology Series 1:1-84. -1928b. The genera of reptiles. Palaeobiologica 1:163-188.

Oreska, M.P.J., M.T. Carrano and K.M. DZIKIEWiCZ. 2013. Vertebrate paleontology of the Cloverly Formation (Lower Cretaceous), I: faunal composition, biogeographic relationships, and sampling. Journal of Vertebrate Paleontology 33:264-292.

Ostrom, J.H. 1970. Stratigraphy and paleontology of the Cloverly Formation (Lower Cretaceous) of the Bighorn Basin Area, Wyoming and Montana. Bulletin of the Peabody Museum of Natural History 35:1-234.

OWEN, R. 1842. Report on British fossil reptiles. In: Report of the Eleventh Meeting of the British Association for the Advancement of Science. London: John Murray. pp. 60-204.

-1853. Monograph on the fossil Reptilia of the Wealden and Purbeck formations. Palaeontographical Society Monograph $7: 1-12$

-1878. On the fossils called "granicones"; being a contribution to the histology of the exo-skeleton in "Reptilia." Journal of the Royal Microscopical Society 1:233-236.

-1886. Description of some fossil remains of two species of a megalanian genus (Meiolania) from "Lord Howe's Island." Philosophical Transactions of the Royal Society, London B179:181-191.

PARKInson, C. 1881. Upper Greensand and Chloritic Marl, Isle of Wight. Quarterly Journal of the Geological Society of London 37:370-375.

Parsons, T.S. And E.E. Williams. 1961. Two Jurassic turtle skulls: a morphological study. Bulletin of the Museum of Comparative Zoology 125:43-107.

Peng, J., A.P. Russell And D.B. Brinkman. 2001. Vertebrate microsite assemblages (exclusive of mammals) from the Foremost and Oldman Formations of the Judith River Group (Campanian) of southeastern Alberta: an illustrated guide. Provincial Museum of Alberta, Natural History Occasional Paper 25:1-54.

Pereda-Suberbiola, X. And P. Galton. 2001. Reappraisal of the nodosaurid ankylosaur Struthiosaurus austriacus Bunzel from the Upper Cretaceous Gosau Beds of Austria. In: K. Carpenter, ed. The Armored Dinosaurs. Bloomington: Indiana University Press. pp. 173-210.

Pereda-Suberbiola, X., X. Murelaga, J.I. Baceta, J.C. CorRAL, A. BADIOLA AND H. AstiBIA. 1999. Nuevos restos fósiles de vertebrados continentales en el Cretácico Superior de Álava (Región Vasco-Cantábrica): sistemática y posición estratigráfica. Geogaceta 26:79-82.

PÉrEZ-GARCíA, A. 2009. Revisión histórica y sistemática de las primeras citas de quelonios del Cretácico español. Revista Española de Paleontología 24:93-104.

Pérez-García, A., X. Murelaga, P. Huerta and F. Torcida FERNÁNDEZ-BALDOR. 2012. Turtles from the Lower Cretaceous of the Cameros Basin (Iberian Range, Spain). Cretaceous Research 33:146-158.

Pérez-García, A., T.M. Scheyer and X. Murelaga. 2013. The turtles from the uppermost Jurassic and Early Cretaceous of Galve (Iberian Range, Spain): anatomical, systematic, biostratigraphic and palaeobiogeographical implications. Cretaceous Research 44:64-82.

PicteT, F.-J. AND G. CAMPICHE. 1858-1860. Description des fossiles du terrain crétacé des environs de Sainte-Croix. Première partie. Matériaux pour la Paléontologie Suisse 2:1-380. 
POMEL, A. 1847. Note sur les mammifères et les reptiles fossiles des terrains éocènes de Paris, inférieurs au dépôt gypseux Archives des Sciences Physiques et Naturelles 4:326-330.

QuenstedT, F.A. 1889. Psammochelys keuperina. Jahreshefte des Vereins für vaterländische Naturkunde in Württemberg 45:120-130.

RABI, M., W.G. JoYCE AND O. Wings. 2010. A review of the Mesozoic turtles of the Junggar Basin (Xinjiang, Northwest China) and the paleobiogeography of Jurassic to Early Cretaceous Asian testudinates. Palaeobiodiversity and Palaeoenvironments 90:259-273.

Rabi, M., V. SuKhanOV, V. Egerova, I.G. DaNilov and W.G. JOYCE. 2014. Osteology, relationships, and ecology of Annemys (Testudines, Eucryptodira) from the Late Jurassic of Shar Teg, Mongolia, and phylogenetic definitions for Xinjiangchelyidae, Sinemydidae, and Macrobaenidae. Journal of Vertebrate Paleontology 34:327-352

Rabi, M., M. Vremir and H. Tong. 2013. Preliminary overview of Late Cretaceous turtle diversity in eastern central Europe. In: D.B. Brinkman, P.A. Holroyd and J.D. Gardner, eds. Morphology and Evolution of Turtles. Dordrecht, Netherlands: Springer. pp. 307-336.

RaBI, M., C.-F. Zhou, O. Wings, S. GE AND W.G. JoYCE. 2013. A new xinjiangchelyid turtle from the Middle Jurassic of Xinjiang, China and the evolution of the basipterygoid process in Mesozoic turtles. BMC Evolutionary Biology 13:203.

ROMER, A.S. 1956. Osteology of the Reptiles. Chicago: University of Chicago Press. $772 \mathrm{pp}$

Rougier, G.W., M.S. DE LA Fuente AND A.B. ARCuCCI. 1995. Late Triassic turtles from South America. Science 268:855-858.

RYlaARSDAM, J.R., B.L. VARBAN, A.G. Plint, L.G. BuCKLEY AND R.T. MCCREA. 2006. Middle Turonian dinosaur paleoenvironments in the Upper Cretaceous Kaskapau Formation, northeast British Columbia. Canadian Journal of Earth Sciences 43:631-652.

SCHEYER, T.M. 2008. Aging the oldest turtles: the placodon affinities of Priscochelys hegnabrunnensis. Naturwissenschaften 95:803-810.

SCHEYER, T.M. AND J. ANQUETIN. 2008. Bone histology of the Middle Jurassic turtle shell remains from Kirtlington, Oxfordshire, England. Lethaia 41:85-96.

SCheYeR, T.M., I.G. Danilov, V.B. SuKhanov and E.V. SYromyatnikova. 2014. The shell bone histology of fossil and extant marine turtles revisited. Biological Journal of the Linnean Society 112:701-718.

Scheyer, T.M., A. Pérez-García and X. Murelaga. 2015. Shell bone histology of solemydid turtles (stem Testudines): palaeoecological implications. Organisms Diversity and Evolution 15:199-212.

SCHEYER, T.M. AND P.M. SANDER. 2007. Shell bone histology indicates terrestrial palaeoecology of basal turtles. Proceedings of the Royal Society B 274:1885-1893.

SCHLEICH, H.H. 1984. Ein neuer Schildkrötennachweis aus Lias-Sedimenten Deutschlands (Testudines: Chelonioidea: ?Thalassemydidae). Naturwissenschaftliche Zeitschrift für Niederbayern 30:56-62.

SCHOCH, R.R. AND H.-D. SuEs. 2015. A Middle Triassic stemturtle and the evolution of the turtle body plan. Nature 523:584-587.
Seeley, H.G. 1869. Index to the Fossil Remains of Aves, Ornithosauria, and Reptilia, from the Secondary System of Strata Arranged in the Woodwardian Museum of the University of Cambridge. Cambridge: Deighton, Bell and Co. $143 \mathrm{pp}$.

-1881 . The reptile fauna of the Gosau Formation preserved in the Geological Museum of the University of Vienna. Quarterly Journal of the Geological Society of London 37:620-702.

-1891. On Saurodesmus Robertsoni (Seeley), a crocodilian reptile from the Rhaetic of Linksfield, in Elgin. Quarterly Journal of the Geological Society 47:166-170.

-1892. On a new reptile from Welte Vreden (Beaufort West), Eunotosaurus africanus (Seeley). Quarterly Journal of the Geological Society 48:583-585.

SMITH, E.T. AND B.P. KeAR. 2013. Spoochelys ormondea gen. et sp. nov., an archaic meiolaniid-like turtle from the Early Cretaceous of Lightning Ridge, Australia. In: D.B. Brinkman, P.A. Holroyd and J.D. Gardner, eds. Morphology and Evolution of Turtles. Dordrecht, Netherlands: Springer. pp. 121-146.

STERLI, J. 2008. A new, nearly complete stem turtle from the Jurassic of South America with implications for turtle evolution. Biology Letters 4:286-289.

-2015. A review of the fossil record of Gondwanan turtles of the clade Meiolaniformes. Bulletin of the Peabody Museum of Natural History 56:21-45.

Sterli, J. AND M.S. DE LA Fuente. 2010. Anatomy of Condorchelys antiqua Sterli, 2008, and the origin of the modern jaw closure mechanism in turtles. Journal of Vertebrate Paleontology 30:351-366.

-2011. A new turtle from the La Colonia Formation (Campanian-Maastrichtian), Patagonia, Argentina, with remarks on the evolution of the vertebral column in turtles. Palaeontology 54:63-78.

-2013. New evidence from the Palaeocene of Patagonia (Argentina) on the evolution and palaeo-biogeography of Meiolaniformes (Testudinata, new taxon name). Journal of Systematic Palaeontology 11:835-852.

Sterli, J., M.S. de la Fuente and I.A. Cerda. 2013. A new species of meiolaniform turtle and a revision of the Late Cretaceous meiolaniformes of South America. Ameghiniana 50:240-256.

SterLI, J., M.S. De LA Fuente AND G.W. Rougier. 2007. Anatomy and relationships of Palaeochersis talampayensis, a Late Triassic turtle from Argentina. Palaeontographica A281:1-61.

Sterli, J., M.S. de La Fuente and A.M. Umazano. 2015. New remains and new insights on the Gondwanan meiolaniform turtle Chubutemys copelloi from the Lower Cretaceous of Patagonia, Argentina. Gondwana Research 27:978-994.

STERLI, J. AND W.G. JoYCE. 2007. The cranial anatomy of the Early Jurassic turtle Kayentachelys aprix. Acta Palaeontologica Polonica 52:675-694.

Sterli, J., J. MÜller, J. Anquetin and A. Hilger. 2010. The parabasisphenoid complex in Mesozoic turtles and the evolution of the testudinate basicranium. Canadian Journal of Earth Sciences 47:1337-1346.

SterLI, J., D. POL AND M. LAURIN. 2013. Incorporating phylogenetic uncertainty on phylogeny-based palaeontological dating and the timing of turtle diversification. Cladistics 29:233-246. 
SukHanov, V.B. 1964. [Subclass Testudinata. Testudines]. In: A.K. Rozhdestvensky and L.P. Tatarinov, eds. [Fundamentals of Paleontology. Amphibians, Reptiles, and Birds]. Moscow: Nauka. pp. 354-438. [in Russian]

-2000. Mesozoic turtles of Middle and Central Asia. In: M.J. Benton, M.A. Shishkin, D.M. Unwin and E.N. Kurochkin, eds. The Age of Dinosaurs in Russia and Mongolia. Cambridge: Cambridge University Press. pp. 309-367.

-2006. An archaic turtle, Heckerochelys romani gen. et sp. nov., from the Middle Jurassic of Moscow Region, Russia. Fossil Turtle Research 1:112-118.

Sulej, T., G. NiedZwiedZKi ANd R. Bronowicz. 2012. A new Late Triassic vertebrate fauna from Poland with turtles, aetosaurs, and coelophysoid dinosaurs. Journal of Vertebrate Paleontology 32:1033-1041.

SUZUKI, S. AND T. CHINZORIG. 2010. A catalog of Mongolochelys collected by the HMNS-MPC Joint Paleontological Expedition. Hayashibara Museum of Natural Sciences Research Bulletin 3:119-131.

SuZUKI, S. AND M. WATABE. 2000. Report on the Japan - Mongolia Joint Paleontological Expedition to the Gobi desert, 1998. Hayashibara Museum of Natural Science Research Bulletin 1:83-98.

SweEtMan, S.C. AND A.N. InSOLE. 2010. The plant debris beds of the Early Cretaceous (Barremian) Wessex Formation of the Isle of Wight, southern England: their genesis and palaeontological significance. Palaeogeography, Palaeoclimatology, Palaeoecology 292:409-424.

SzCZYGIELSKI, T. AND T. SUlEJ. 2016. Revision of the Triassic European turtles Proterochersis and Murrhardtia (Reptilia, Testudinata, Proterochersidae), with the description of new taxa from Poland and Germany. Zoological Journal of the Linnean Society 177:395-427.

Theodori, L. 1831. Über die Knochen vom Genus Pterodactylus aus der Lias-Formation in der Gegend von Banz. Isis von Oken 1831:276-281.

Tong, H., E. Buffetaut, J. Le Loeuff, L. Cavin and V. MarTIN. 1993. Découverte de restes de vertébrés dans le Crétacé supérieur de Montséret (Corbières orientales, Aude). Bulletin de la Société d'Etudes Scientifiques de l'Aude 93: 161-164.

Tong, H., E. Buffetaut and V. Suteethorn. 2002. Middle Jurassic turtles from southern Thailand. Geological Magazine 139:687-697.

Tong, H., J. Claude, W. Naksri, V. Suteethorn, E. BuffeTAut, S. Khansubha, K. WongKo and P. YuangdetKla. 2009. Basilochelys macrobios n. gen. and n. sp., a large cryptodiran turtle from the Phu Kradung Formation (latest Jurassic-earliest Cretaceous) of the Khorat Plateau, NE
Thailand. Geological Society, London, Special Publications 315:153-173.

Tong, H., I. Danilov, Y. Ye, H. OuYang and G. Peng. 2012 Middle Jurassic turtles from the Sichuan Basin, China: a review. Geological Magazine 149:675-695.

Tong, H., I. Danilov, Y. Ye, H. OuYang, G. Peng And K. Li. 2012. A revision of xinjiangchelyid turtles from the Late Jurassic of Sichuan Basin, China. Annales de Paléontologie 98:73-114.

Torices, A., F. Barroso-Barcenilla, O. Cambra-Moo, A. Pérez-García And M. Segura. 2012. Palaeontological and palaeobiogeographical implications of the new Cenomanian site of Algora, Guadalajara, Spain. Cretaceous Research 37:231-239.

VILLINGER, E. 2002. Bodenübersichtskarte von Baden-Württemberg 1:200.000; Blatt CC 7918 Stuttgart-Süd, Karte und tabellarische Erläuterung. Stuttgart: Geologisches Landesamt Baden-Württemberg.

Vullo, R., F. de Lapparent de Broin, D. Néraudeau and N. DurRIEU. 2010. Turtles from the early Cenomanian paralic deposits (Late Cretaceous) of Charentes, France. Oryctos 9:37-48.

WARREN, J.W. 1969. A fossil chelonian of probable Lower Cretaceous age from Victoria, Australia. Memoirs of the National Museum of Victoria 29:23-28.

Werneburg, I., J. Hinz, M. Gumpenberger, V. Volpato, N NATCHEV AND W.G. JoYCE. 2015. Modeling neck mobility in fossil turtles. Journal of Experimental Zoology Part B: Molecular and Developmental Evolution 324:230-243.

WHITE, T.E. 1973. Catalogue of the genera of dinosaurs. Annals of Carnegie Museum 44:117-155.

WILD, R. 1972. Die Wirbeltierfaunen der fränkischen und südalpinen Mitteltrias. Zeitschrift der Deutschen Geologischen Gesellschaft 123:229-234.

-1974. Lebensbilder württembergischer Triassaurier. Stuttgarter Beiträge zur Naturkunde C1:20-27.

WiLLIAMS, E.E. 1950. Variation and selection in the cervical articulation of living turtles. Bulletin of the American Museum of Natural History 94:509-561.

WOODWARD, A.S. 1939. A supposed chelonian carapace from the Permian. Geological Magazine 76:143.

YE, Y. AND X. Pr. 1997. A new genus of Chengyuchelyidae from Dashanpu, Zigong, Sichuan. Vertebrata PalAsiatica 35:182-188. [in Chinese with English abstract]

ZANGERL, R. 1969. The turtle shell. In: C. Gans, A. Bellairs and T.S. Parsons, eds. The Biology of the Reptilia, Volume 1. London: Academic Press. pp. 311-339.

ZHOU, C.-F. AND M. RABI. 2015. A sinemydid turtle from the Jehol Biota provides insights into the basal divergence of crown turtles. Scientific Reports 5:16299.

Editor's note: This article is intended to be included with others in a forthcoming book being coordinated by Walter G. Joyce to elucidate the fossil record of turtles. The individual articles that will form the components of this book are being published separately in the next several volumes of the Bulletin of the Peabody Museum of Natural History. 